\title{
Enantioselective Total Synthesis of Avrainvillamide and the Stephacidins
}

Phil S. Baran* Benjamin D. Hafensteiner, Narendra B. Ambhaikar, Carlos A.

Guerrero, and John D. Gallagher

Contribution from the Department of Chemistry, The Scripps Research Institute, 10550 North Torrey Pines Road, La Jolla, California 92037

\section{Spectra}



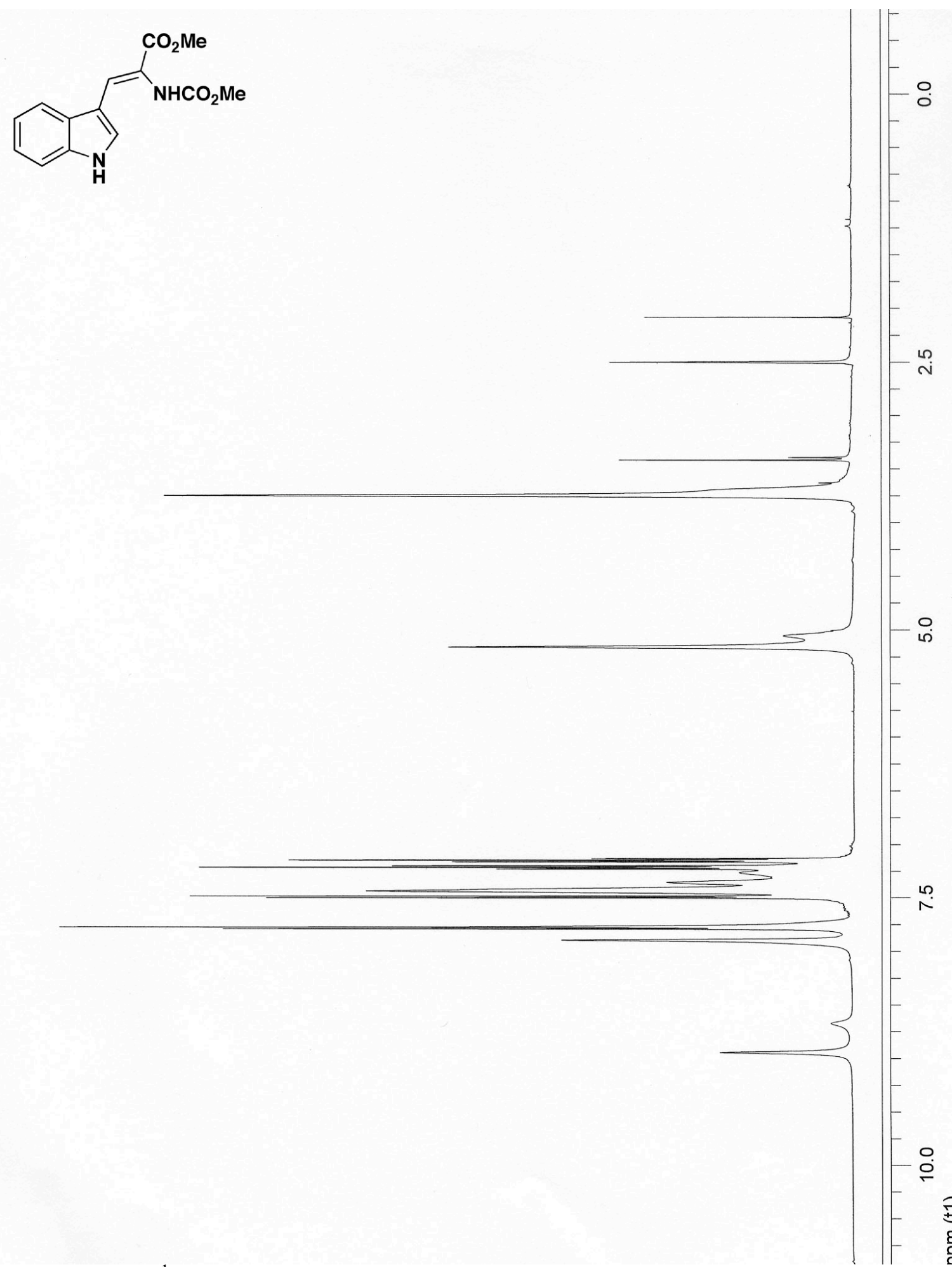

Compound 10: ${ }^{1} \mathrm{H}$ NMR (500 MHz, DMSO- $\left.d_{6}\right)$ 

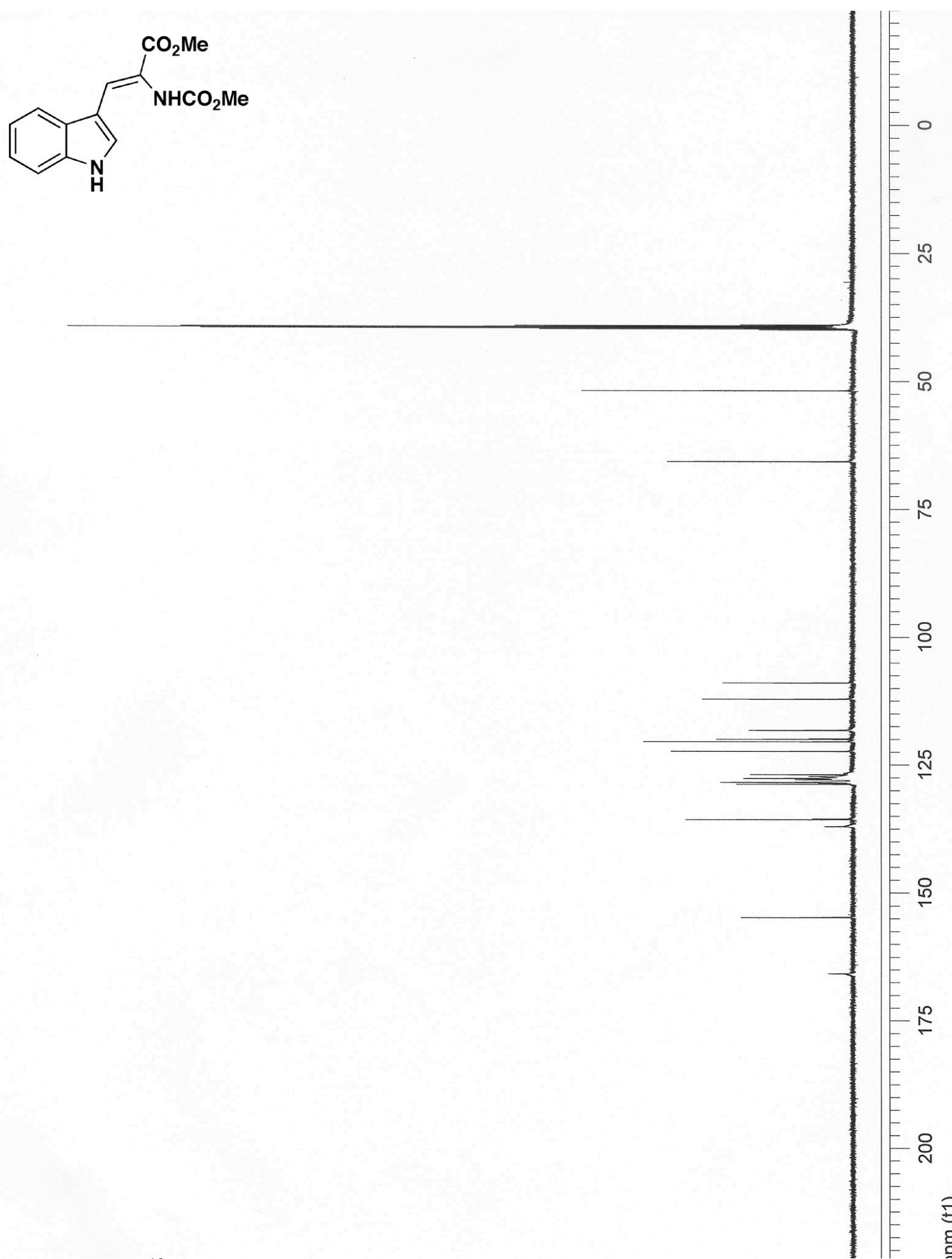

Compound 10: ${ }^{13} \mathrm{C}$ NMR (125 MHz, DMSO- $d_{6}$ ) 

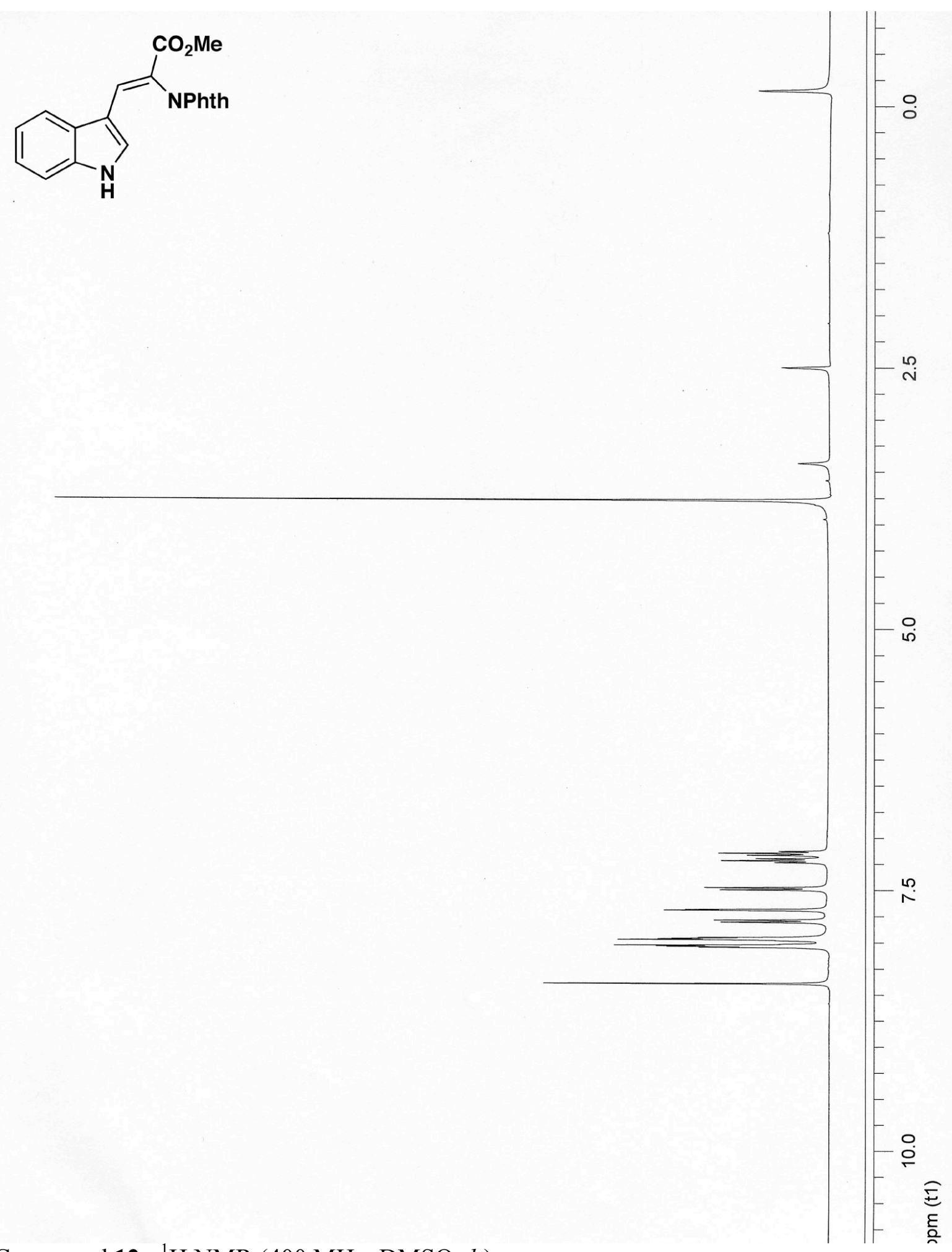

Compound 12: ${ }^{1} \mathrm{H}$ NMR (400 MHz, DMSO- $d_{6}$ ) 

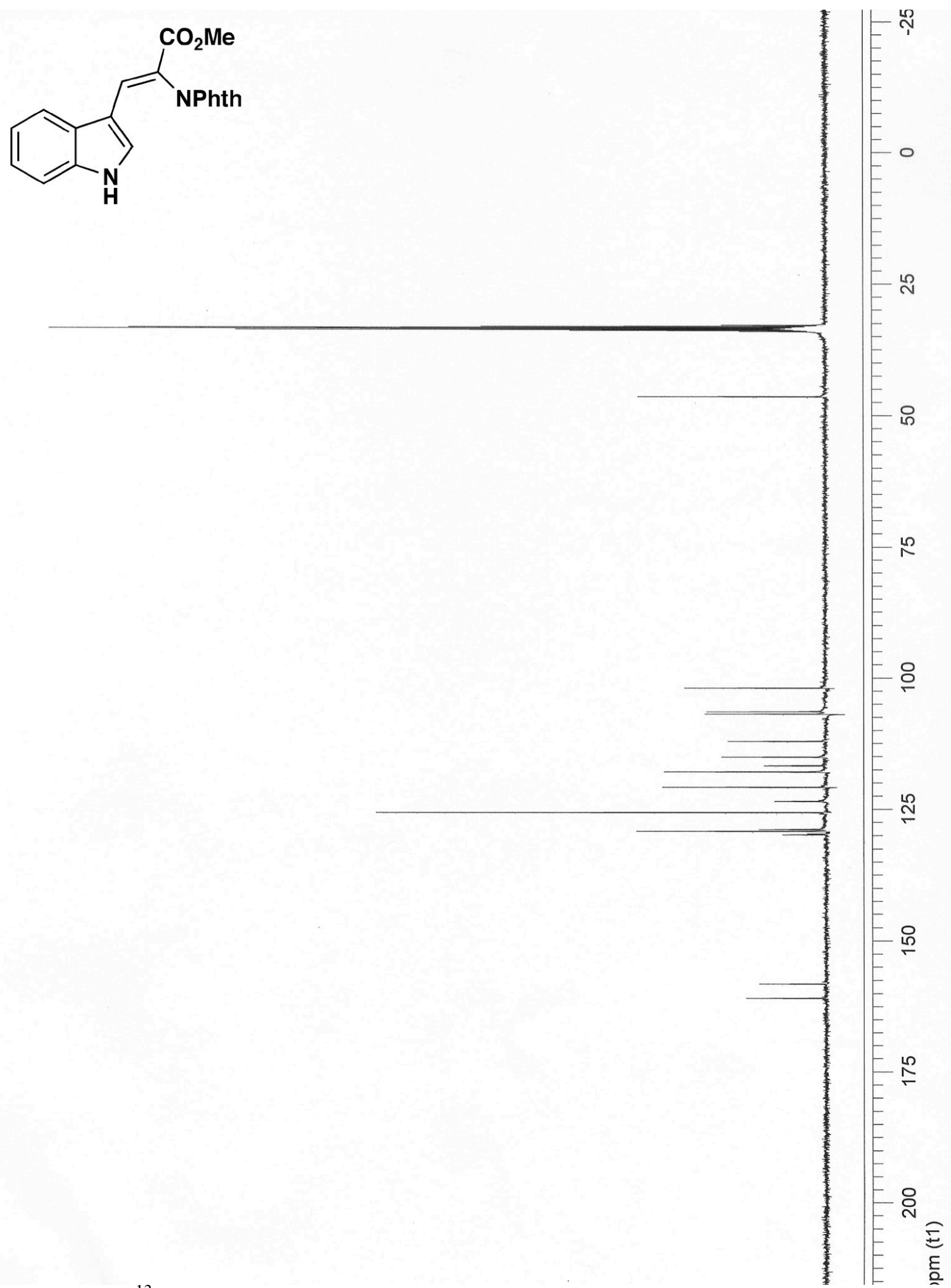

Compound 12: ${ }^{13} \mathrm{C}$ NMR (100 MHz, DMSO- $\left.d_{6}\right)$ 

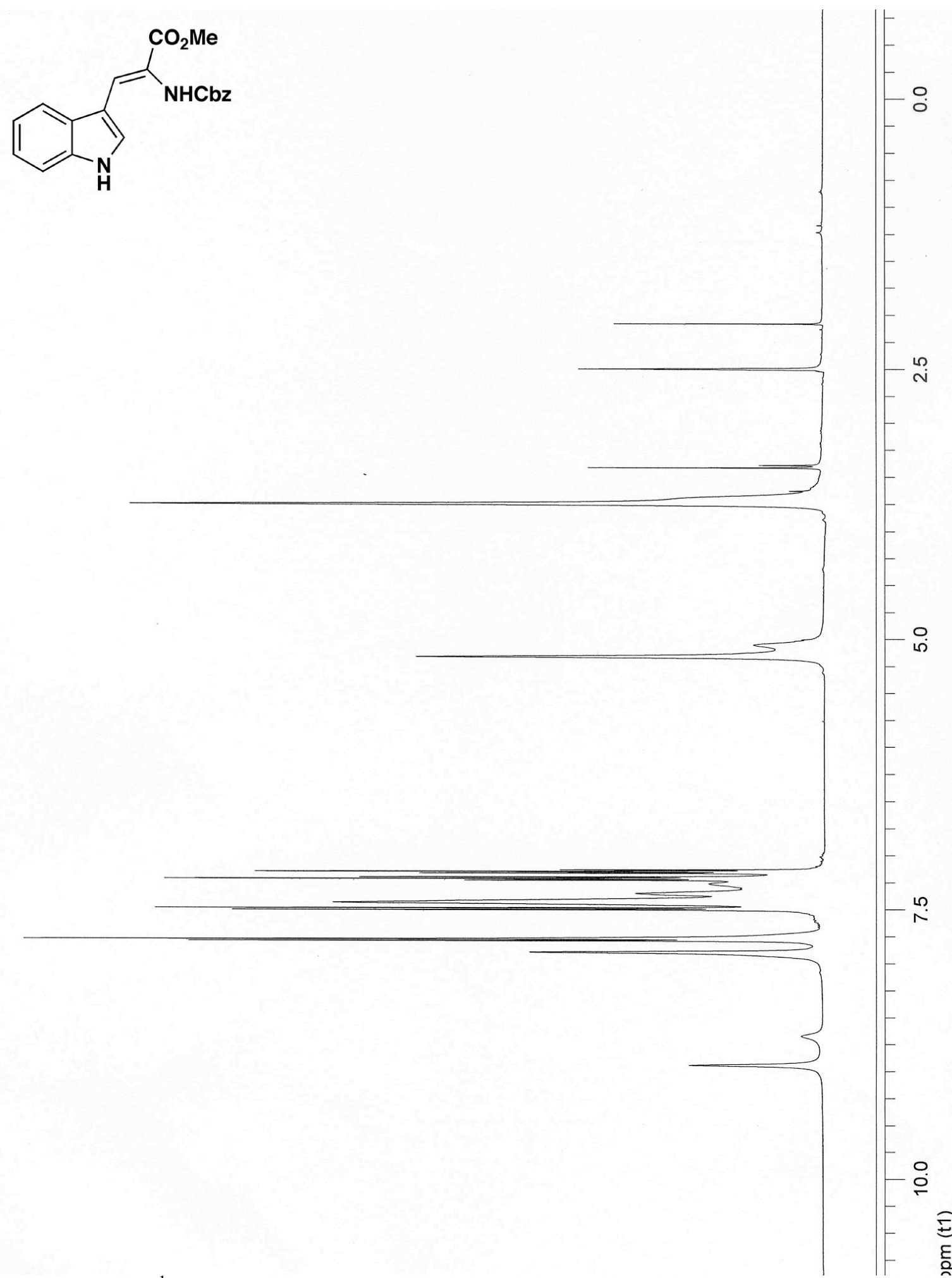

Compound 14: ${ }^{1} \mathrm{H}$ NMR (500 MHz, DMSO- $d_{6}$ ) 


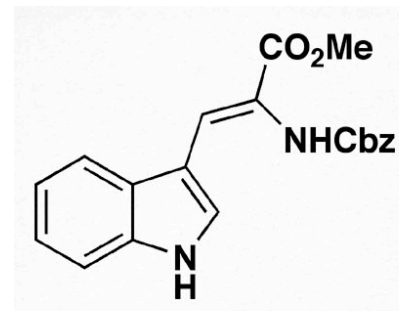

Compound 14: ${ }^{13} \mathrm{C}$ NMR (125 MHz, DMSO- $d_{6}$ )

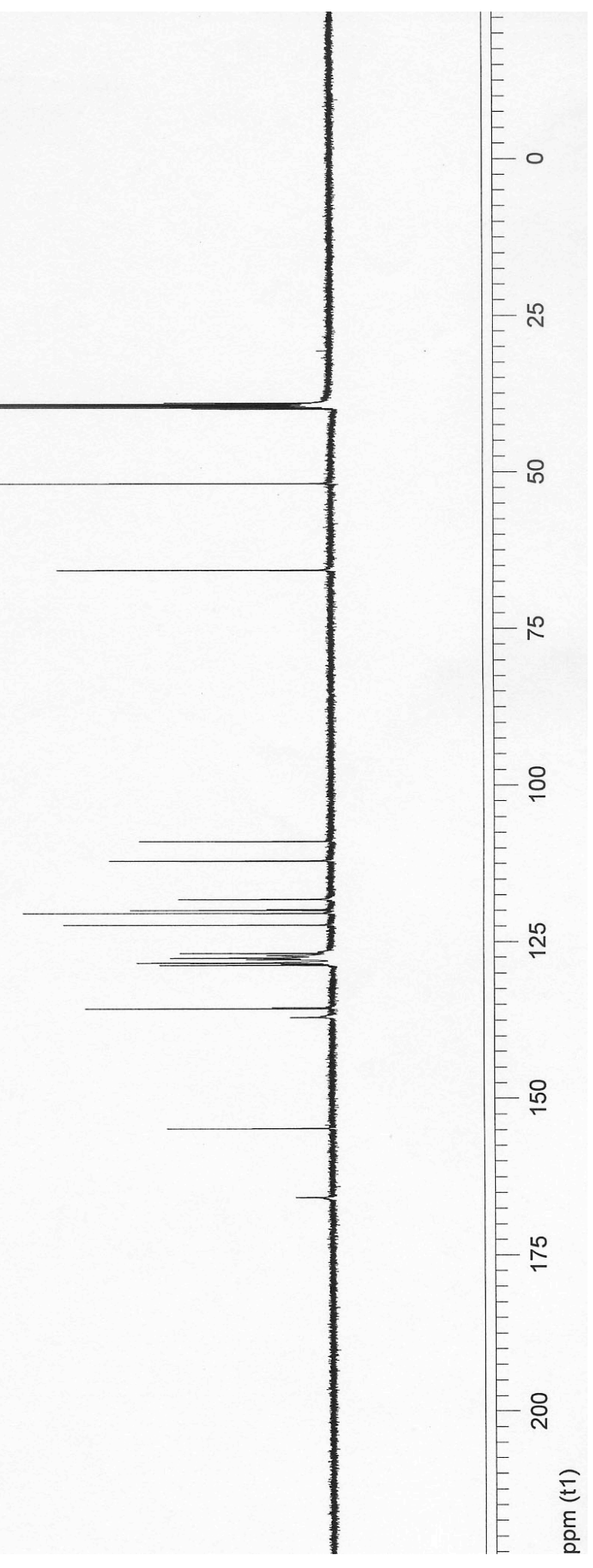



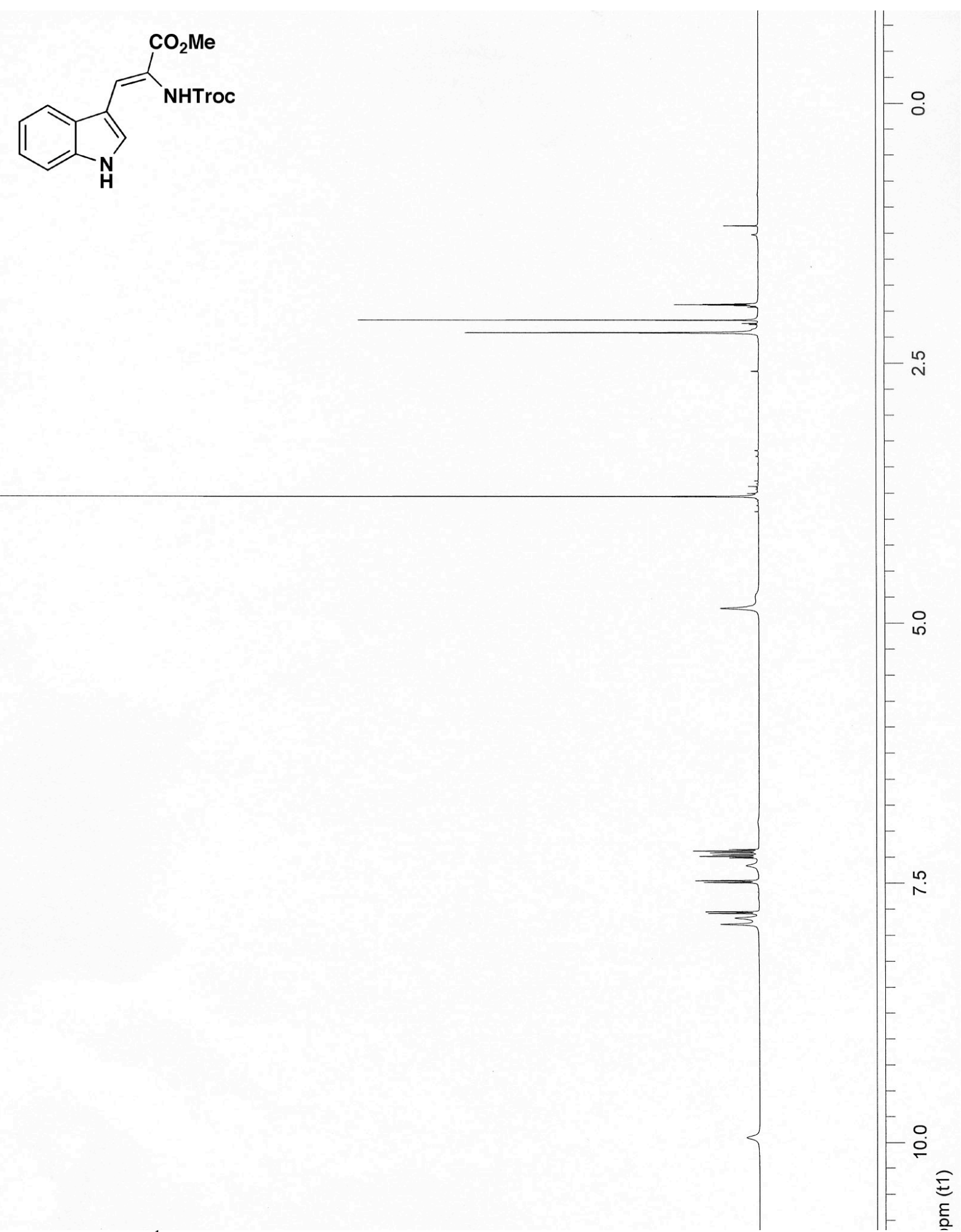

Compound 16: ${ }^{1} \mathrm{H}$ NMR $\left(500 \mathrm{MHz}, \mathrm{CD}_{3} \mathrm{CN}\right)$ 


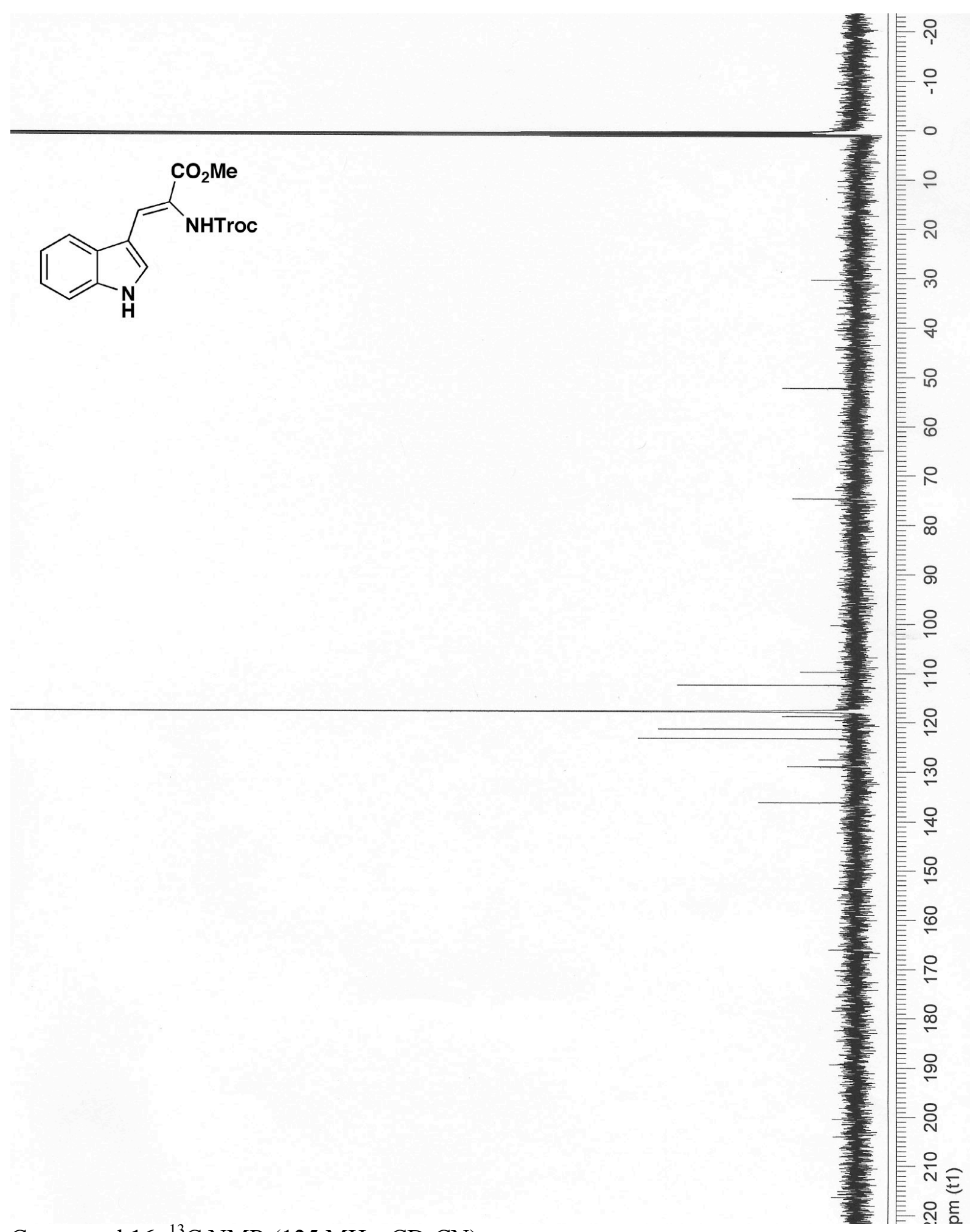

Compound 16: ${ }^{13} \mathrm{C}$ NMR (125 MHz, $\mathrm{CD}_{3} \mathrm{CN}$ ) 

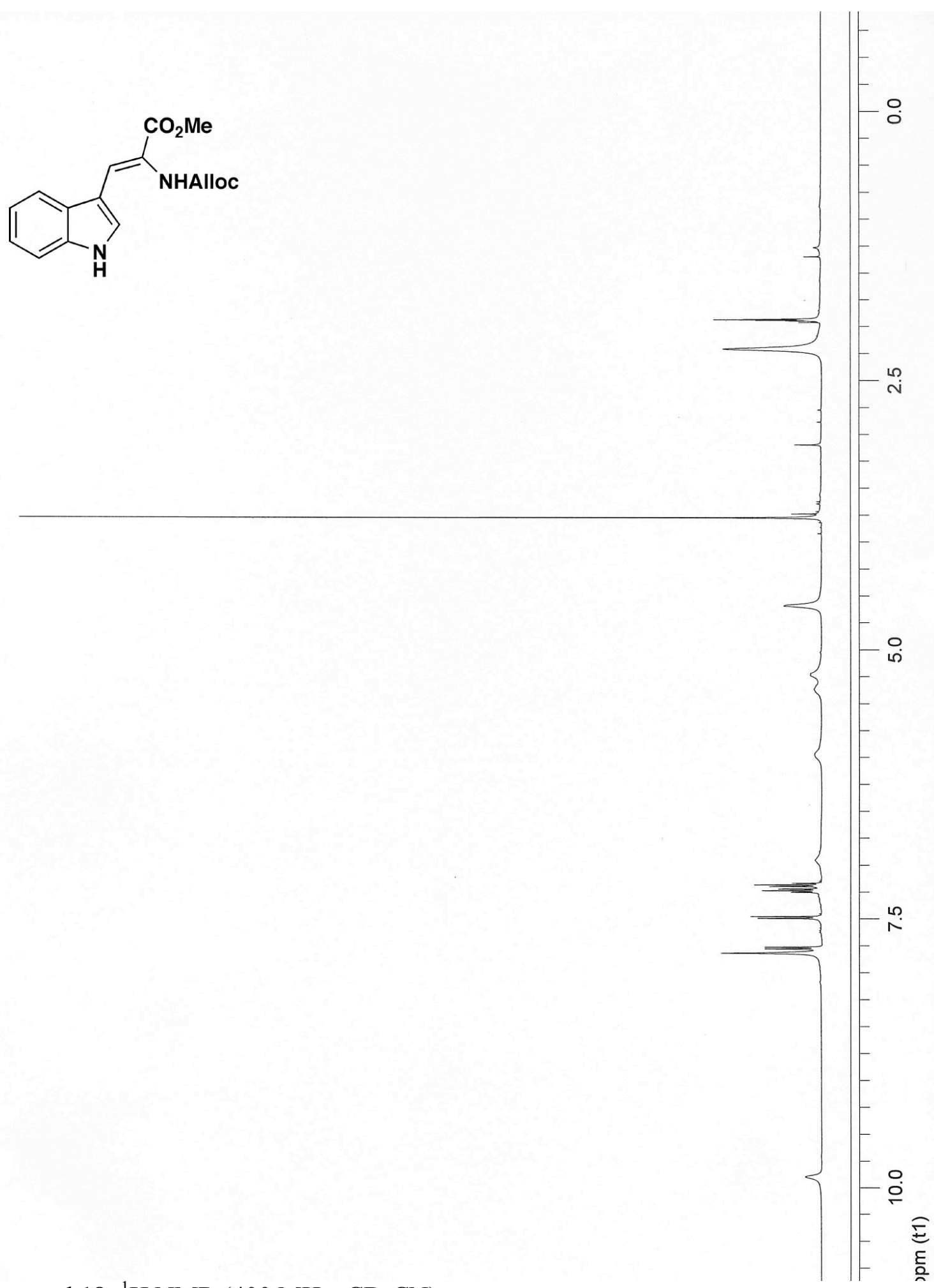

Compound 18: ${ }^{1} \mathrm{H}$ NMR (400 MHz, $\mathrm{CD}_{3} \mathrm{CN}$ ) 


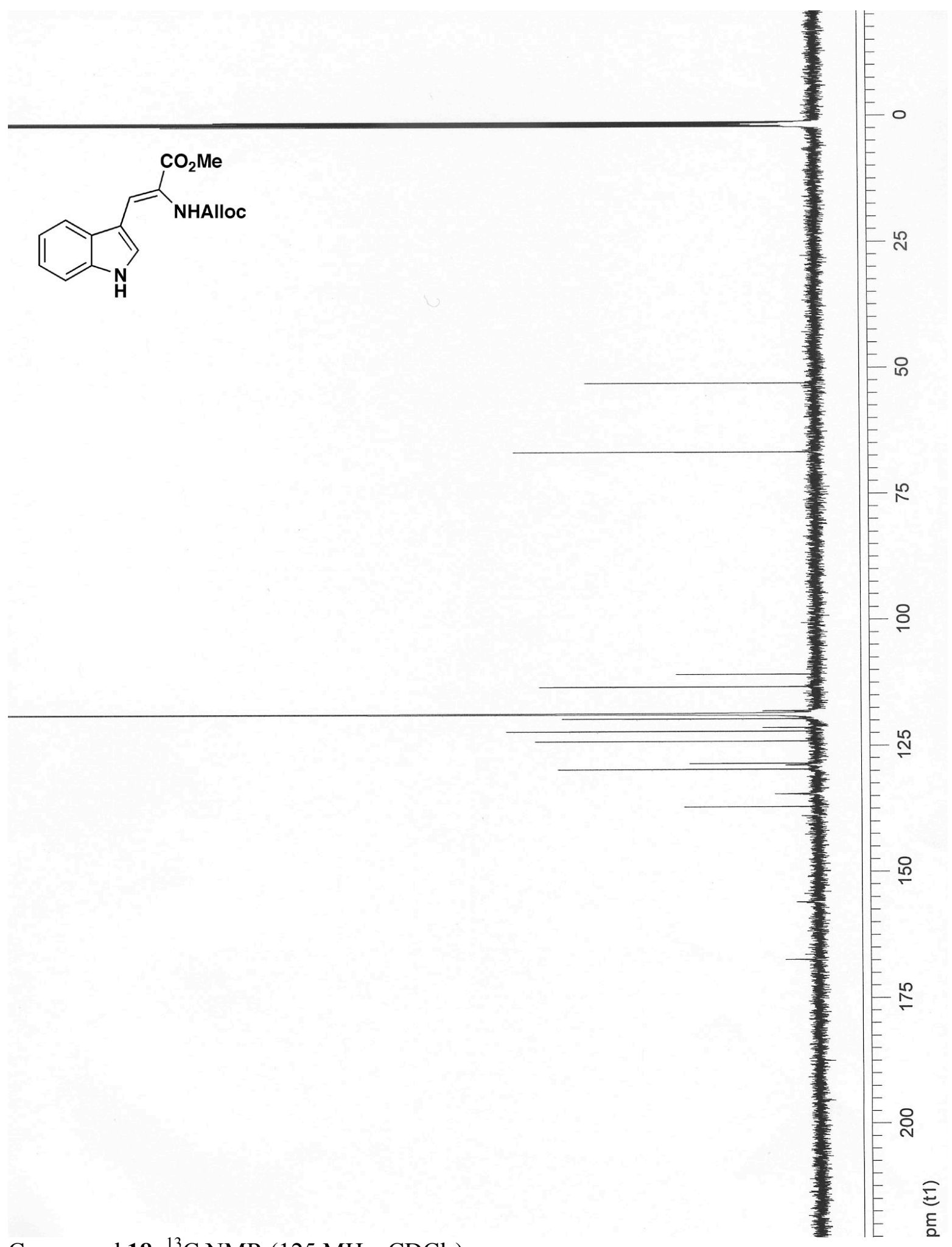

Compound 18: ${ }^{13} \mathrm{C}$ NMR (125 MHz, $\mathrm{CDCl}_{3}$ ) 

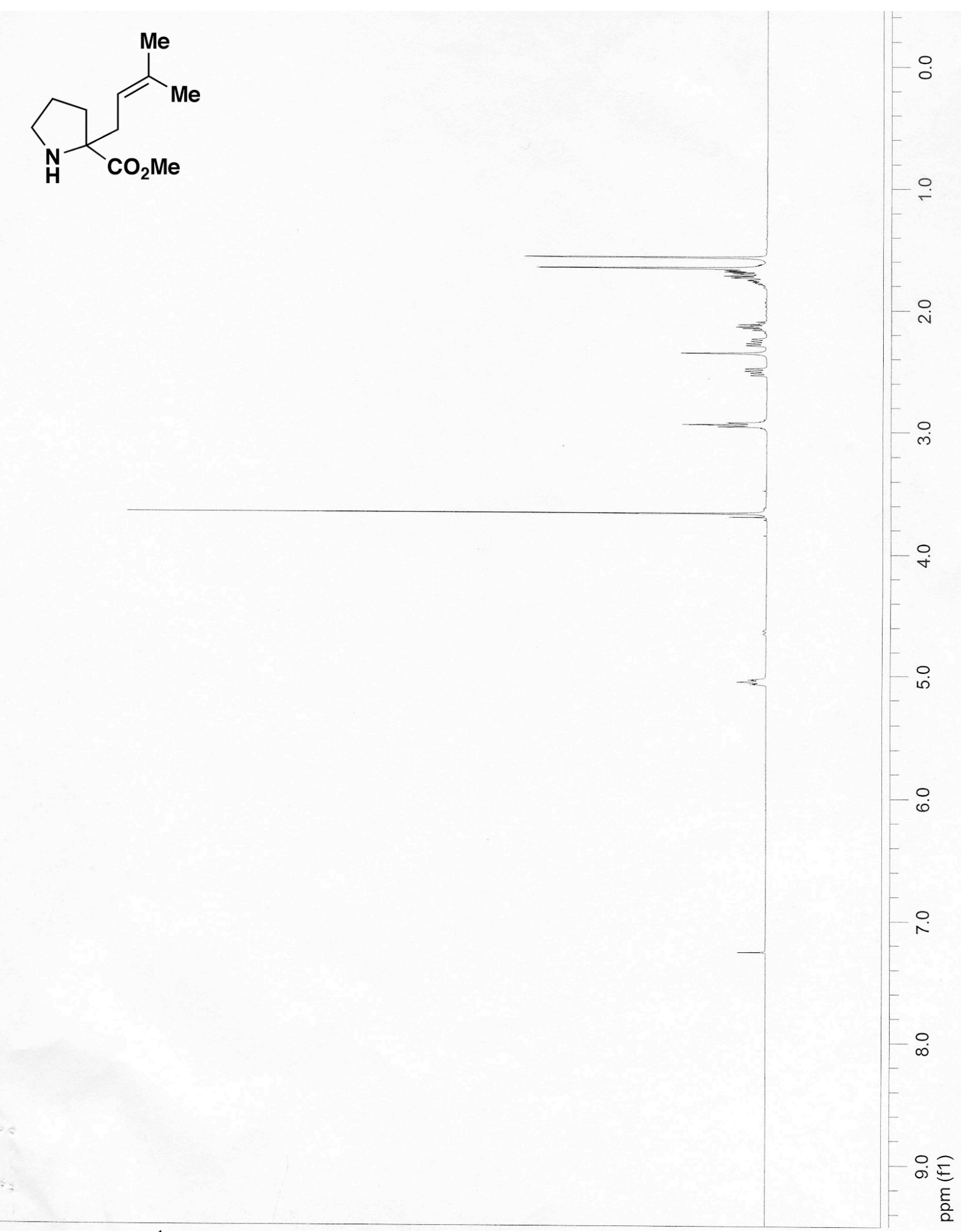

Compound 26: ${ }^{1} \mathrm{H}$ NMR (400 MHz, $\mathrm{CDCl}_{3}$ ) 


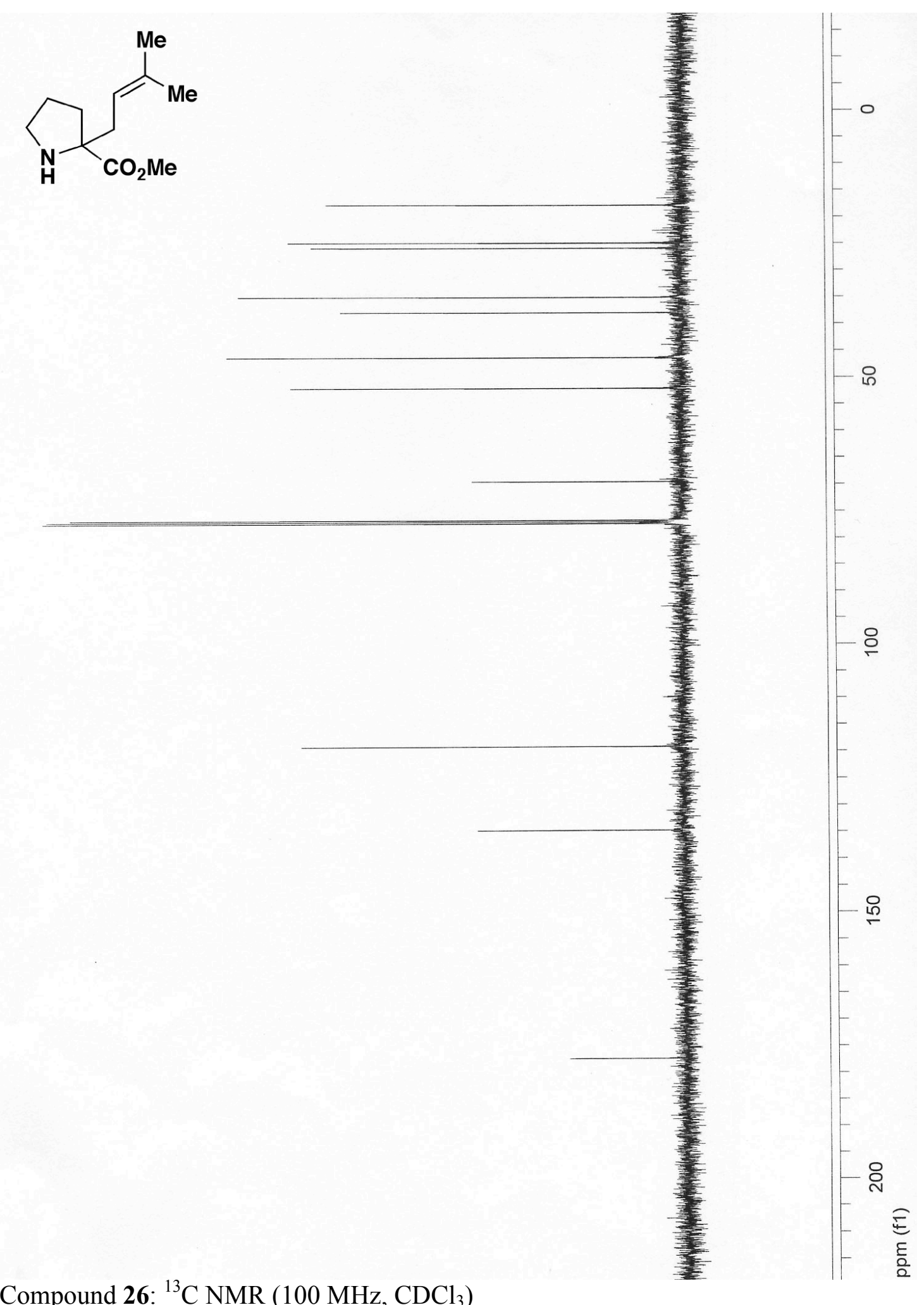




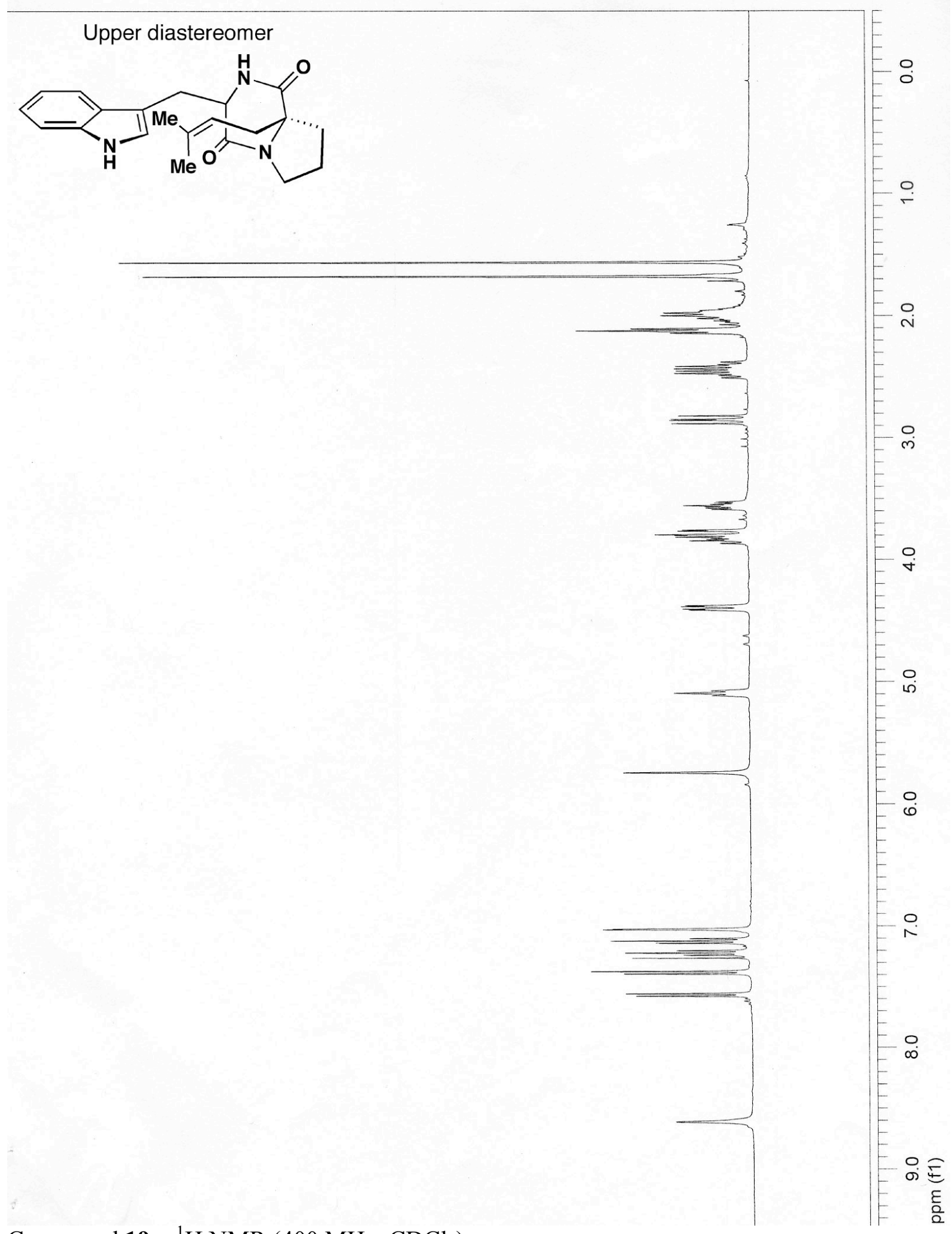

Compound 19a: ${ }^{1} \mathrm{H} \mathrm{NMR}\left(400 \mathrm{MHz}, \mathrm{CDCl}_{3}\right.$ ) 

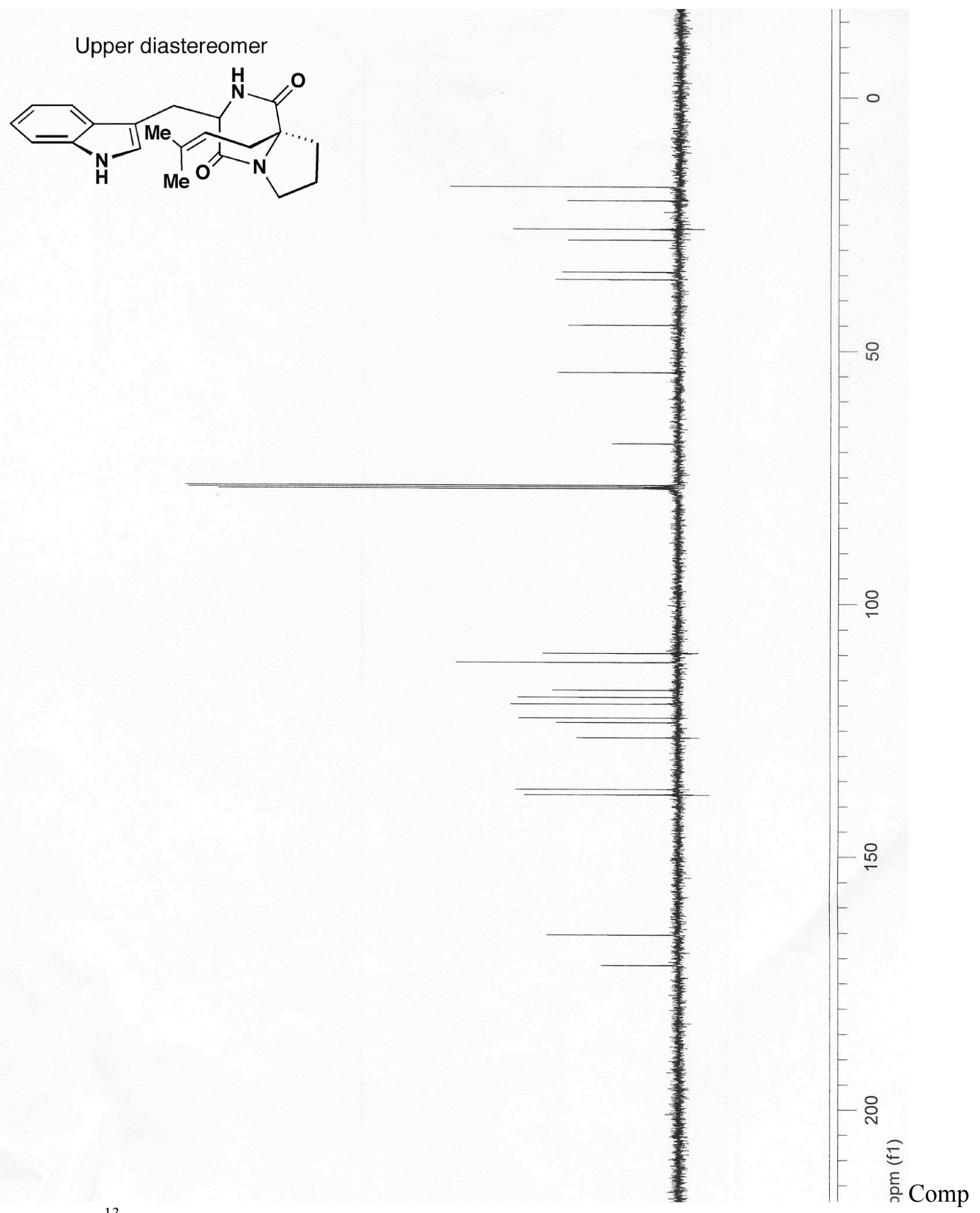

ound 19a: ${ }^{13} \mathrm{C}$ NMR (100 MHz, $\left.\mathrm{CDCl}_{3}\right)$ 


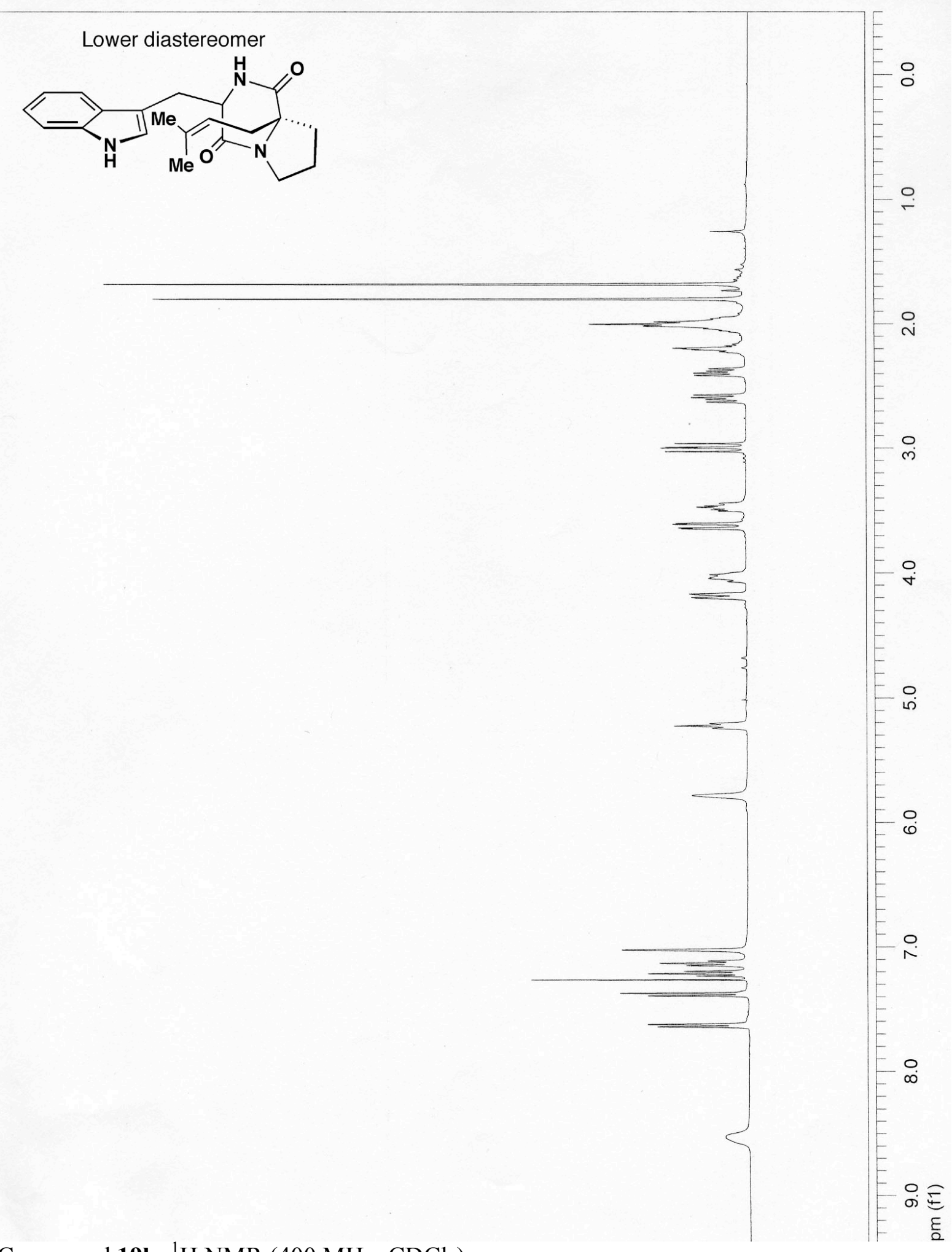

Compound 19b: ${ }^{1} \mathrm{H} \mathrm{NMR}\left(400 \mathrm{MHz}, \mathrm{CDCl}_{3}\right.$ ) 
J. Am. Chem. Soc.

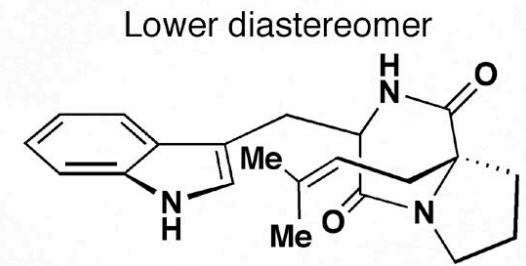

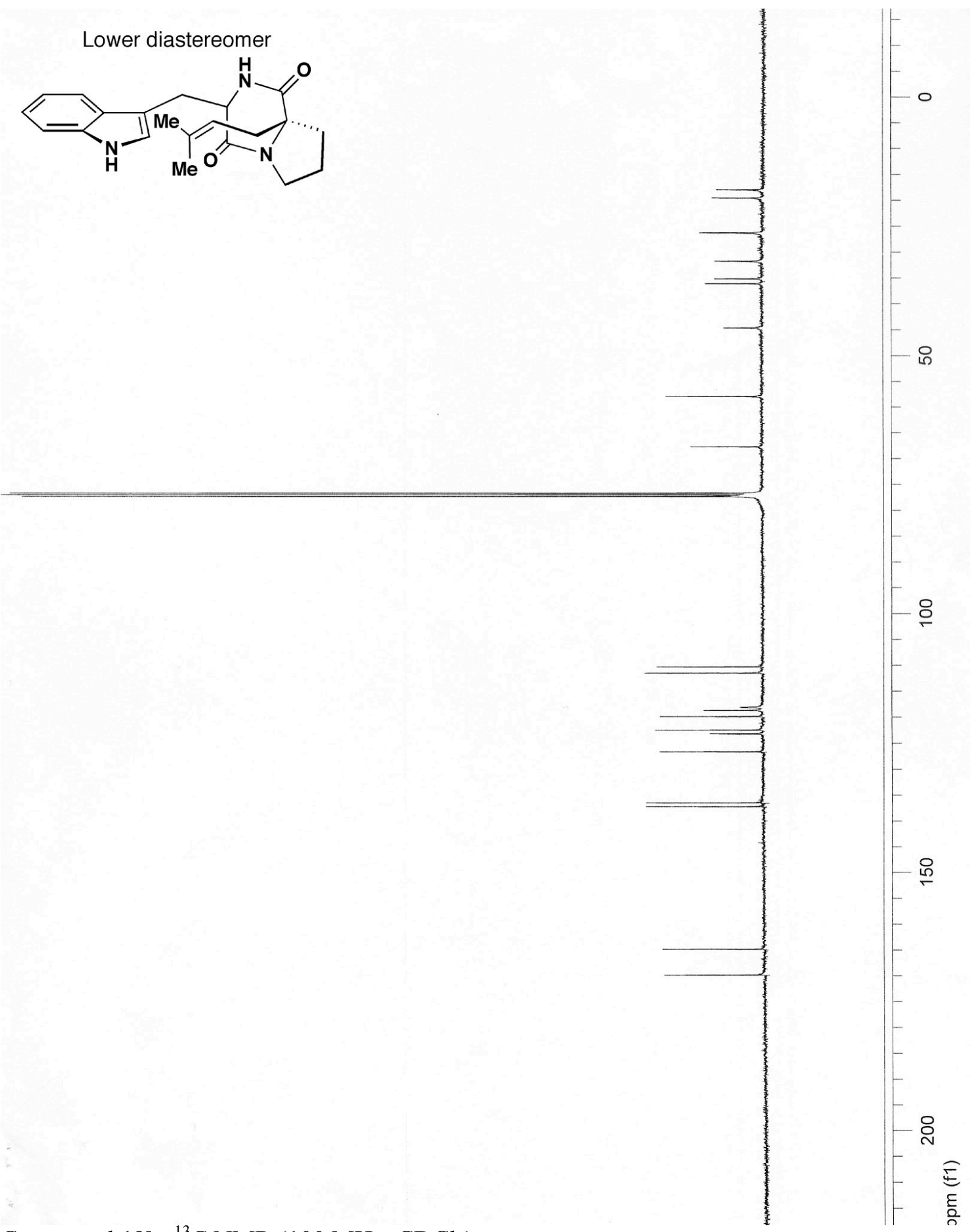

Compound 19b: ${ }^{13} \mathrm{C}$ NMR (100 MHz, $\left.\mathrm{CDCl}_{3}\right)$ 

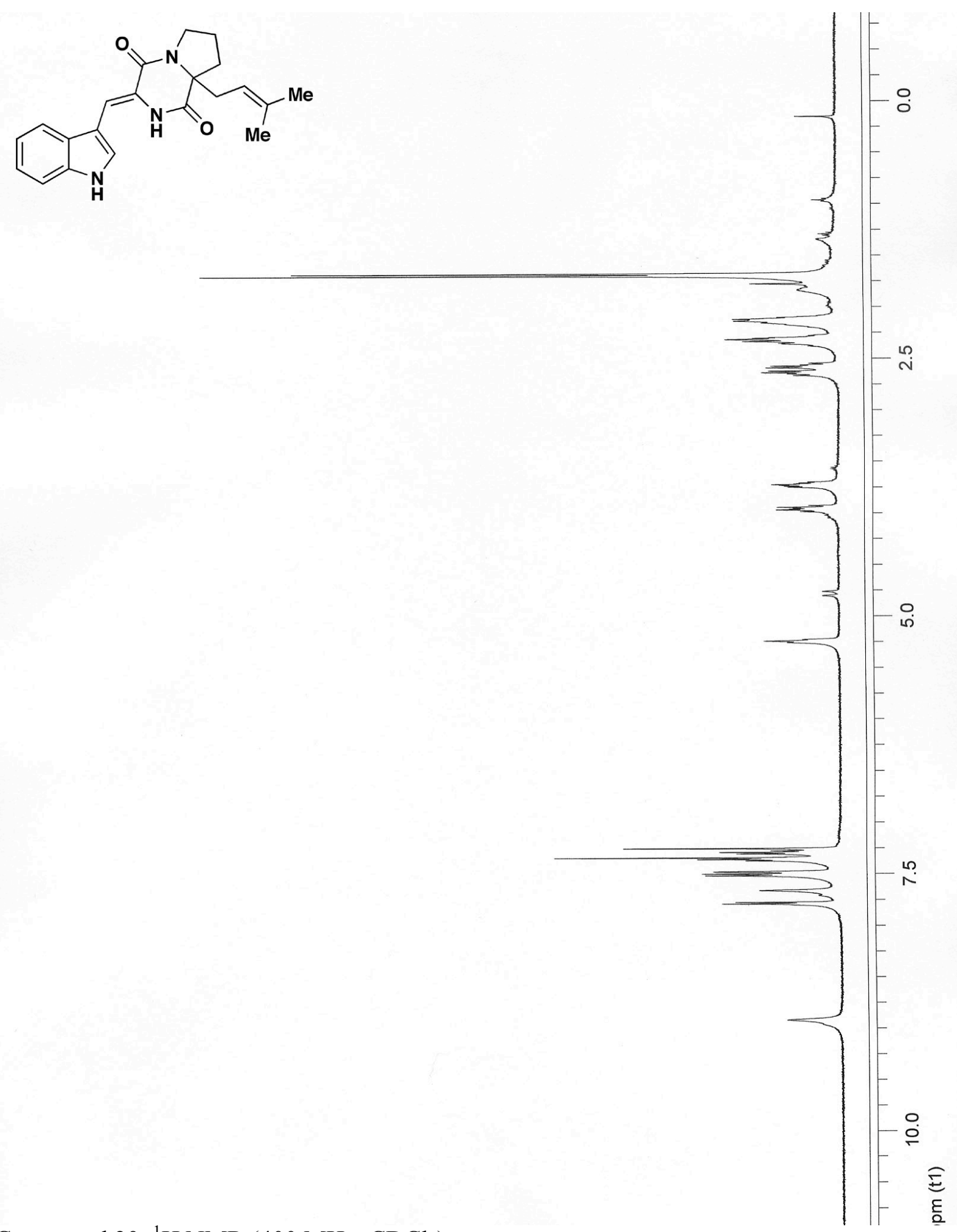

Compound 20: ${ }^{1} \mathrm{H}$ NMR (400 MHz, $\mathrm{CDCl}_{3}$ ) 

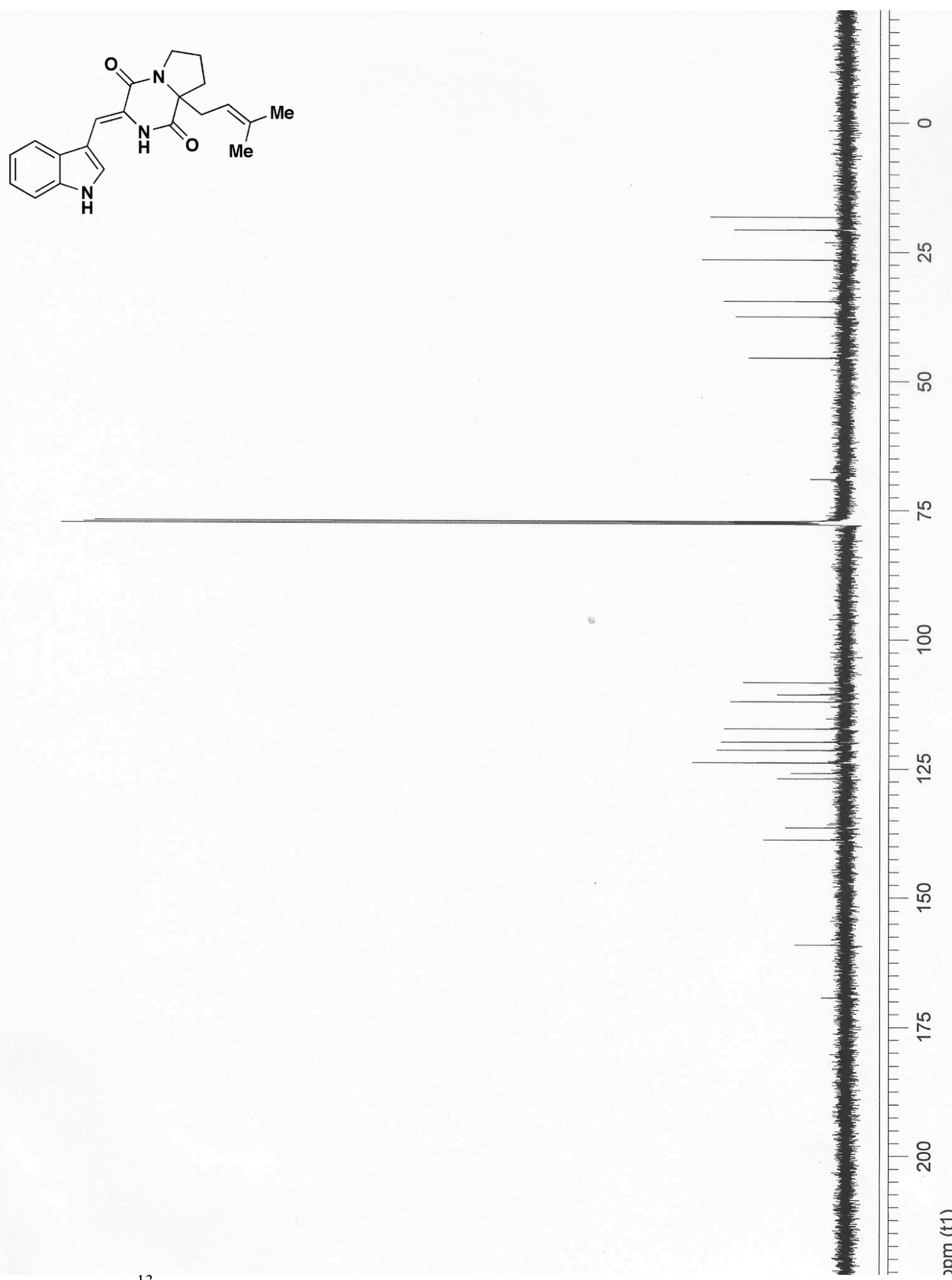

Compound 20: ${ }^{13} \mathrm{C}$ NMR (100 MHz, $\mathrm{CDCl}_{3}$ ) 

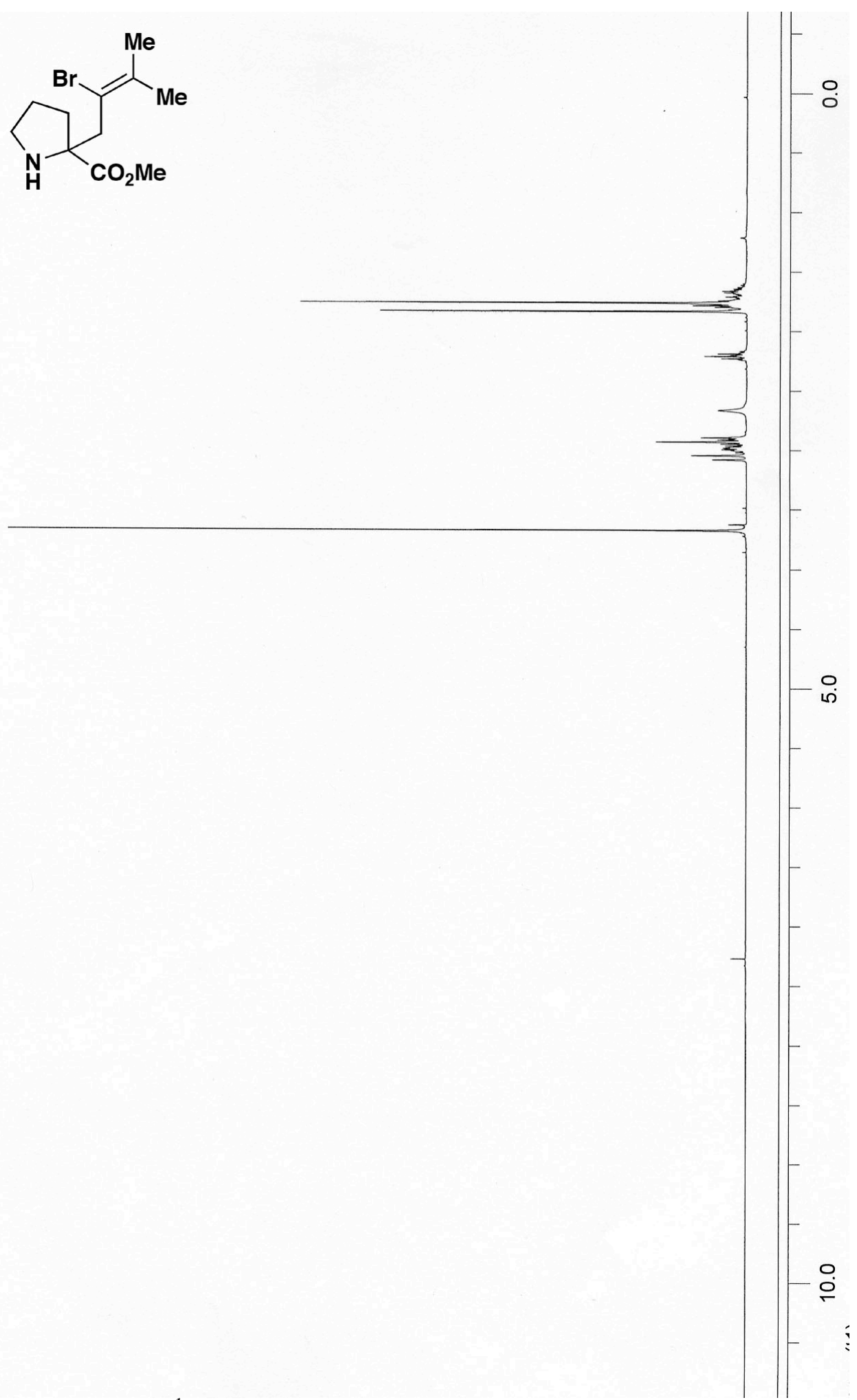

Compound 35: ${ }^{1} \mathrm{H}$ NMR (400 MHz, $\mathrm{CDCl}_{3}$ ) 


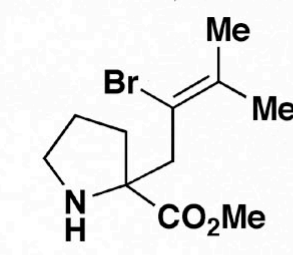

Compound 35: ${ }^{13} \mathrm{C}$ NMR (100 MHz, $\mathrm{CDCl}_{3}$ )

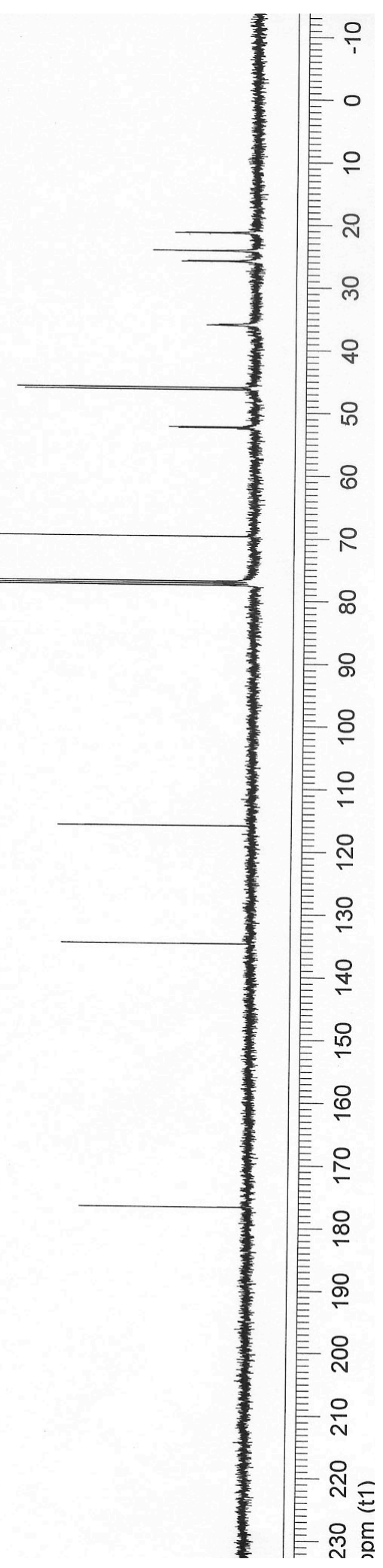



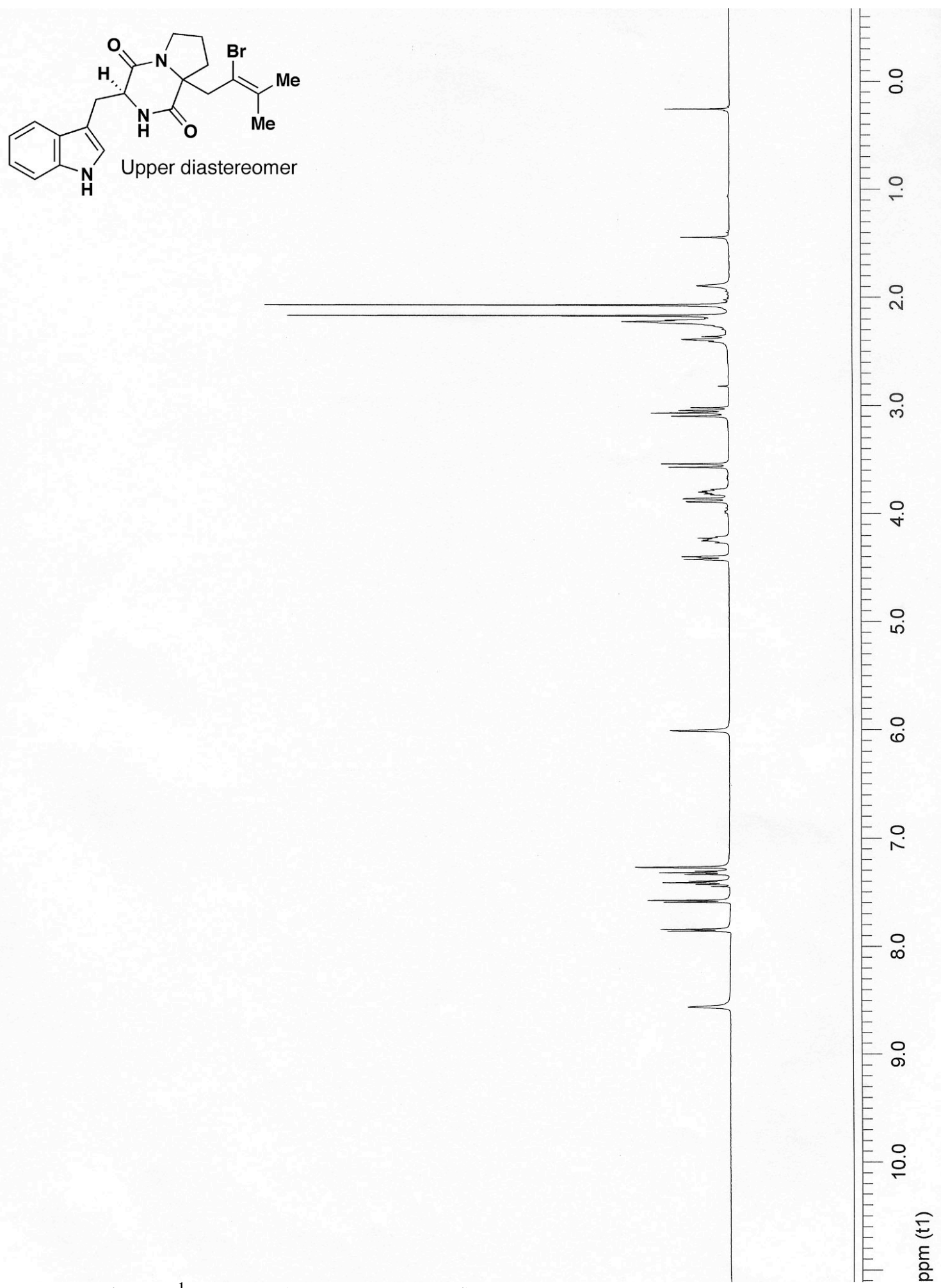

Compound 21a: ${ }^{1} \mathrm{H}$ NMR (500 MHz, CDCl) 

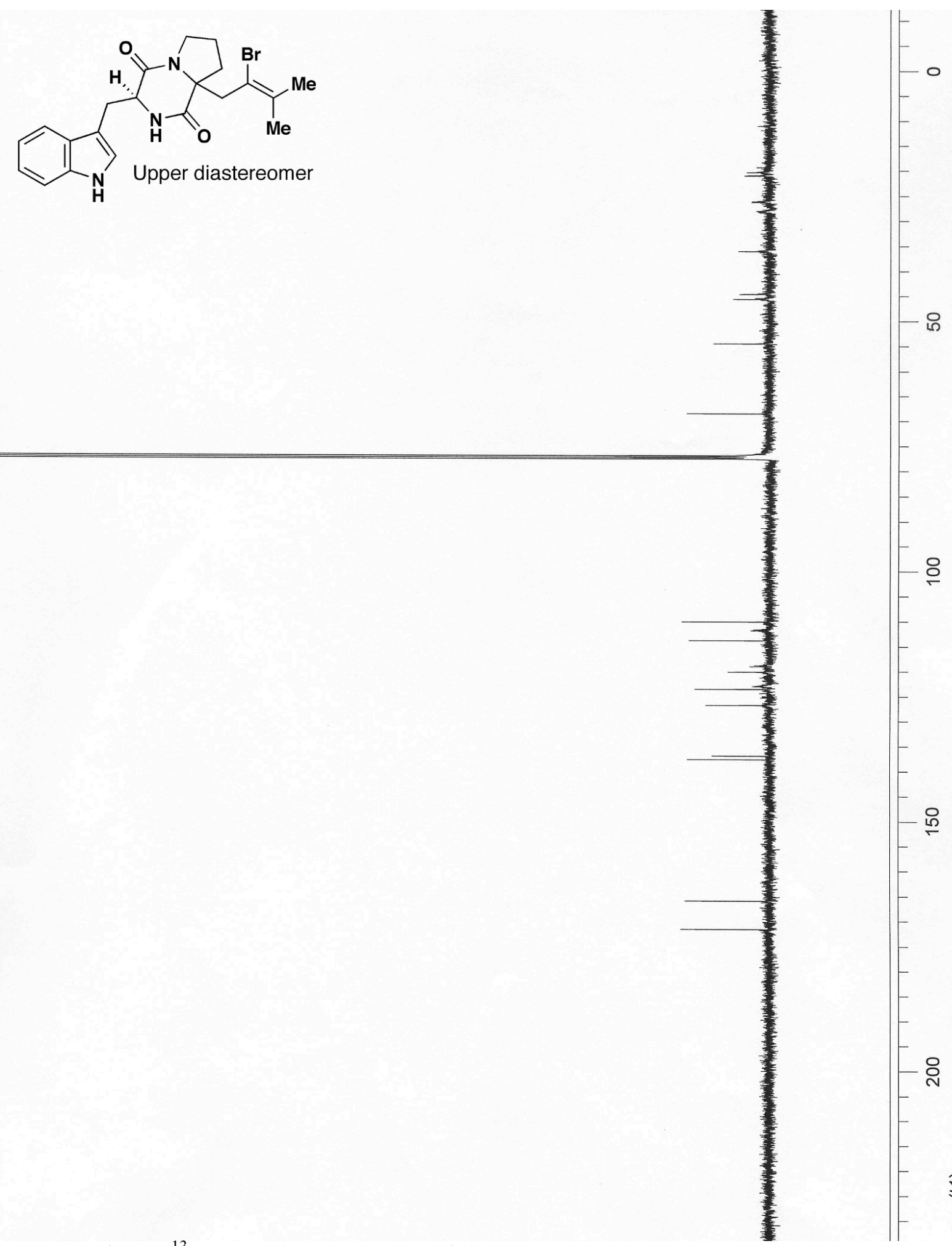

Compound 21a: ${ }^{13} \mathrm{C}$ NMR $\left(100 \mathrm{MHz}, \mathrm{CDCl}_{3}\right)$ 

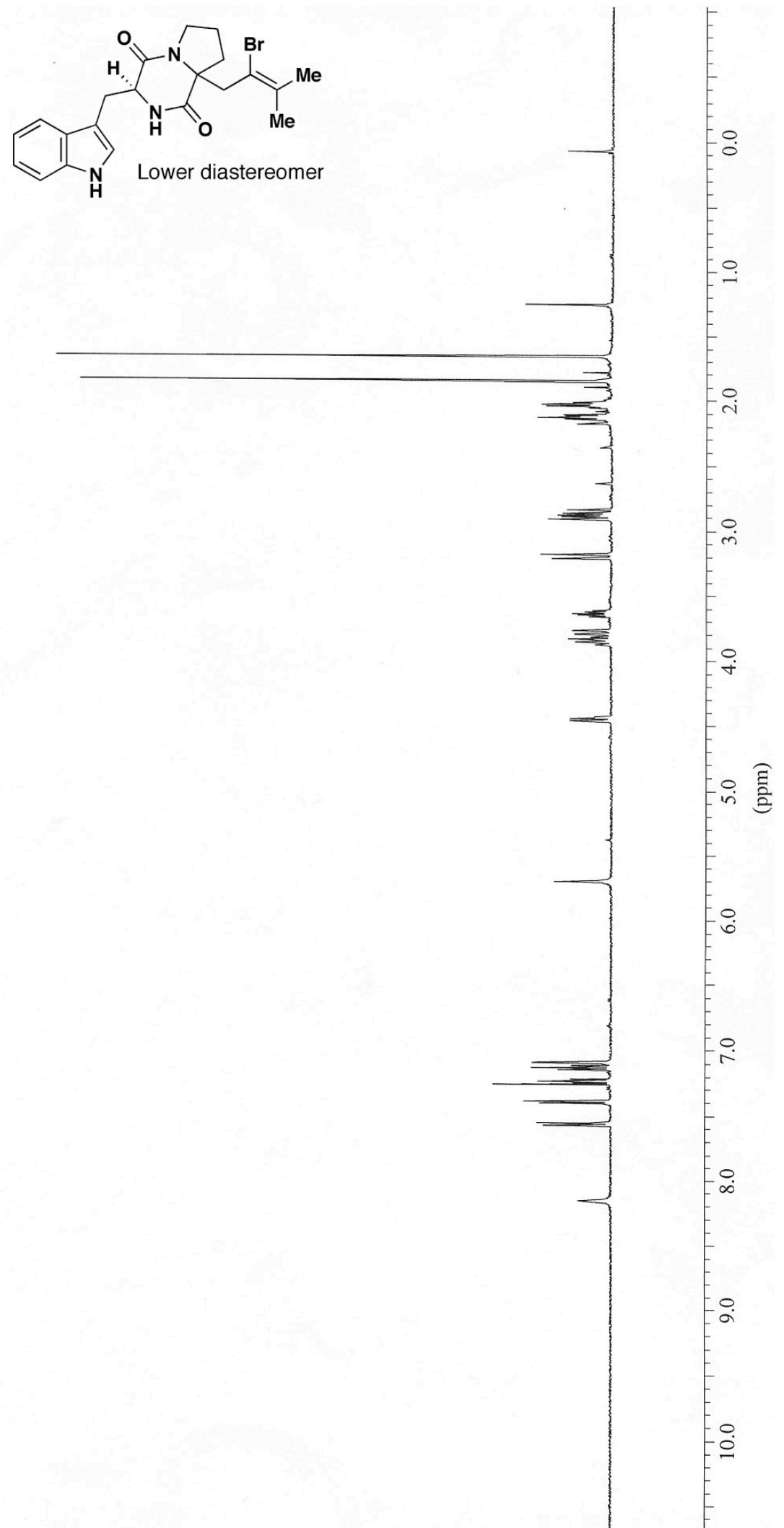

Compound 21b: ${ }^{1} \mathrm{H}$ NMR (500 MHz, $\mathrm{CDCl}_{3}$ ) 

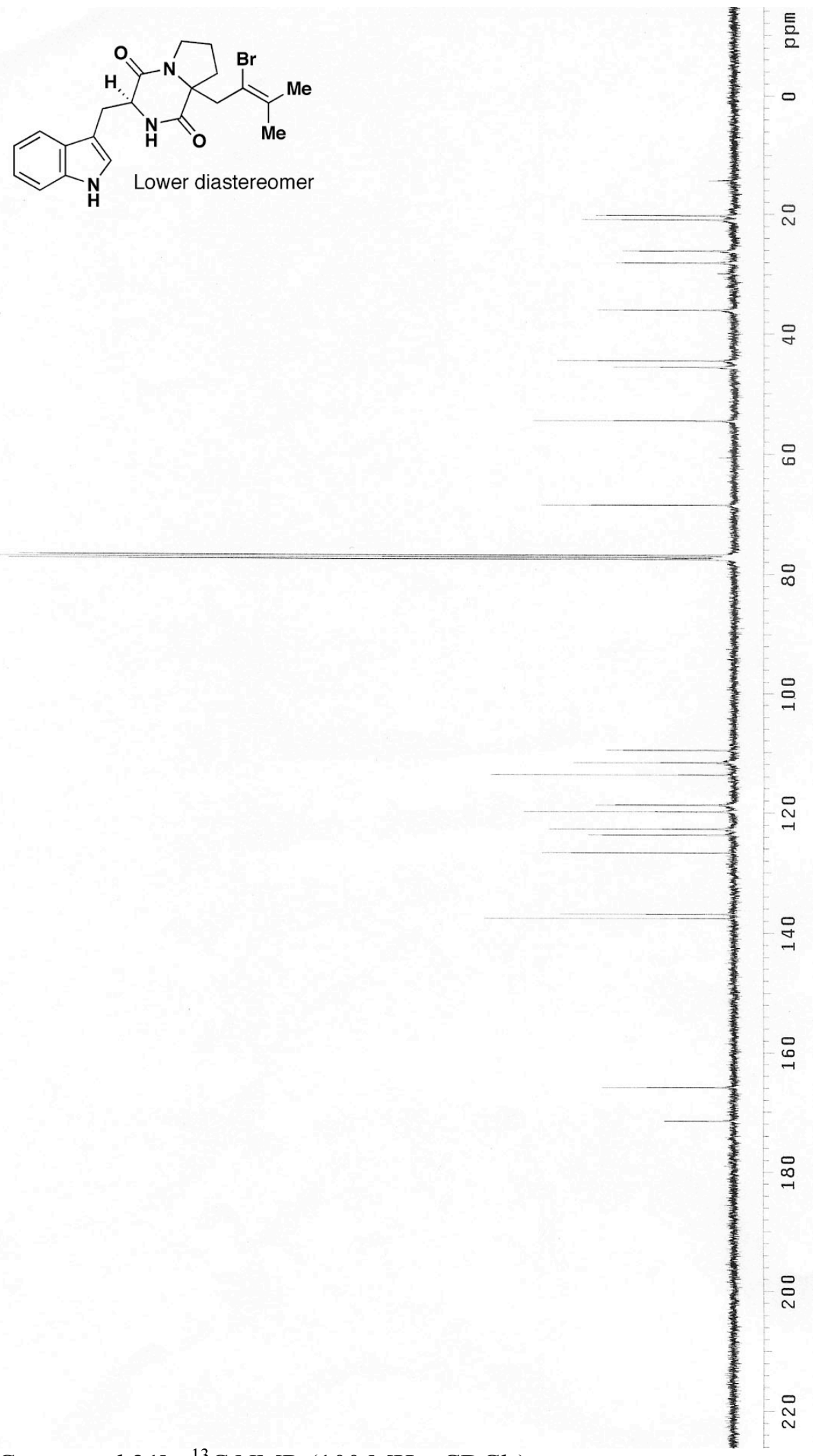

Compound 21b: ${ }^{13} \mathrm{C}$ NMR (100 MHz, $\left.\mathrm{CDCl}_{3}\right)$ 

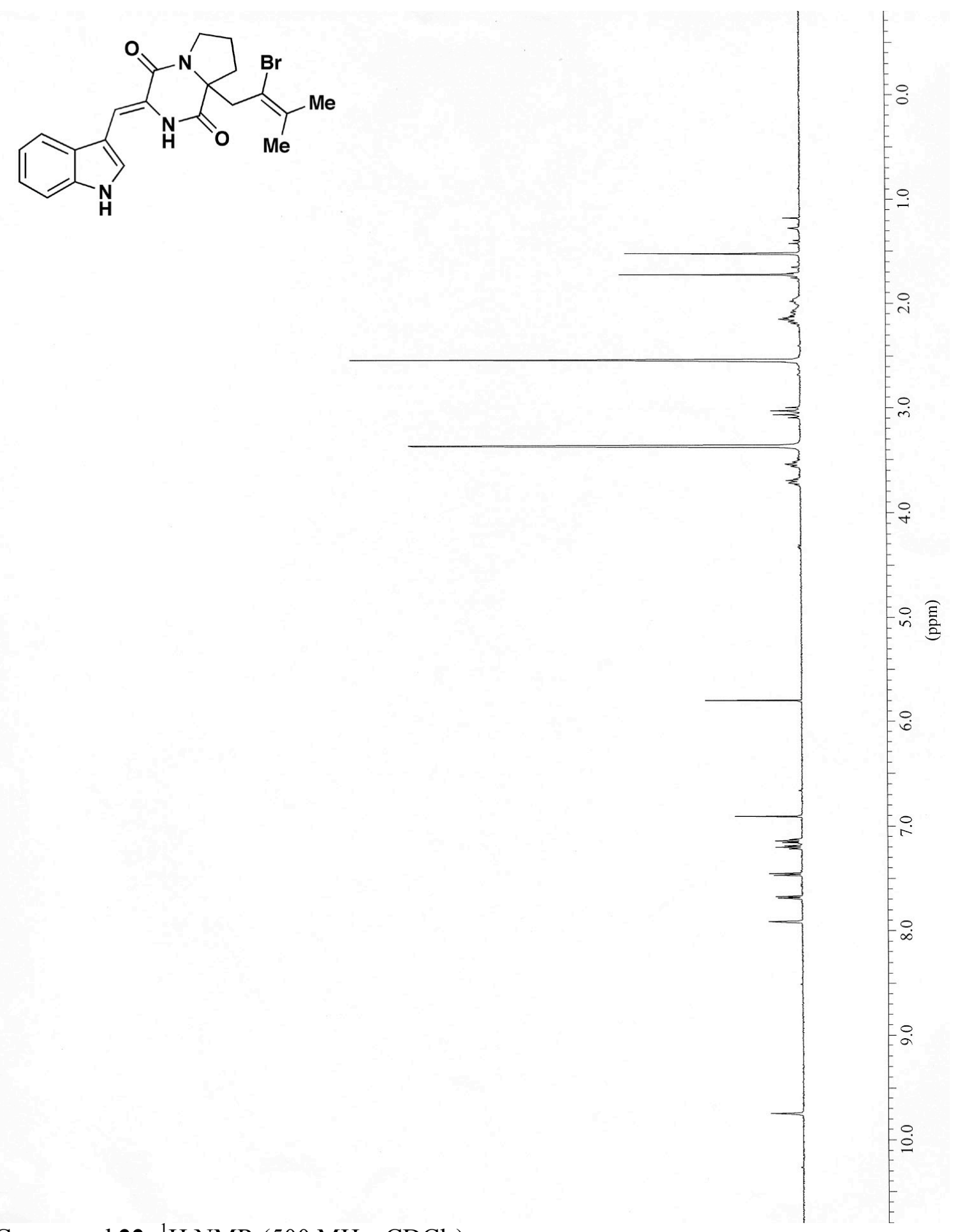

Compound 22: ${ }^{1} \mathrm{H}$ NMR (500 MHz, $\mathrm{CDCl}_{3}$ ) 

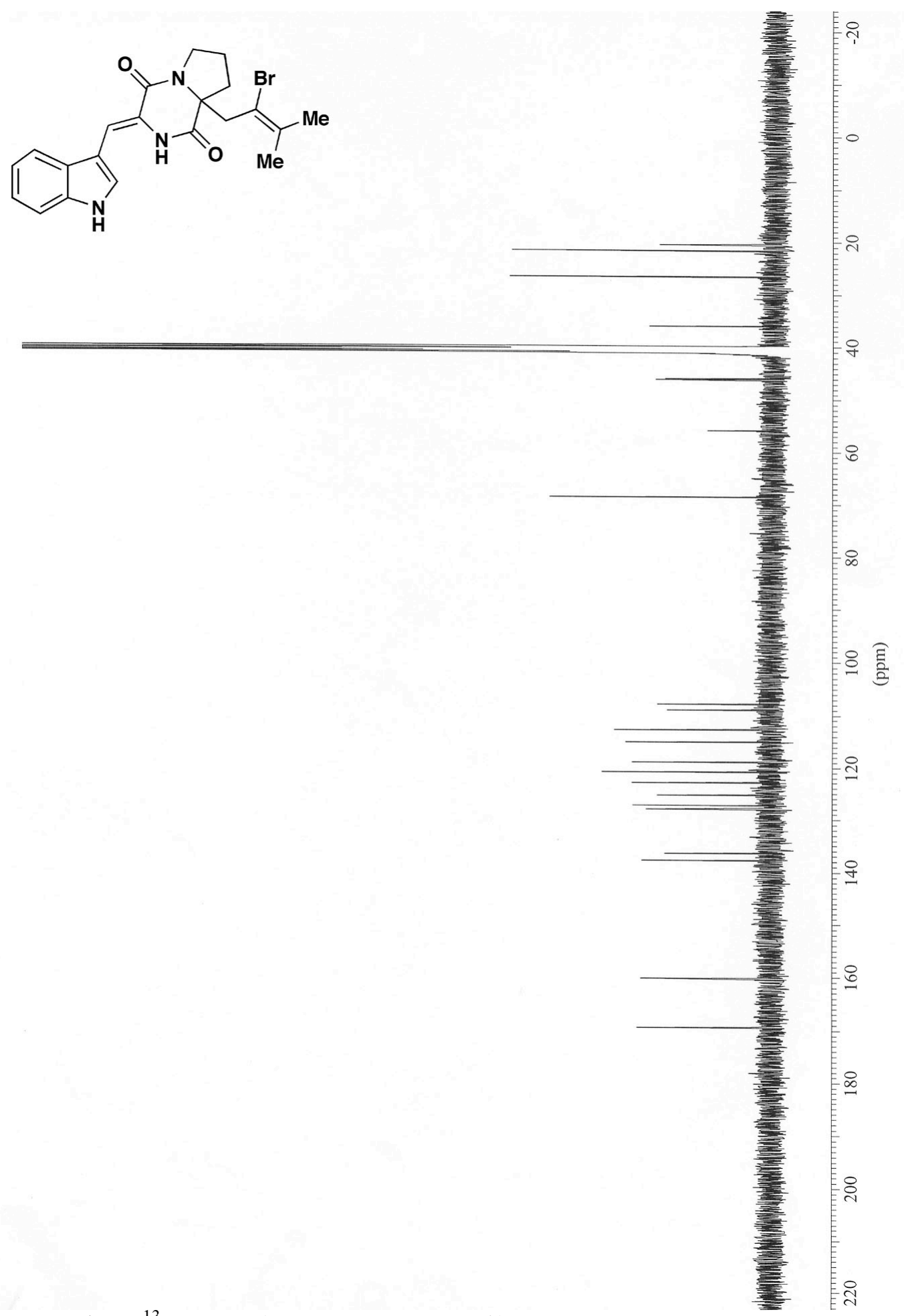

Compound 22: ${ }^{13} \mathrm{C}$ NMR (125 MHz, DMSO- $d_{6}$ ) 


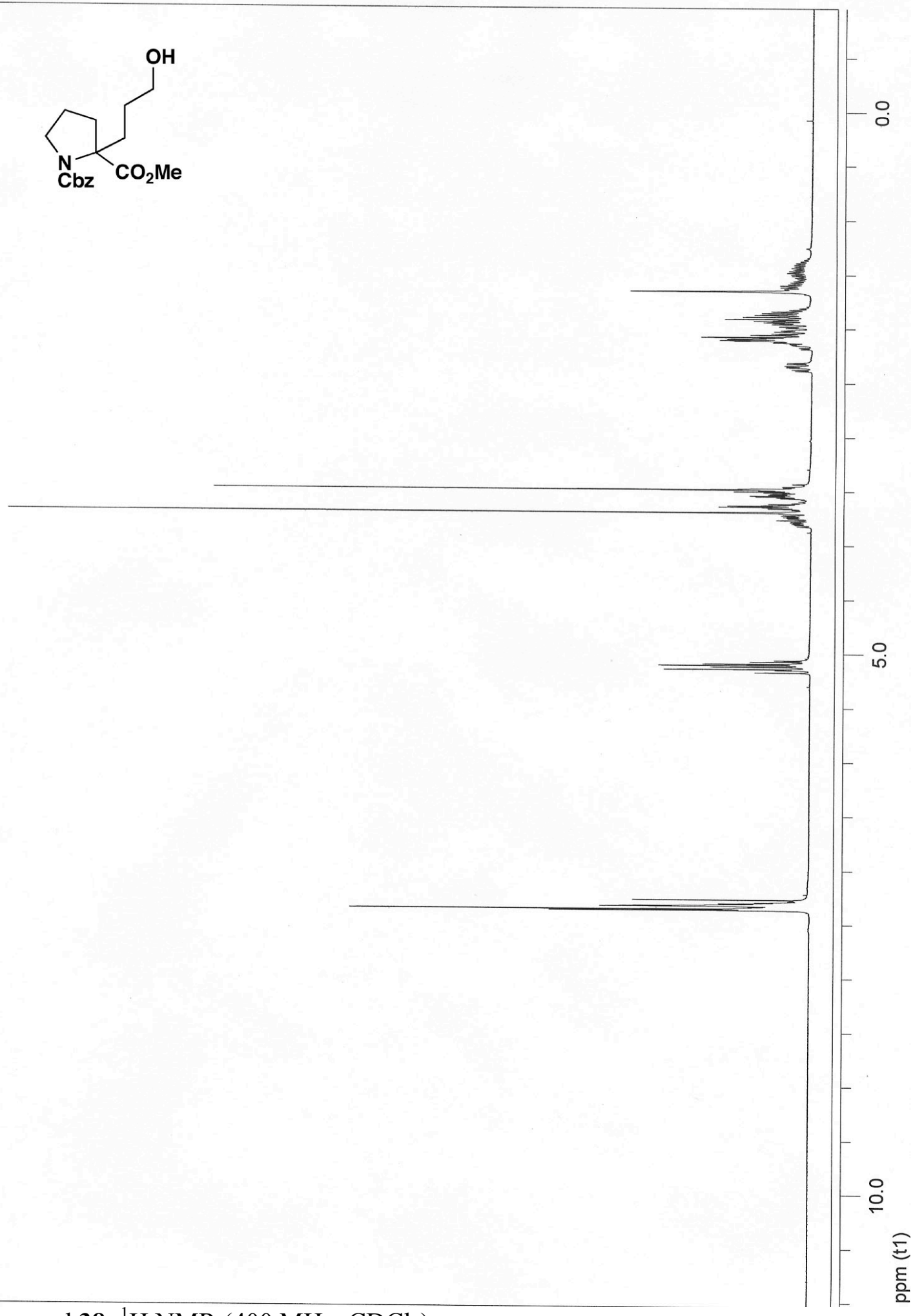

Compound 38: ${ }^{1} \mathrm{H}$ NMR (400 MHz, $\mathrm{CDCl}_{3}$ ) 


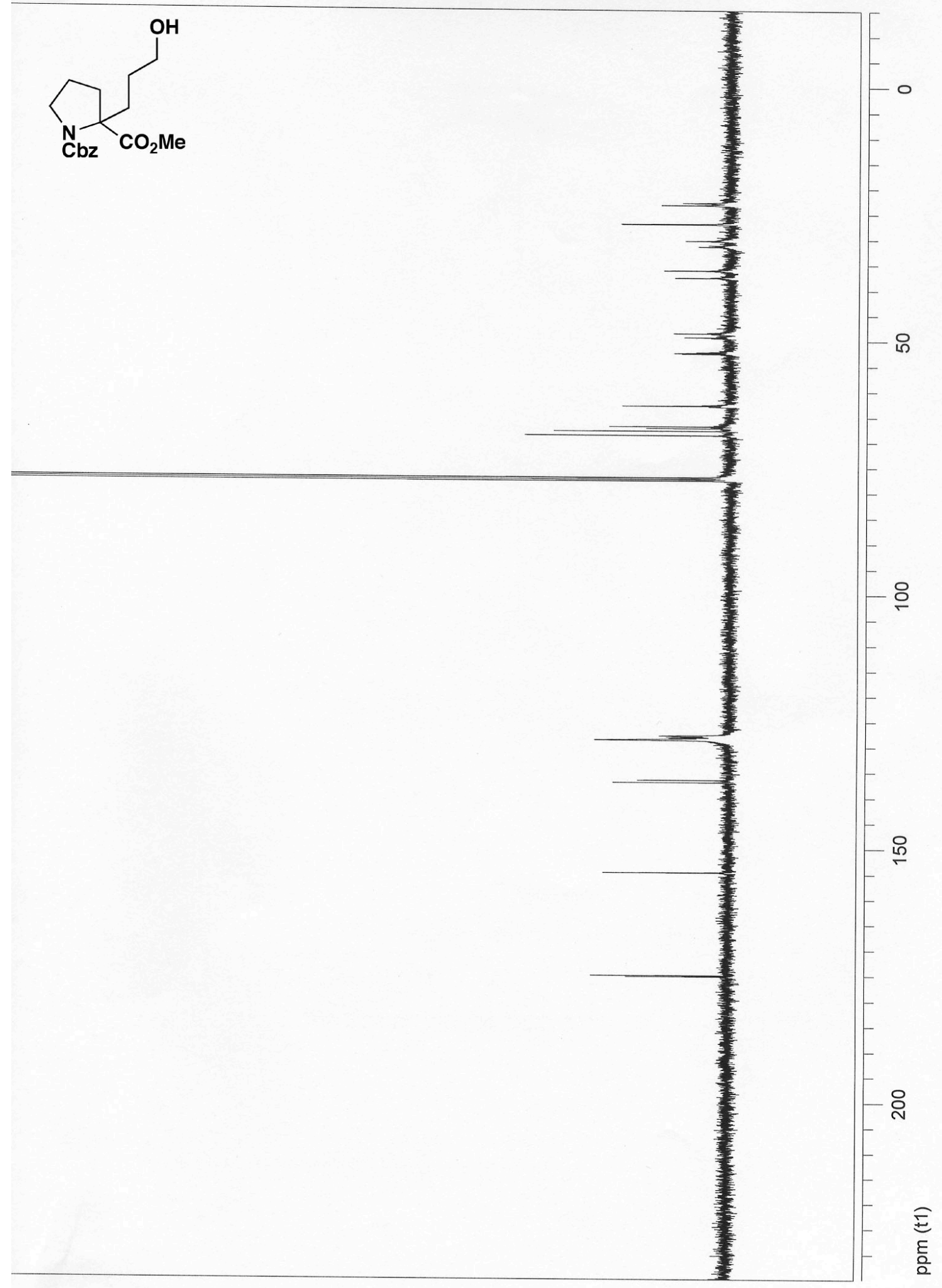

Compound 38: ${ }^{13} \mathrm{C}$ NMR (100 MHz, $\mathrm{CDCl}_{3}$ ) 


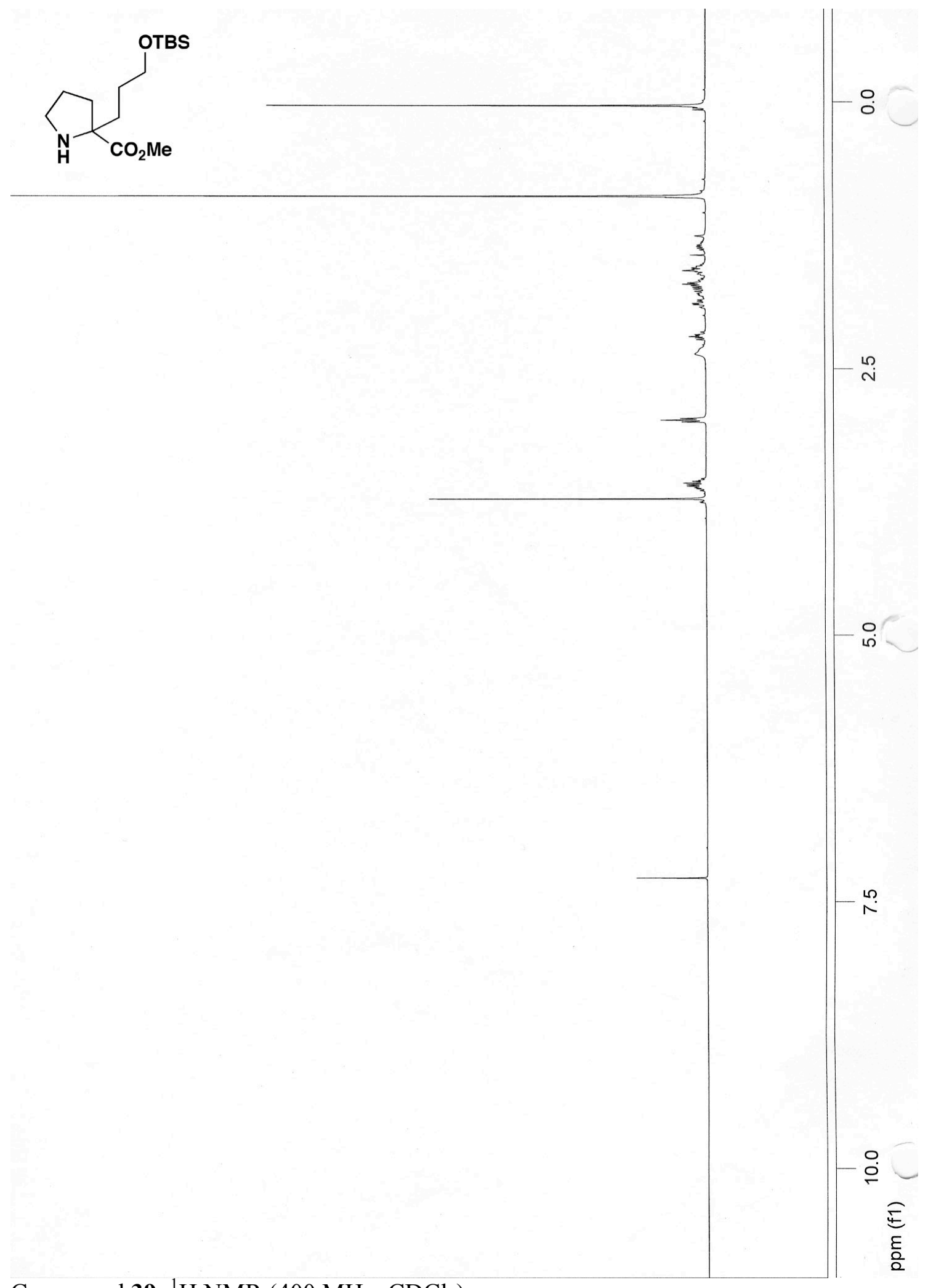

Compound 39: ${ }^{1} \mathrm{H}$ NMR (400 MHz, $\mathrm{CDCl}_{3}$ ) 

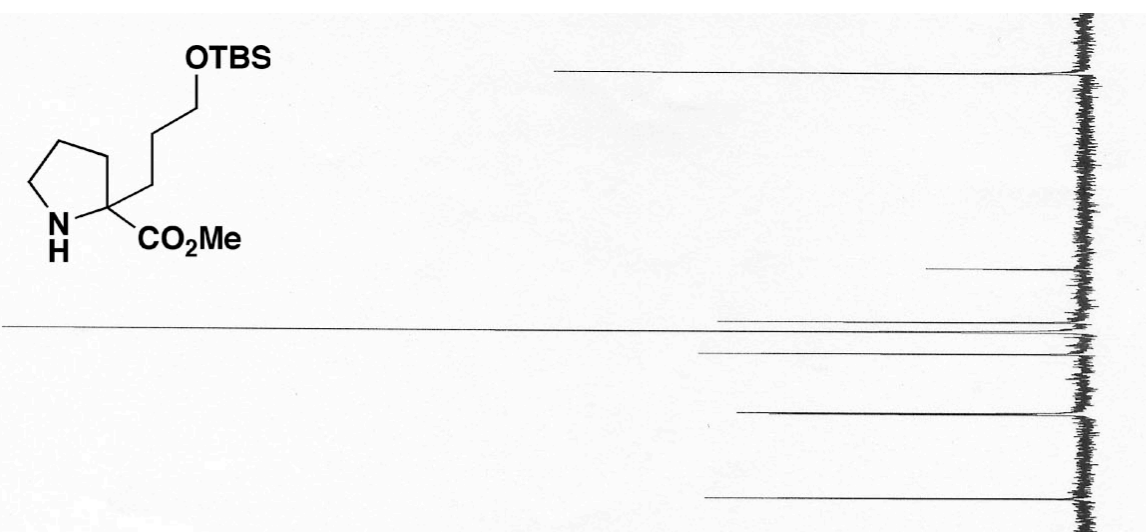

Compound 39: ${ }^{13} \mathrm{C}$ NMR (100 MHz, $\mathrm{CDCl}_{3}$ )

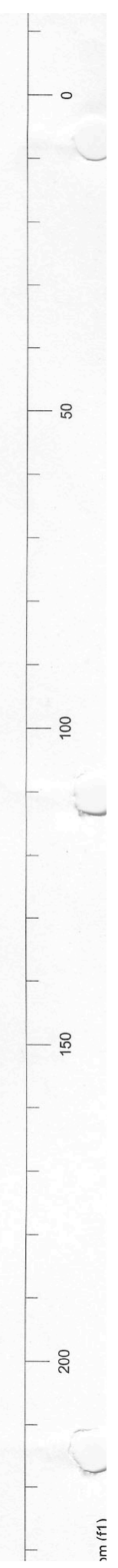




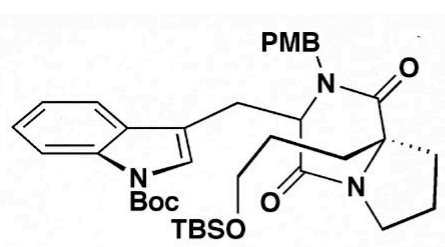

Upper diastereomer

Compound 43a: ${ }^{1} \mathrm{H}$ NMR (500 MHz, $\mathrm{CDCl}_{3}$ )

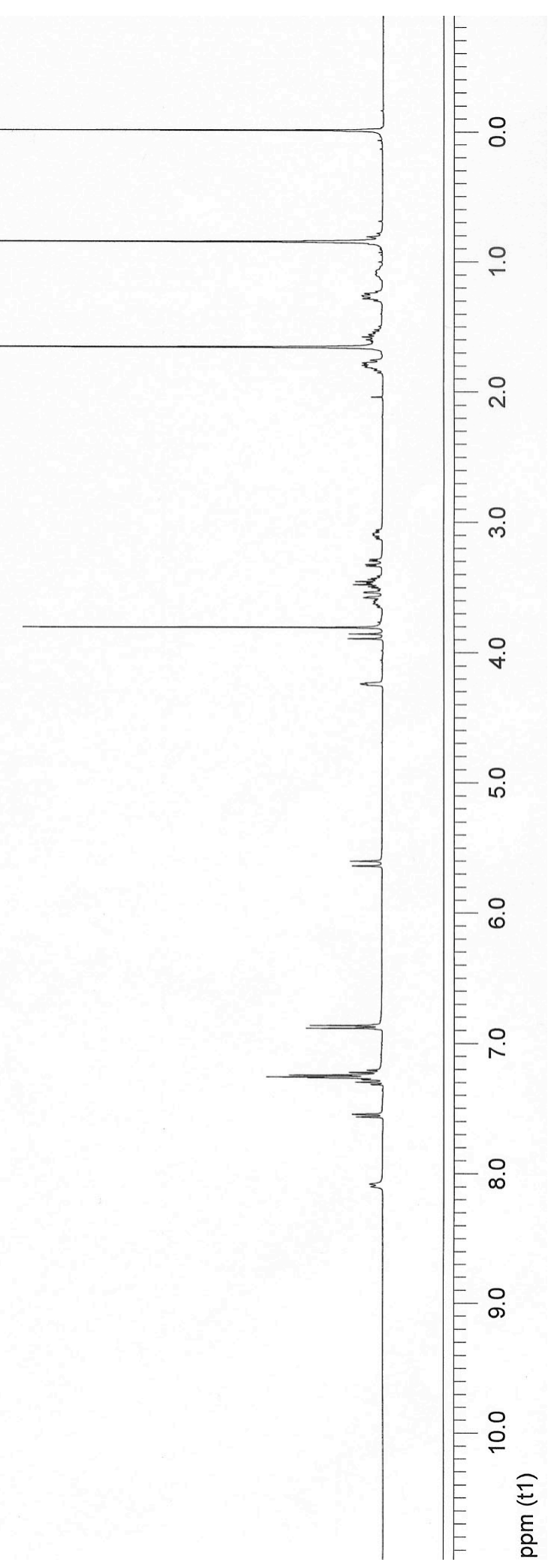




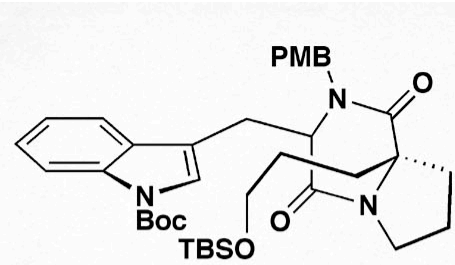

Upper diastereomer

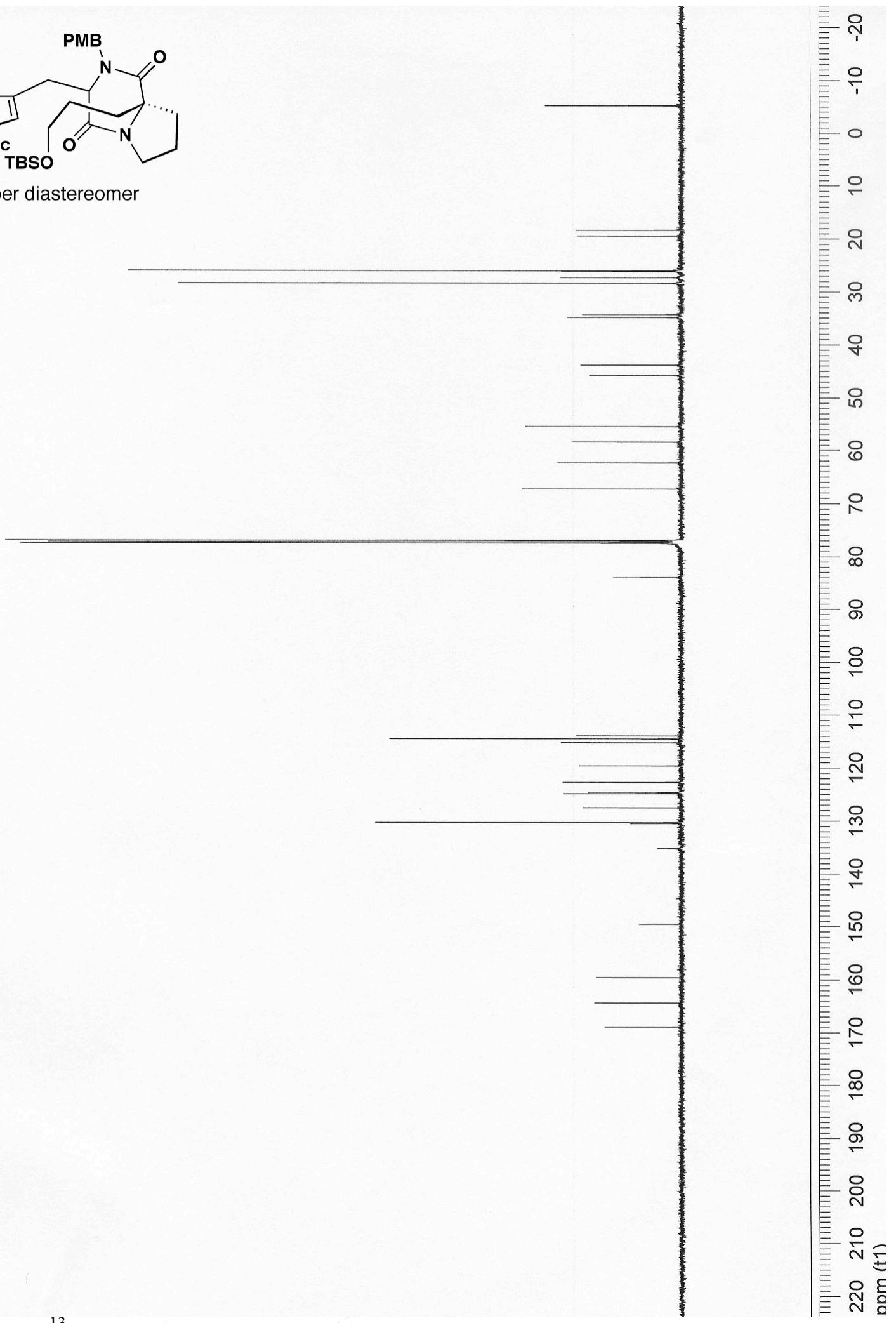

Compound 43a: ${ }^{13} \mathrm{C}$ NMR (100 MHz, $\left.\mathrm{CDCl}_{3}\right)$ 


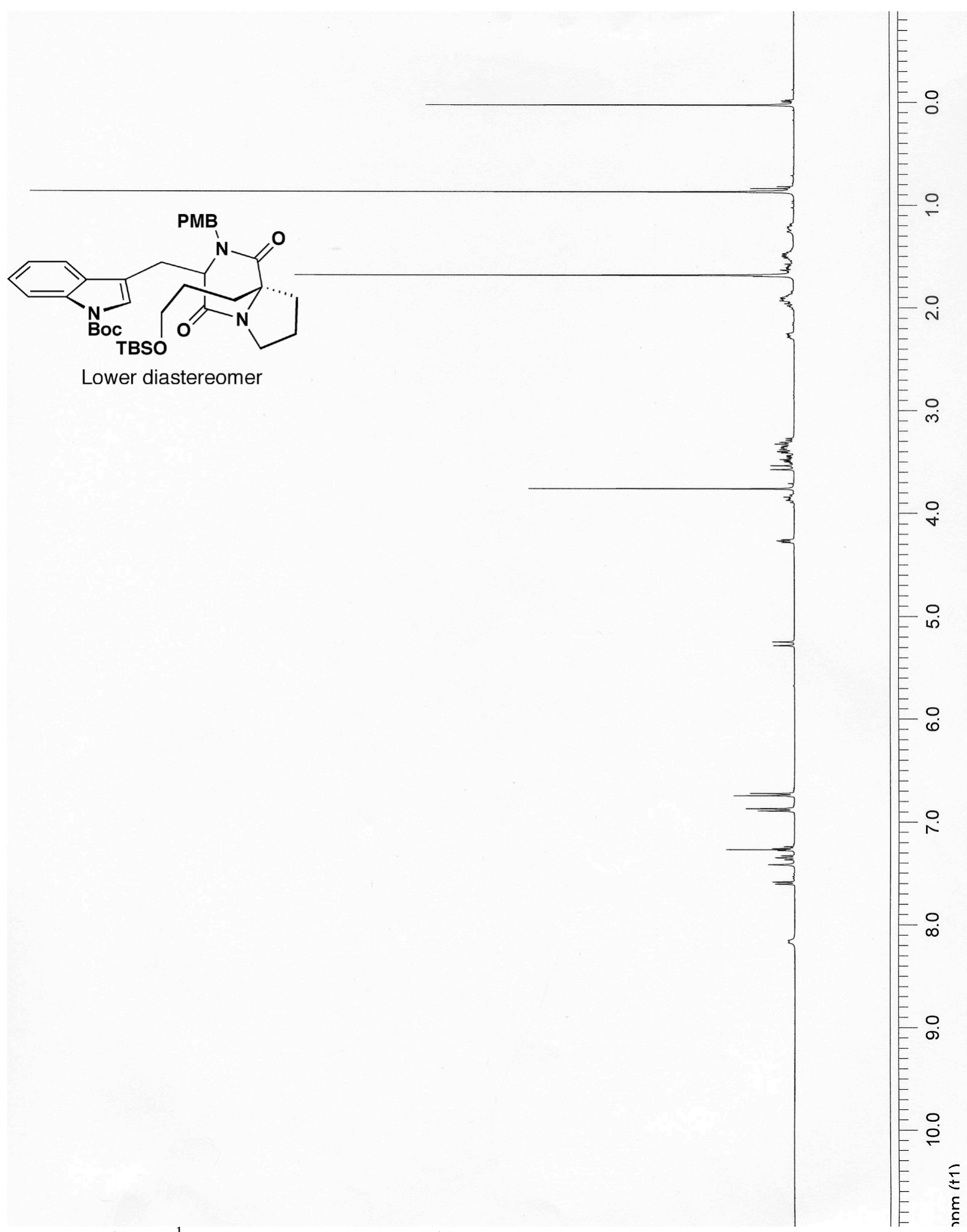

Compound 43b: ${ }^{1} \mathrm{H}$ NMR (400 MHz, $\mathrm{CDCl}_{3}$ ) 

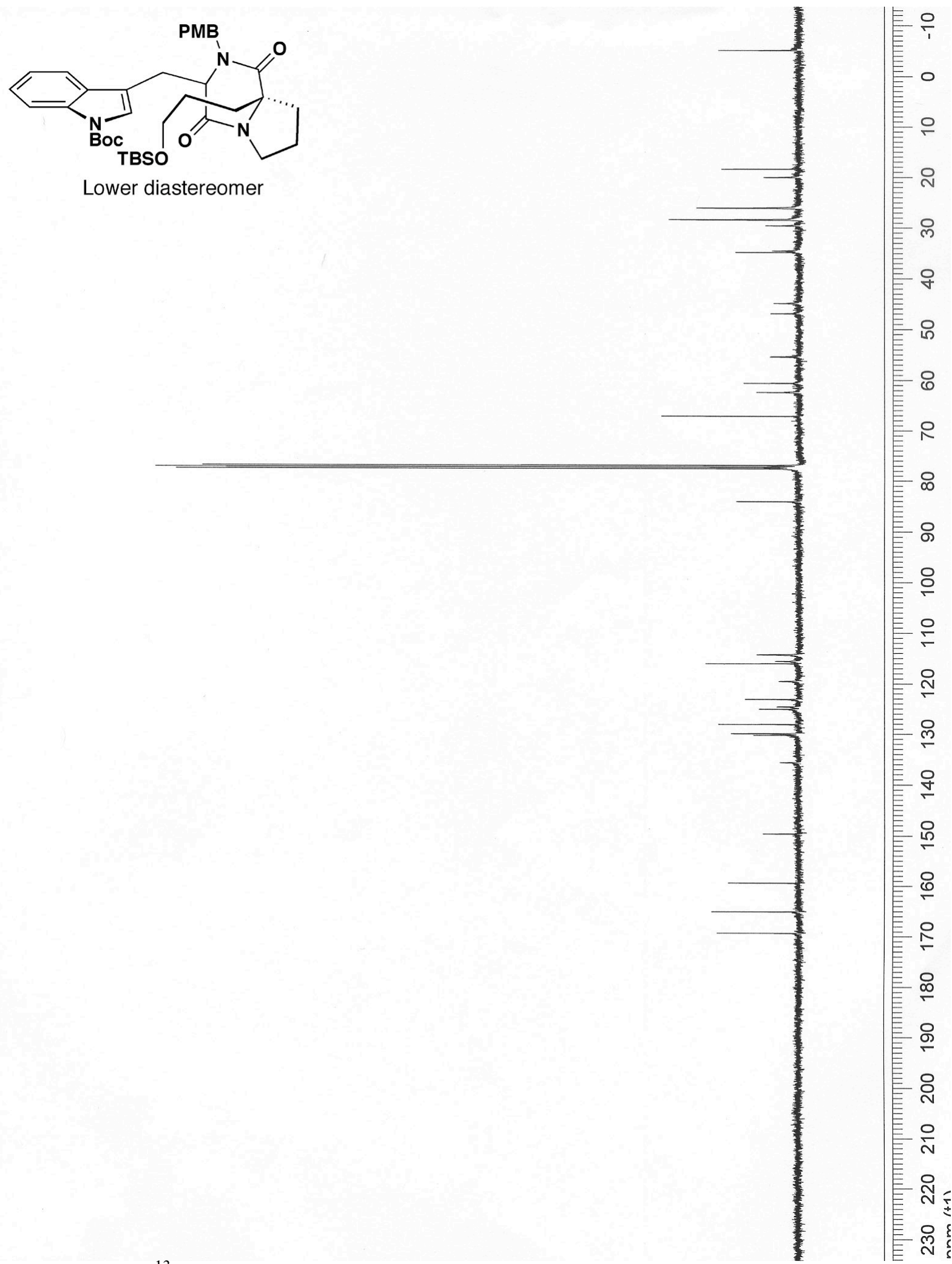

Compound 43b: ${ }^{13} \mathrm{C}$ NMR (100 MHz, $\left.\mathrm{CDCl}_{3}\right)$ 


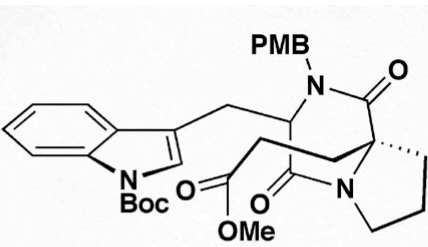

Upper diastereomer

1

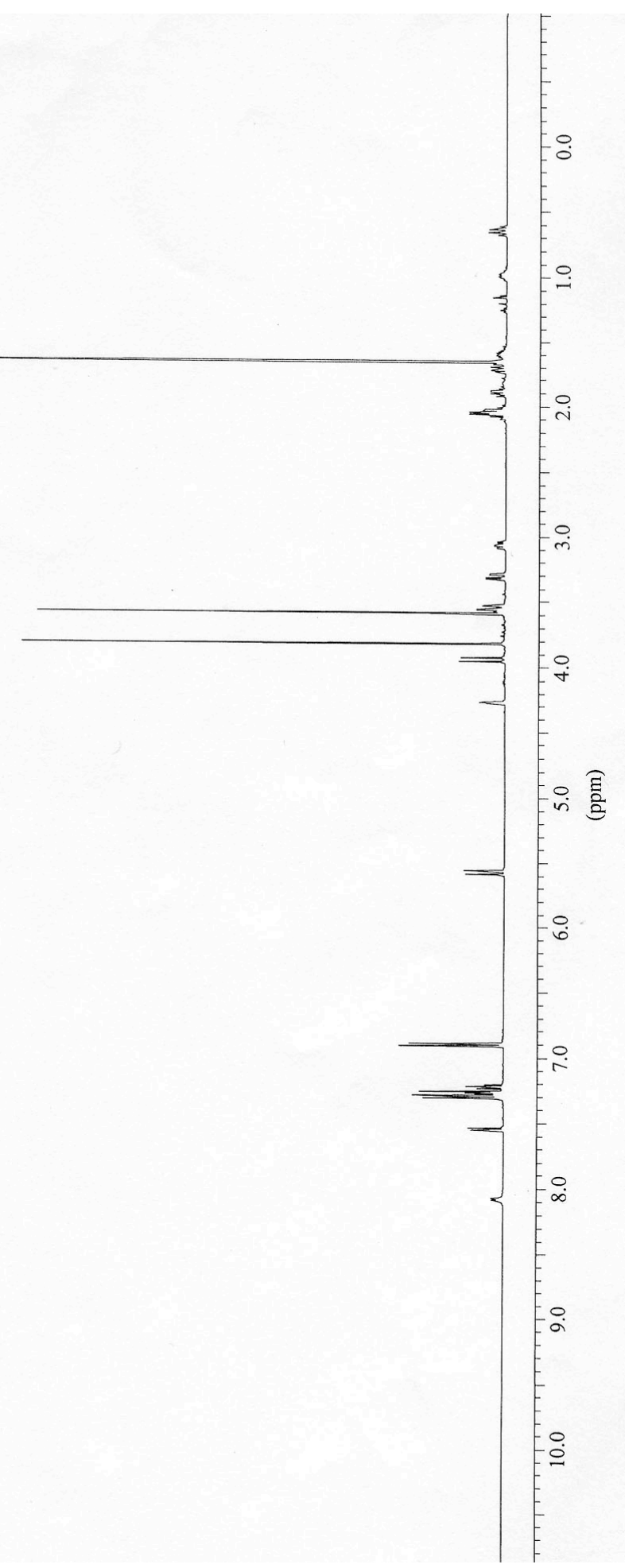

Compound 44a: ${ }^{1} \mathrm{H}$ NMR $\left(500 \mathrm{MHz}, \mathrm{CDCl}_{3}\right)$ 


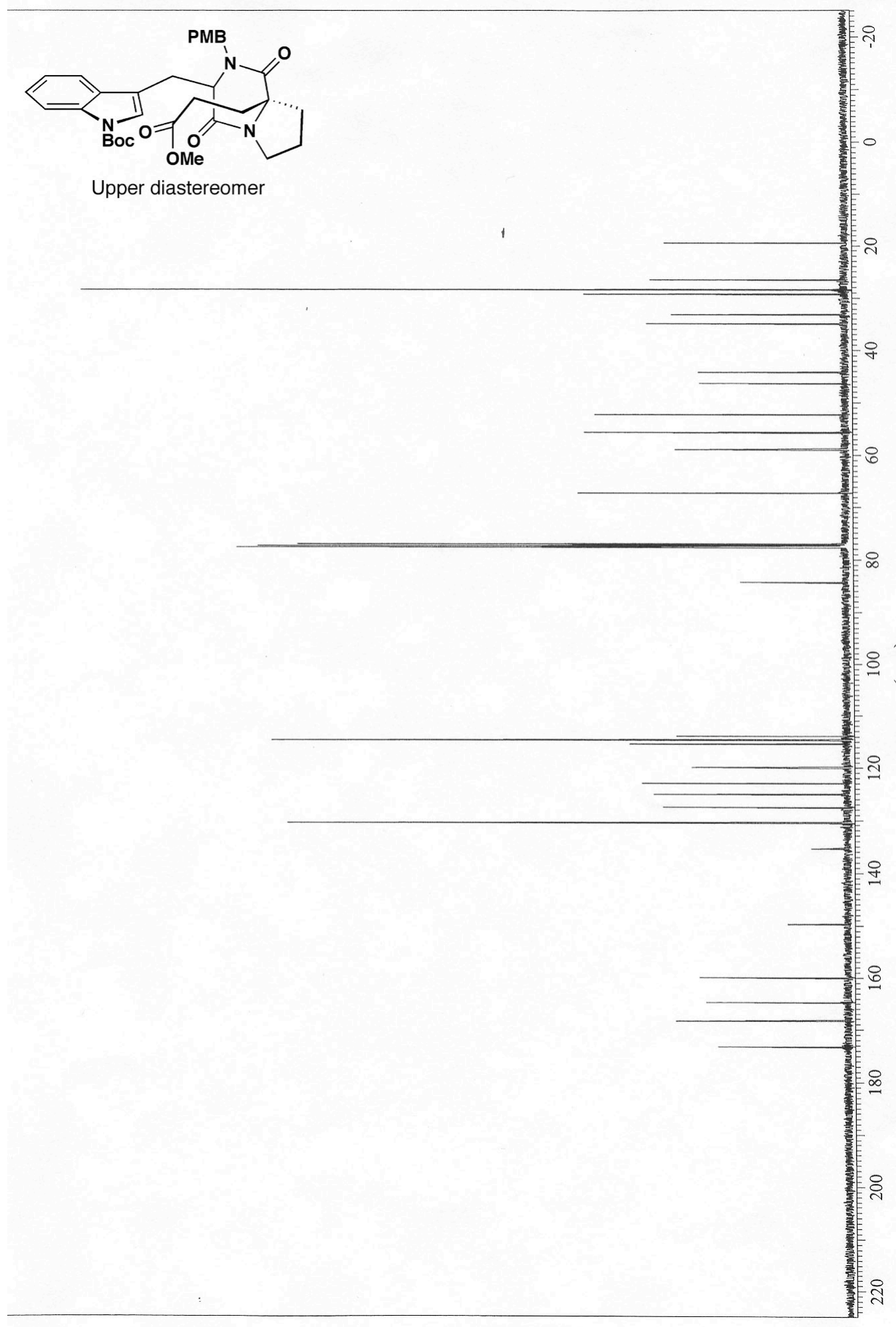

Compound 44a: ${ }^{13} \mathrm{C}$ NMR (125 MHz, $\mathrm{CDCl}_{3}$ ) 


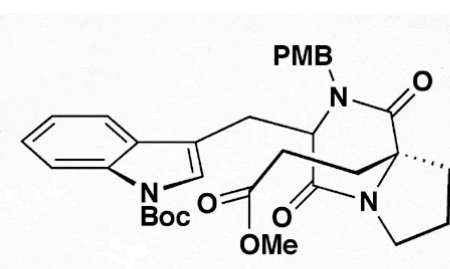

Lower diastereomer

Compound 44b: ${ }^{1} \mathrm{H}$ NMR $\left(400 \mathrm{MHz}, \mathrm{CDCl}_{3}\right)$ 


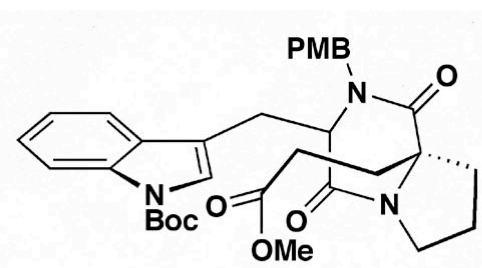

Lower diastereomer
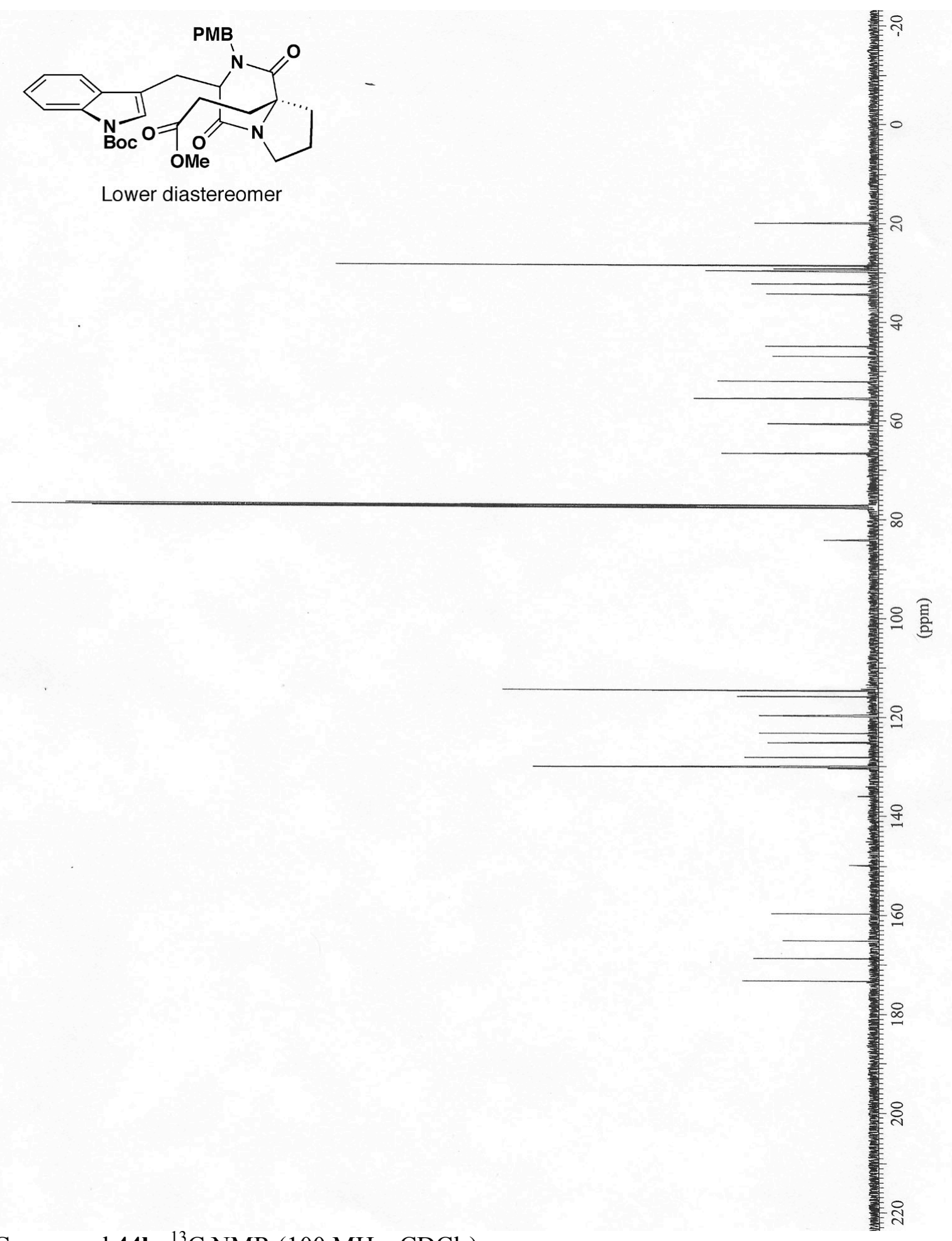

Compound 44b: ${ }^{13} \mathrm{C}$ NMR (100 MHz, $\left.\mathrm{CDCl}_{3}\right)$ 


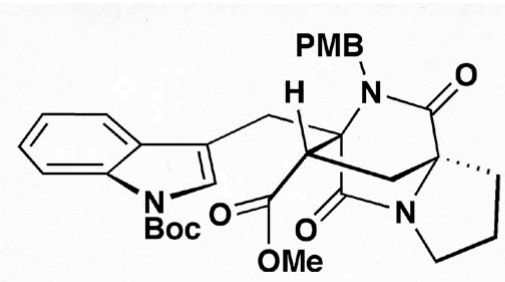

Compound 45: ( ${ }^{1} \mathrm{H}$ NMR (600 MHz, $\mathrm{CDCl}_{3}$ ) 


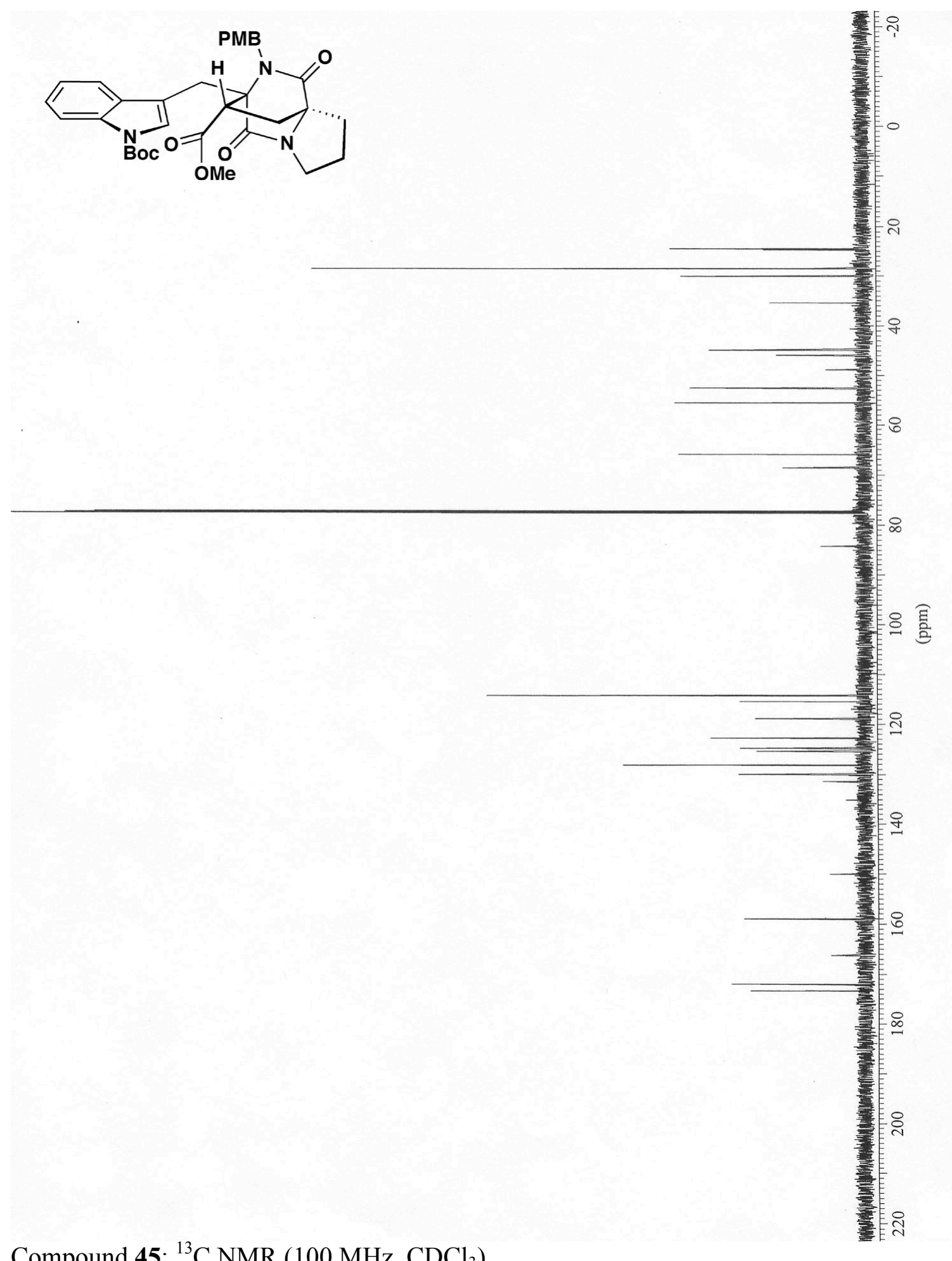

Compound 45: ${ }^{13} \mathrm{C}$ NMR (100 MHz, $\mathrm{CDCl}_{3}$ ) 


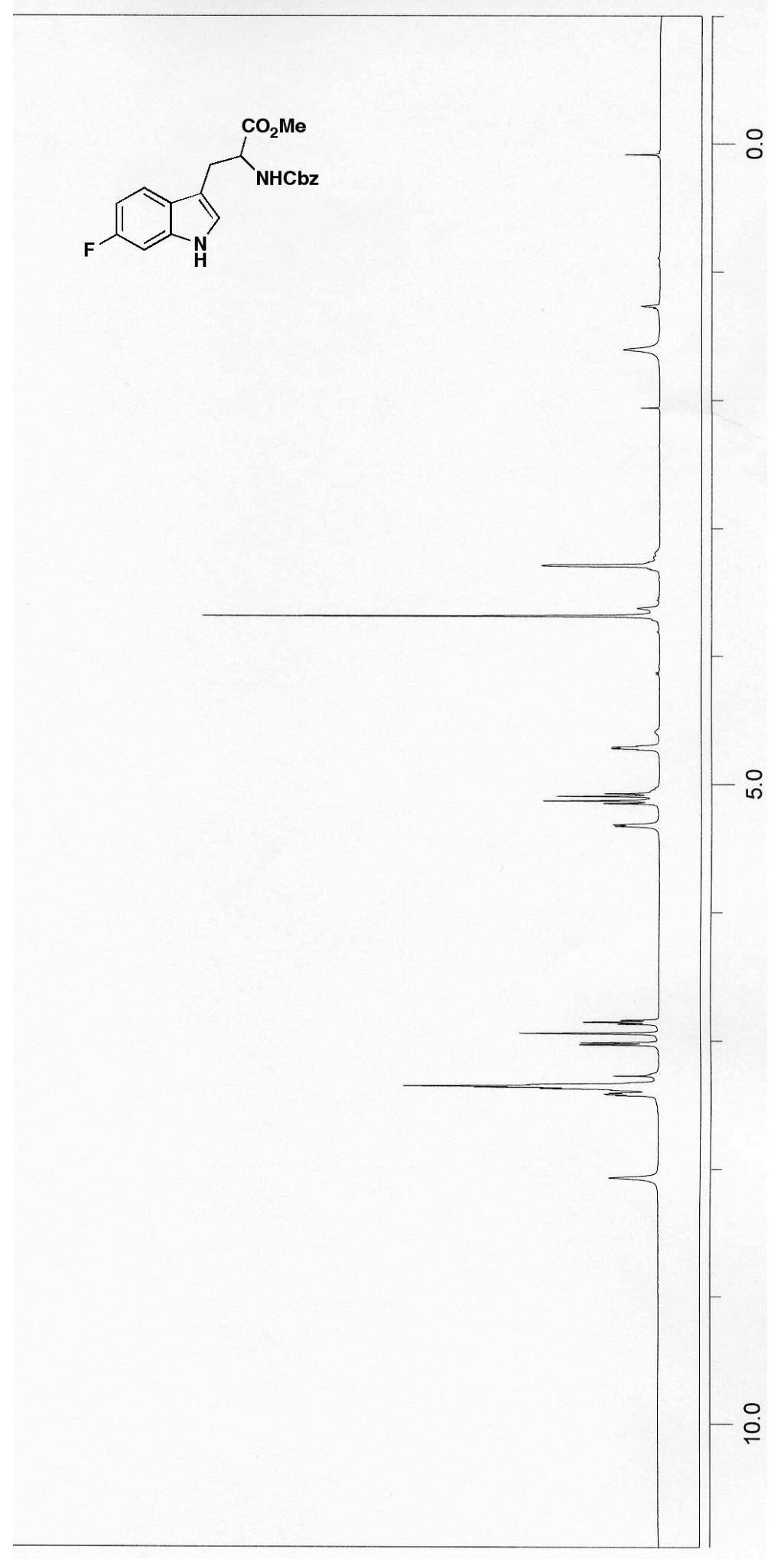

Compound 58: ${ }^{1} \mathrm{H}$ NMR (500 MHz, $\mathrm{CDCl}_{3}$ ) 


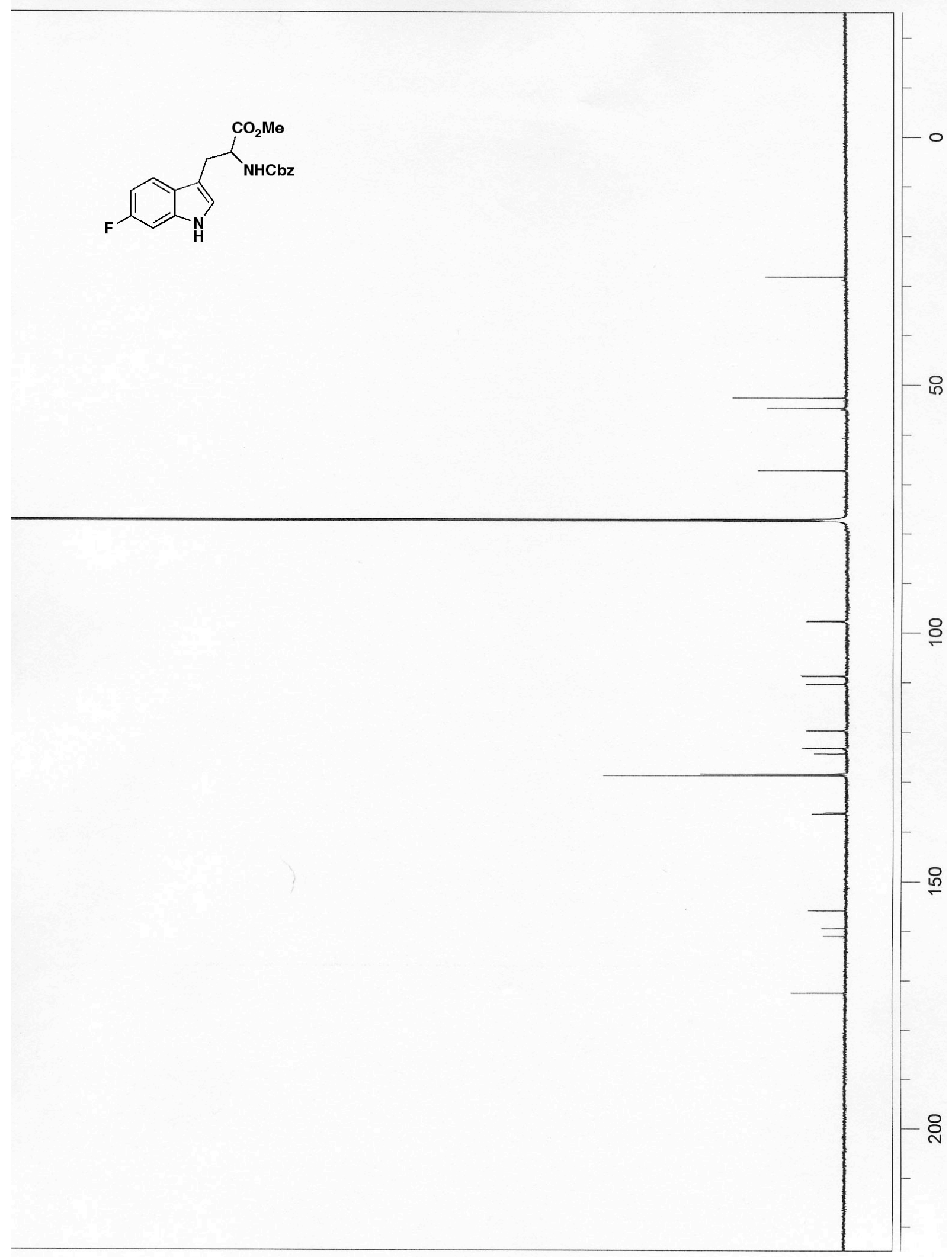

Compound 58: ${ }^{13} \mathrm{C}$ NMR (125 MHz, $\mathrm{CDCl}_{3}$ ) 

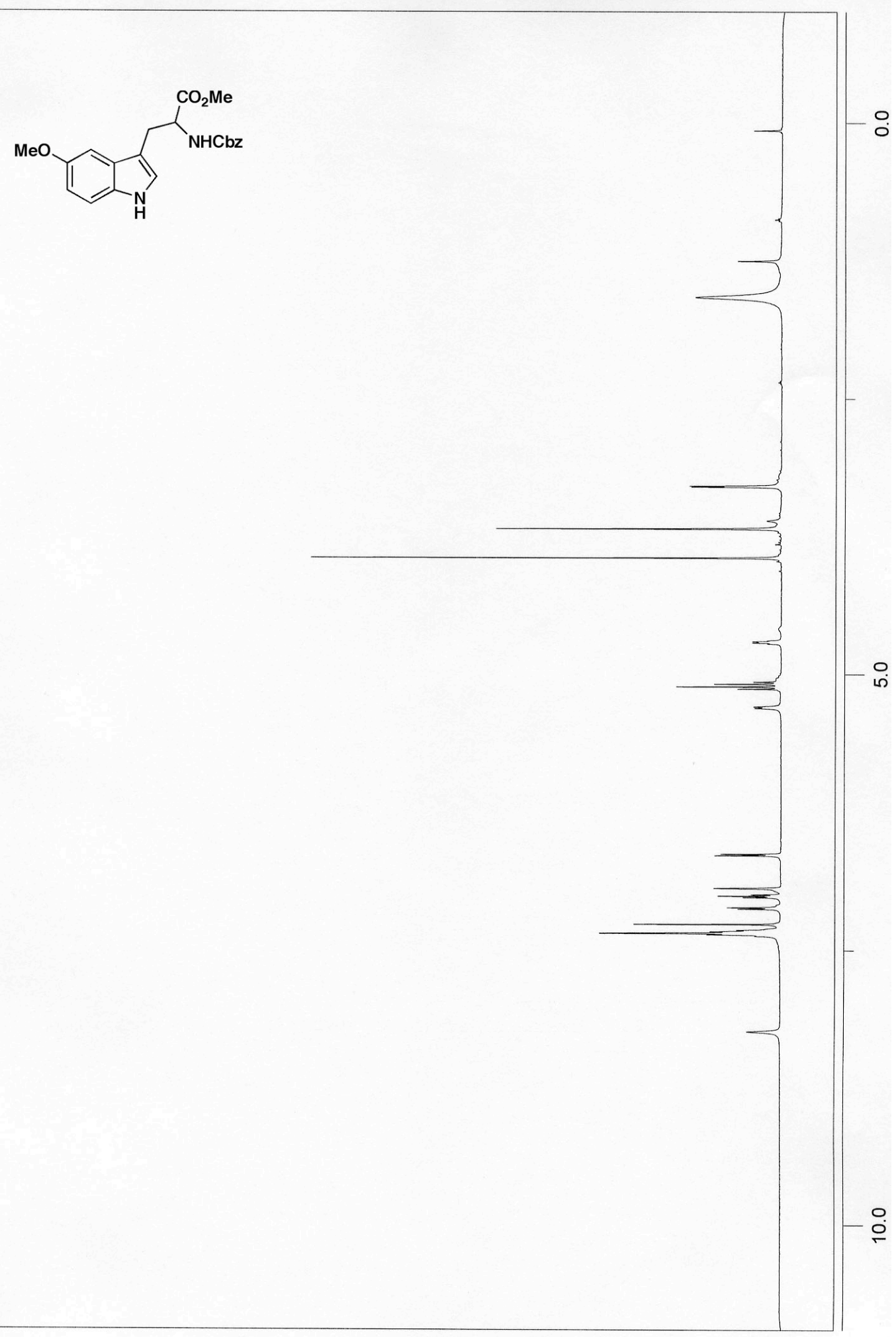

Compound 59: ${ }^{1} \mathrm{H}$ NMR (500 MHz, $\mathrm{CDCl}_{3}$ ) 


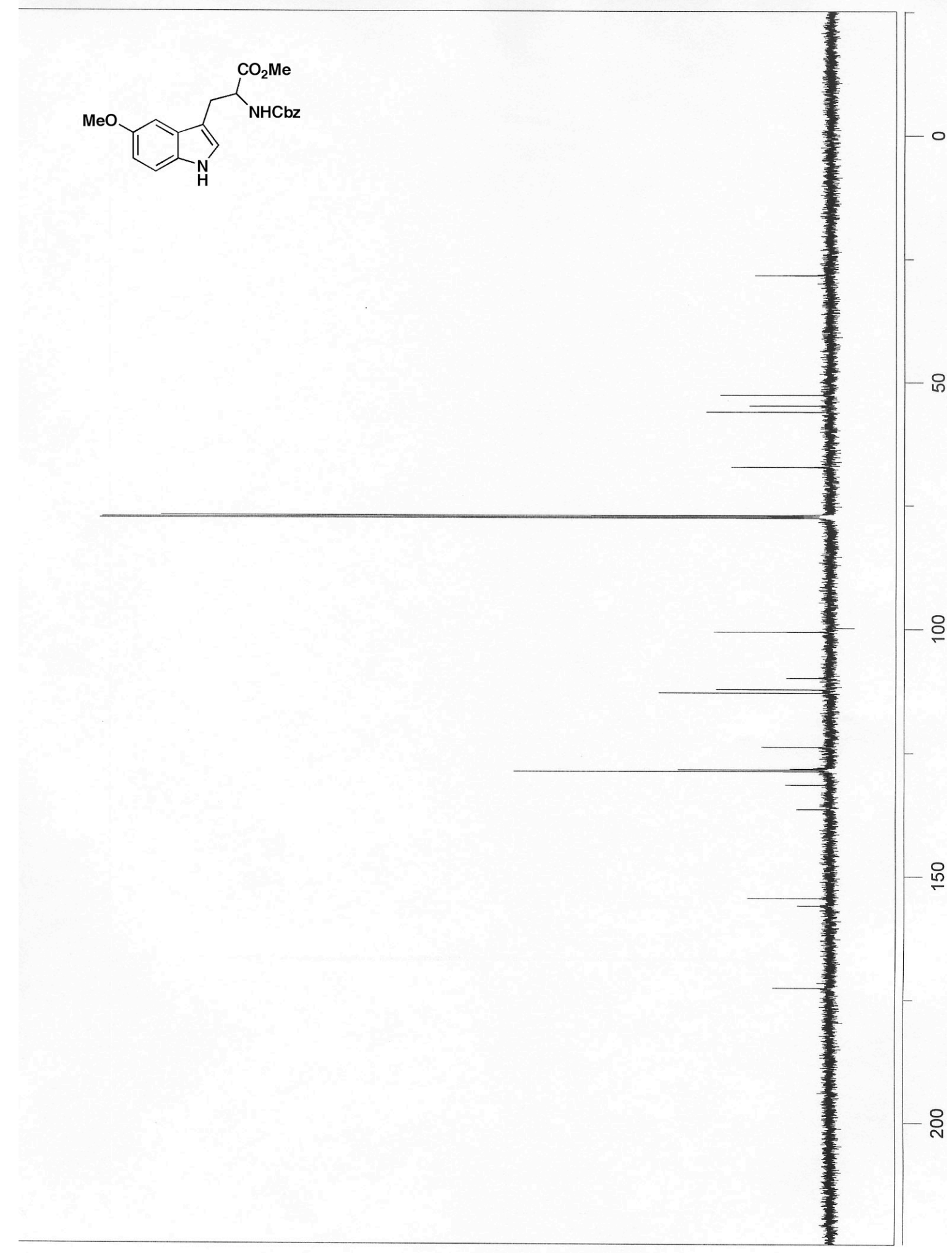

Compound 59: ${ }^{13} \mathrm{C}$ NMR (125 MHz, $\mathrm{CDCl}_{3}$ ) 


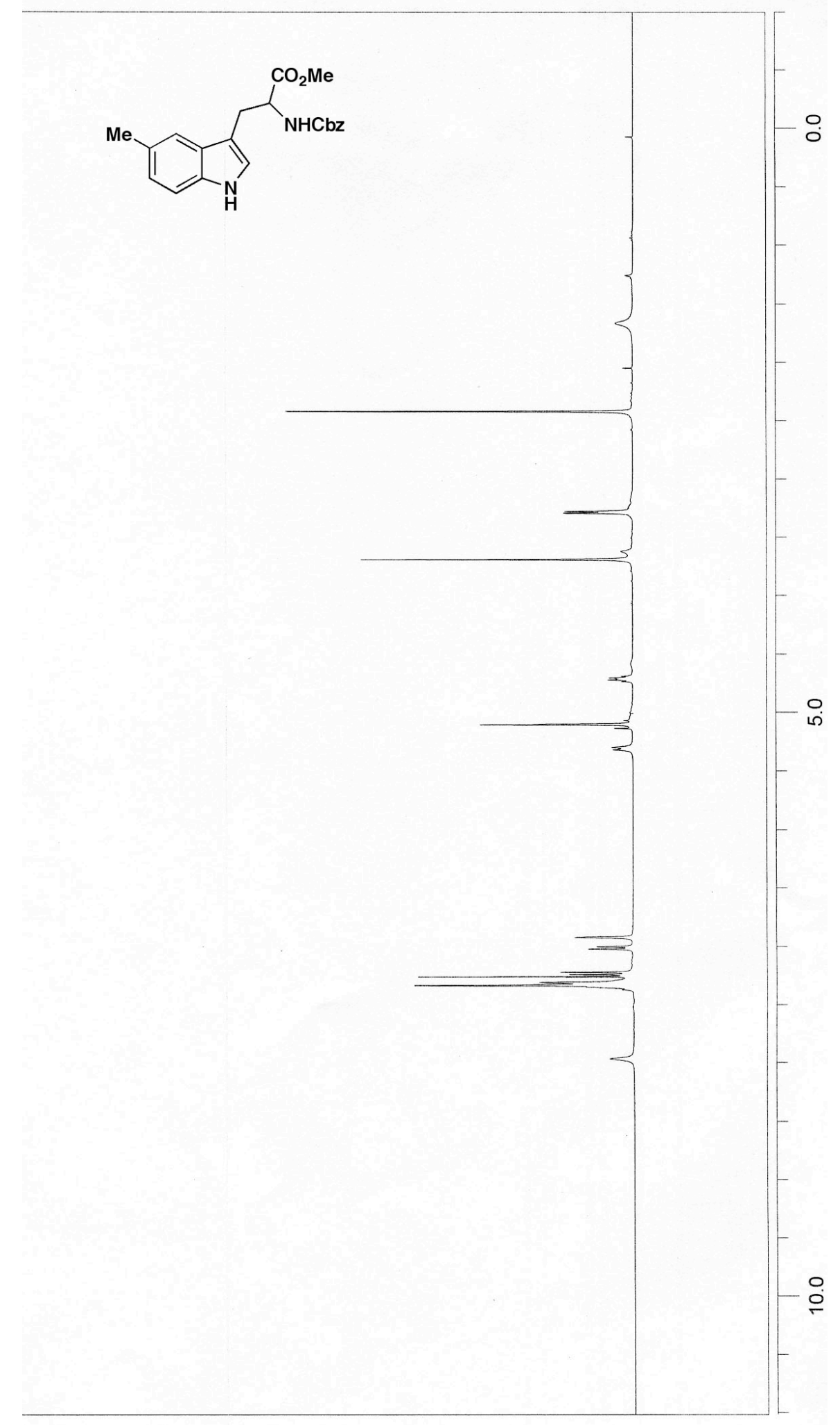

Compound 60: ${ }^{1} \mathrm{H}$ NMR (400 MHz, $\mathrm{CDCl}_{3}$ ) 


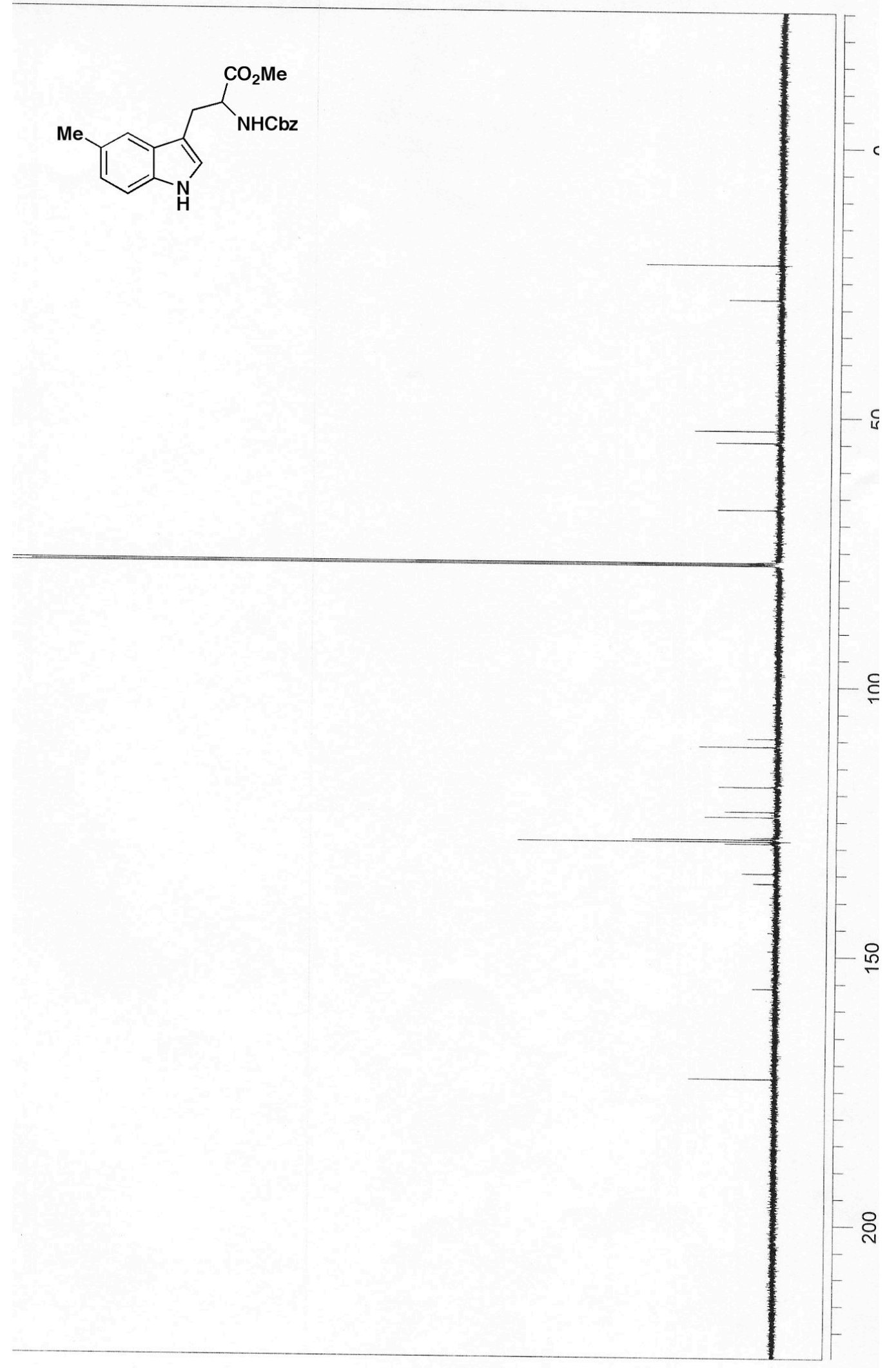

Compound 60: ${ }^{13} \mathrm{C}$ NMR (125 MHz, $\mathrm{CDCl}_{3}$ ) 


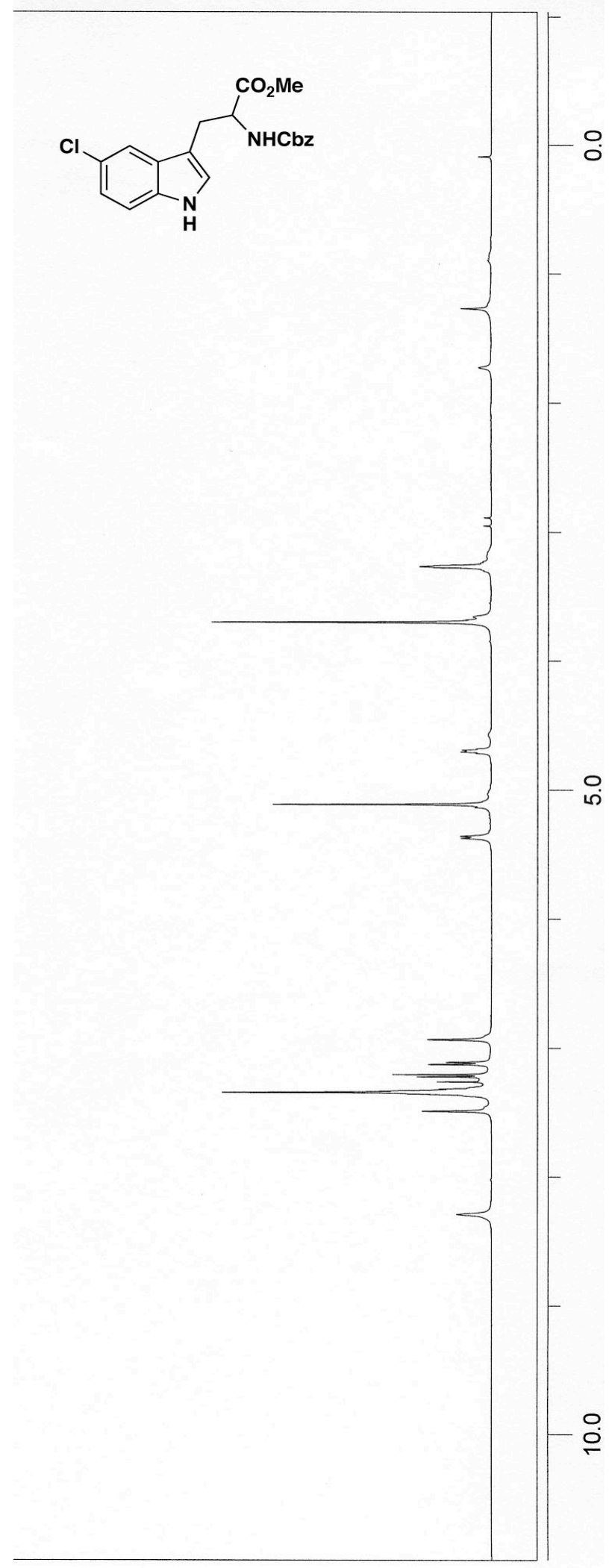

Compound 61: ${ }^{1} \mathrm{H}$ NMR (500 MHz, $\mathrm{CDCl}_{3}$ ) 


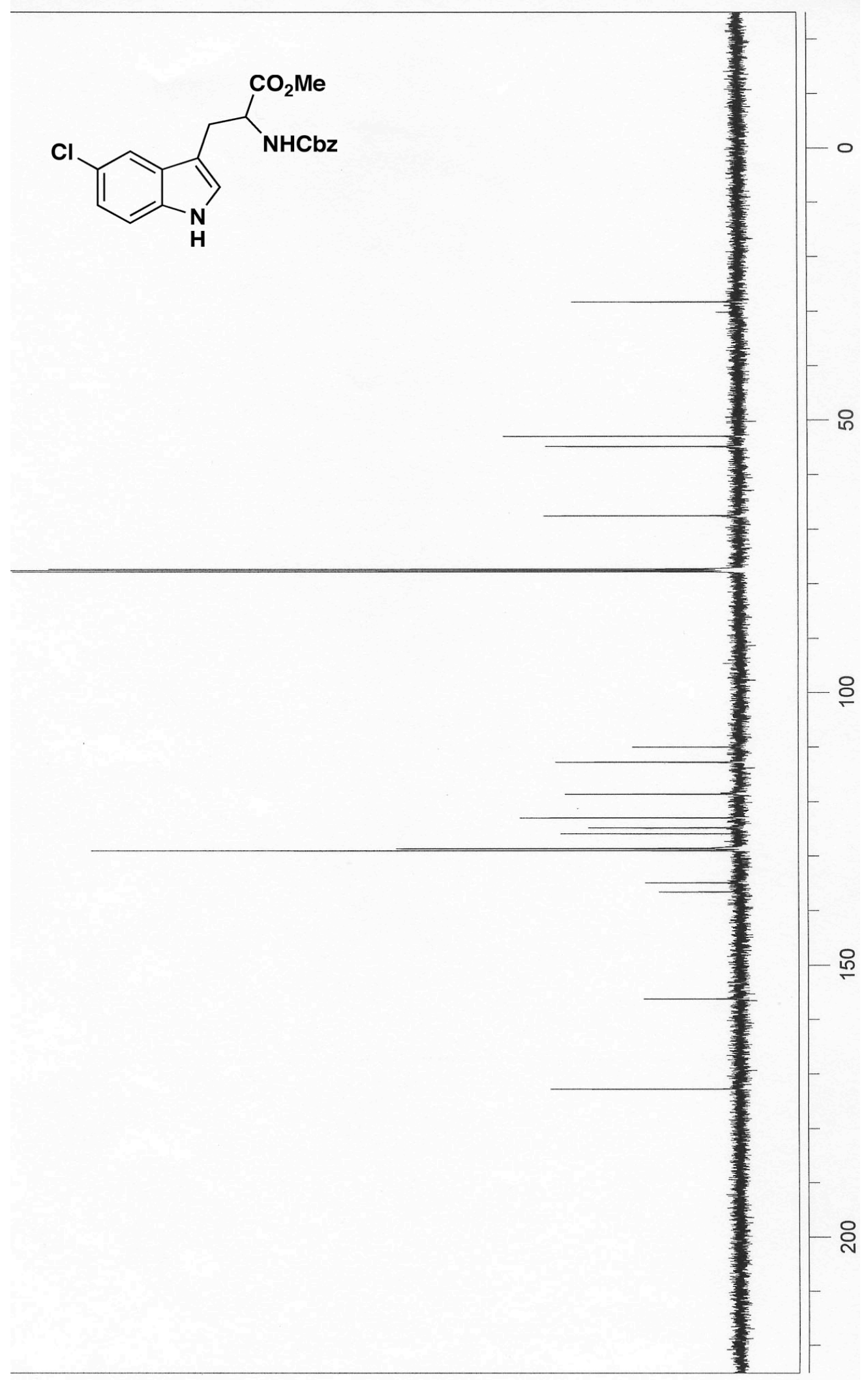

Compound 61: ${ }^{13} \mathrm{C}$ NMR (125 MHz, $\mathrm{CDCl}_{3}$ ) 


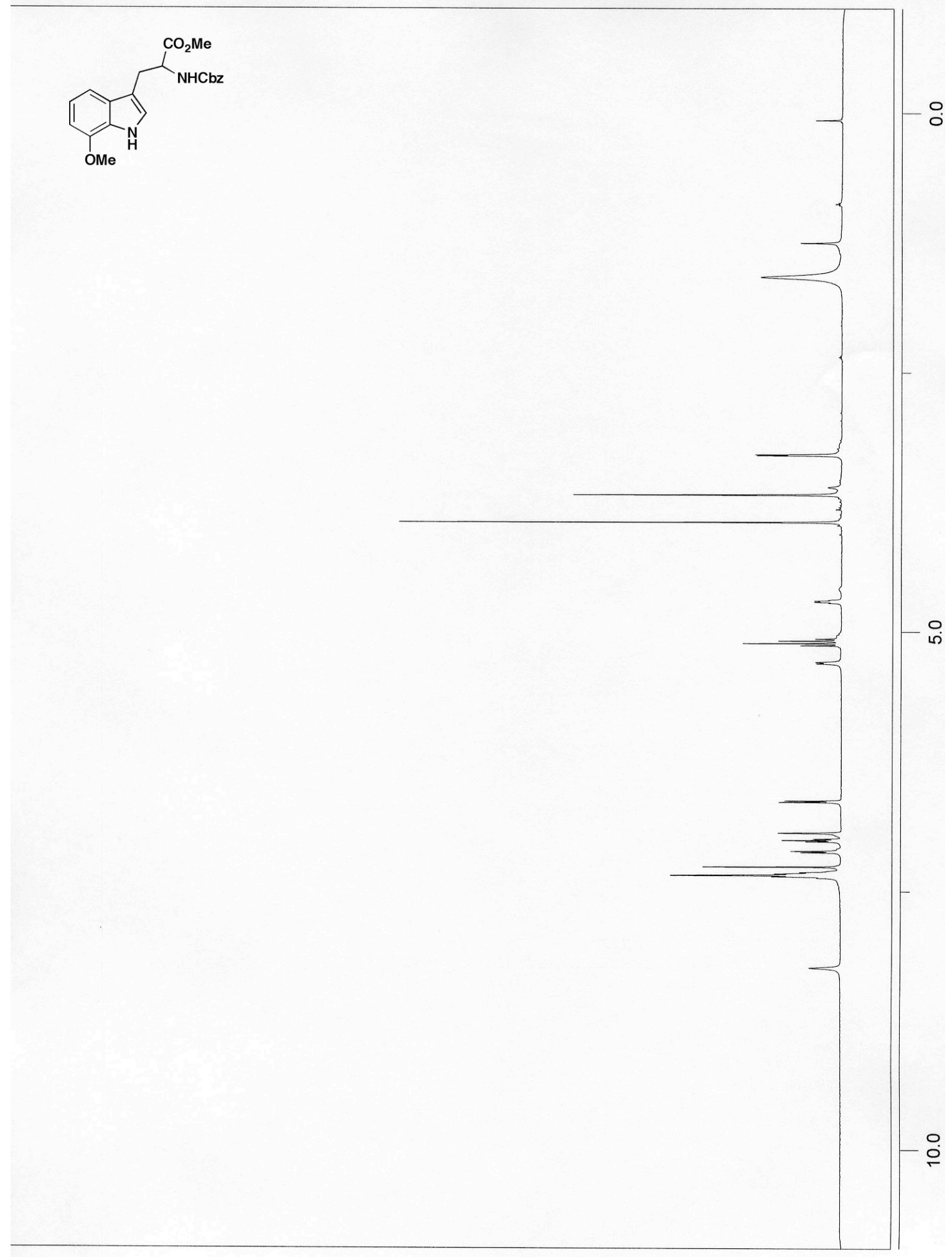

Compound 62: ${ }^{1} \mathrm{H}$ NMR (600 MHz, $\mathrm{CDCl}_{3}$ ) 


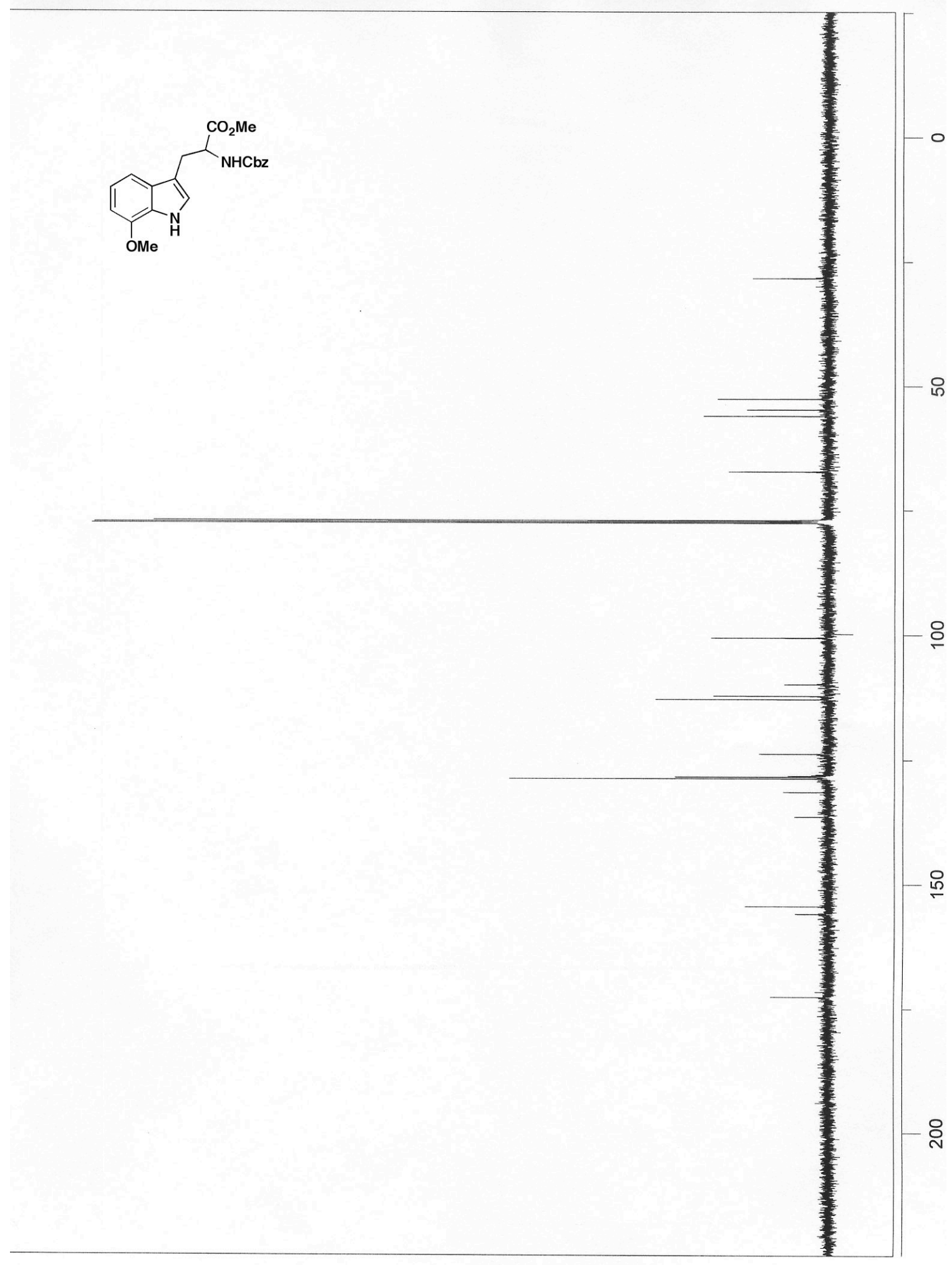

Compound 62: ${ }^{13} \mathrm{C}$ NMR (125 MHz, $\mathrm{CDCl}_{3}$ ) 


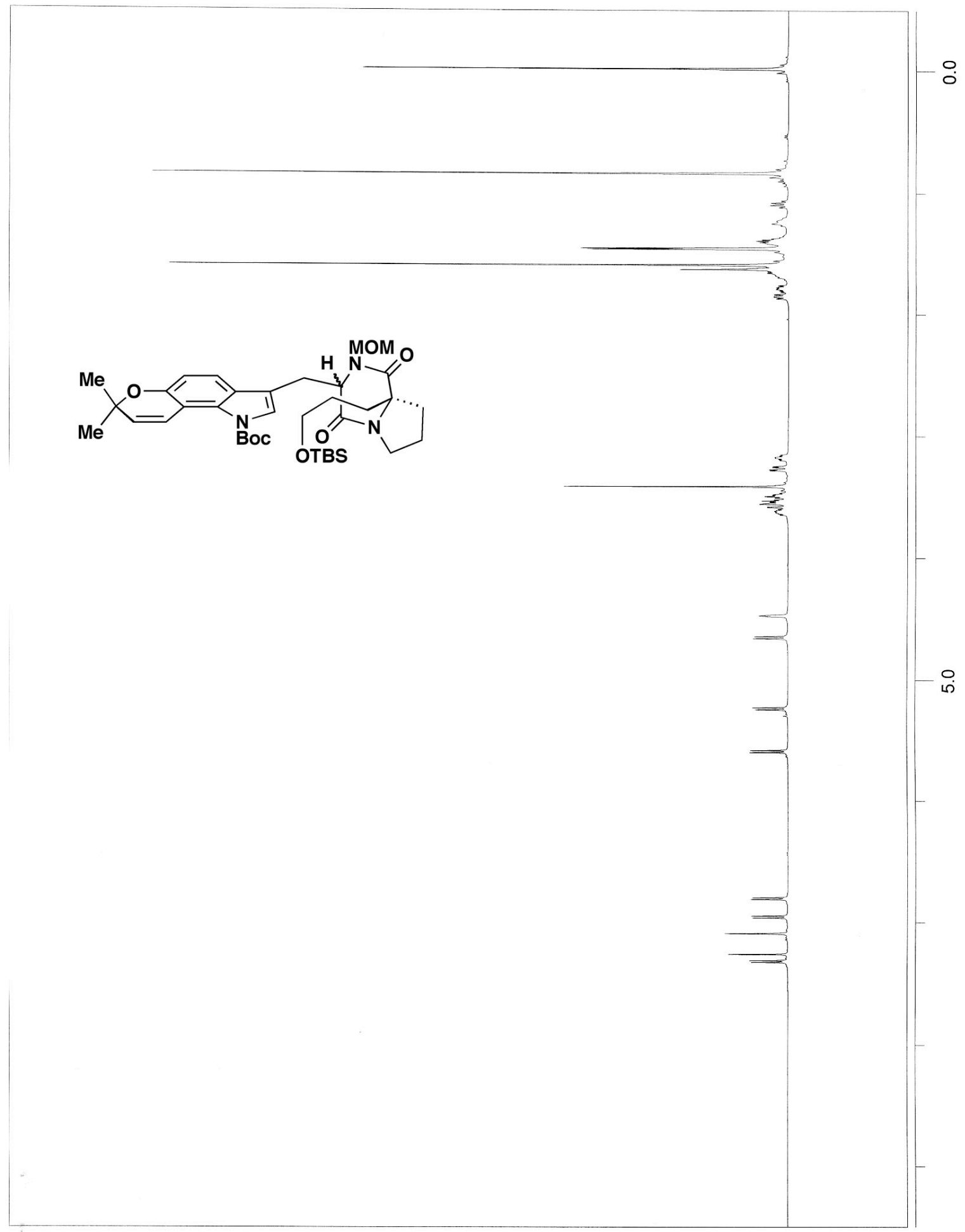

Compound 74: ${ }^{1} \mathrm{H}$ NMR (600 MHz, $\mathrm{CDCl}_{3}$ ) 


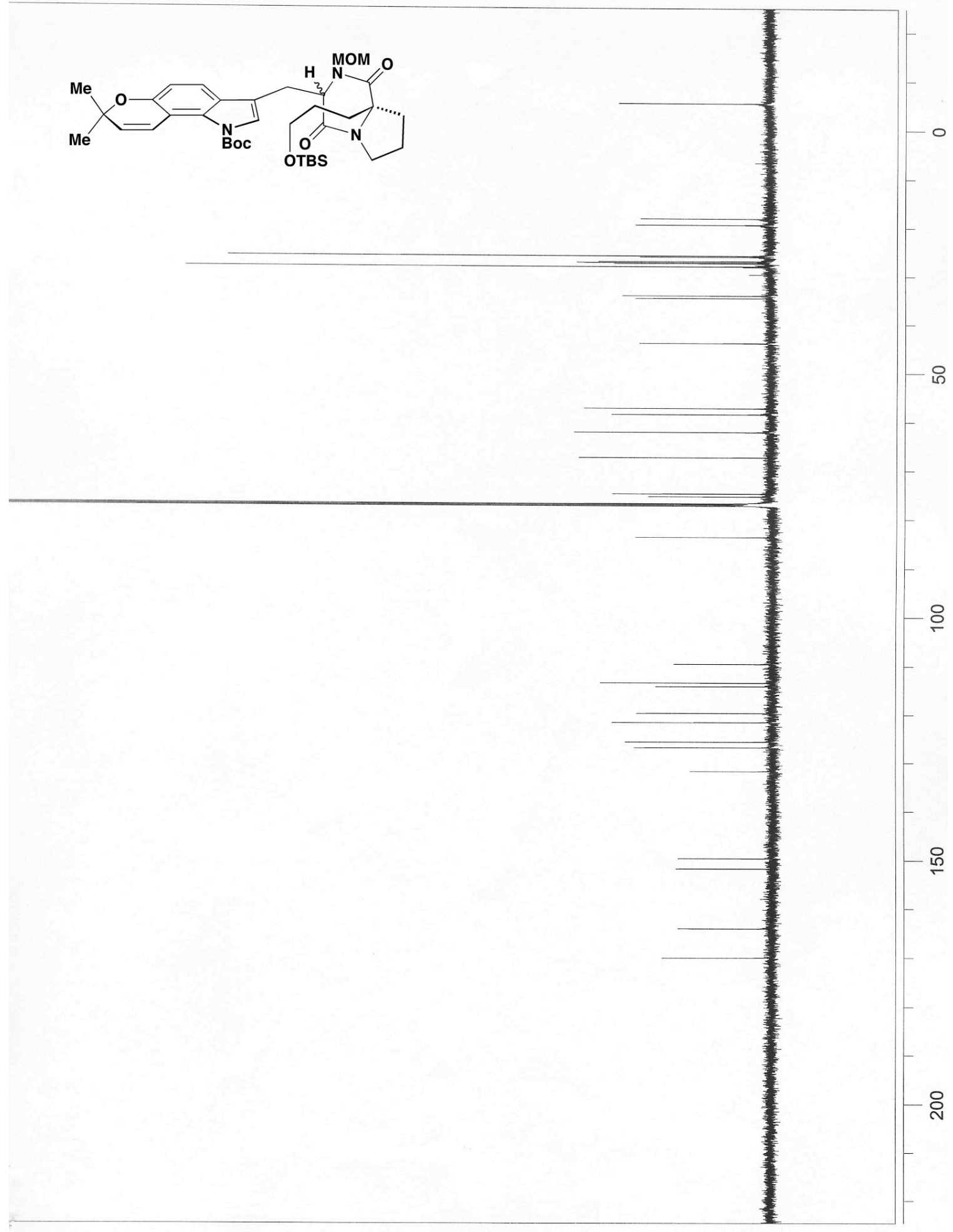

Compound 74: ${ }^{13} \mathrm{C}$ NMR (150 MHz, $\mathrm{CDCl}_{3}$ ) 

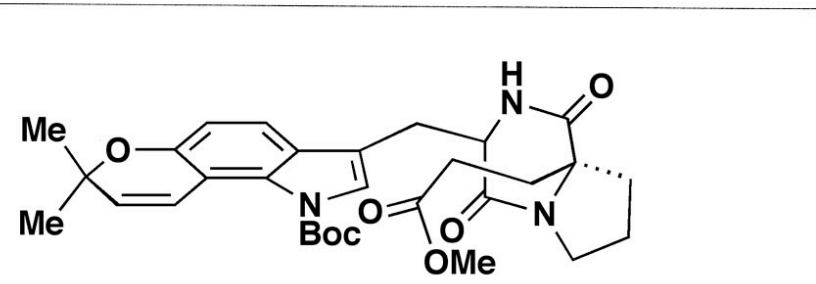


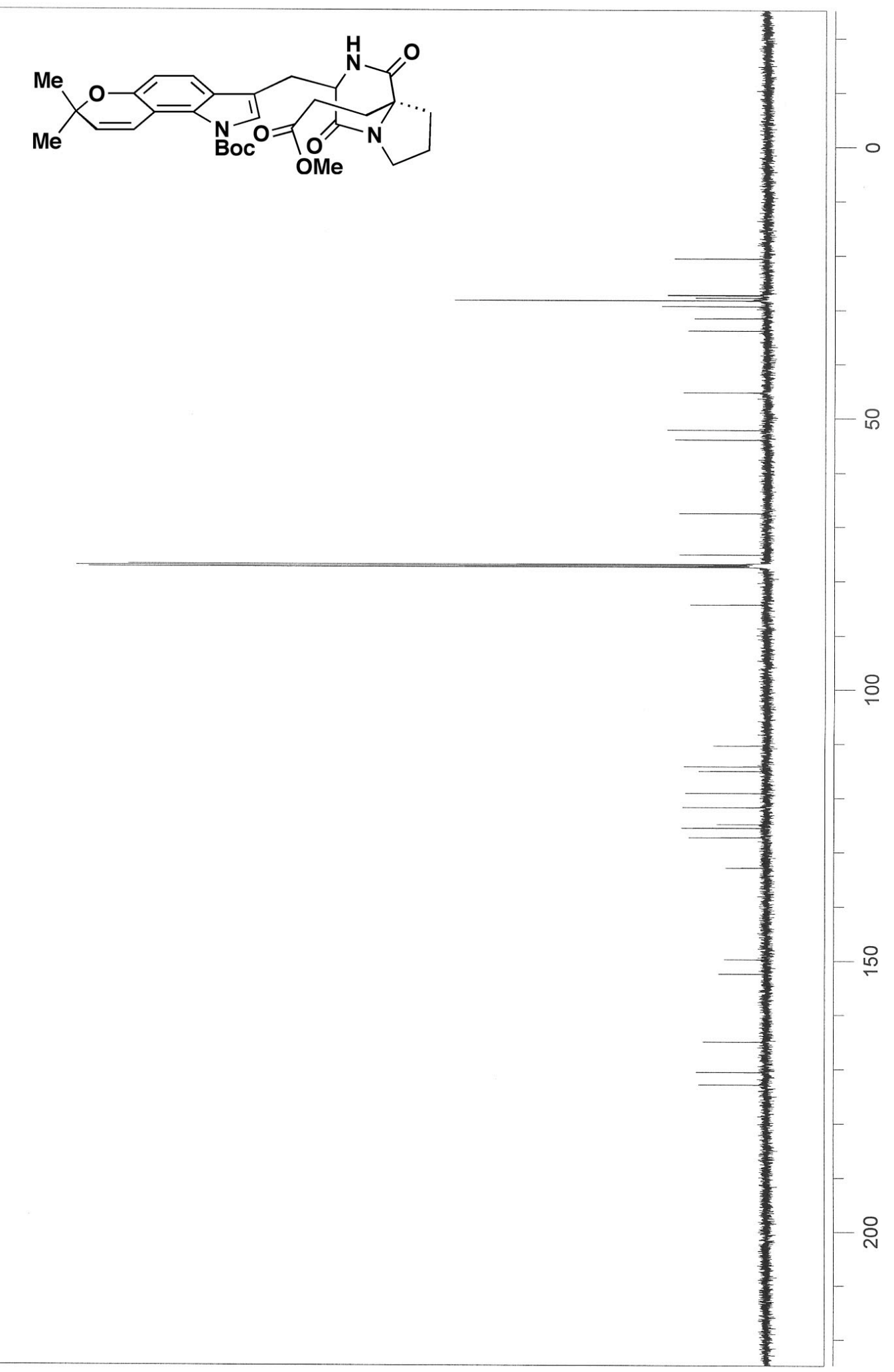

Compound 75 precursor (unprotected DKP, upper diastereomer): ${ }^{13} \mathrm{C}$ NMR $\left(125 \mathrm{MHz}, \mathrm{CDCl}_{3}\right.$ ) 


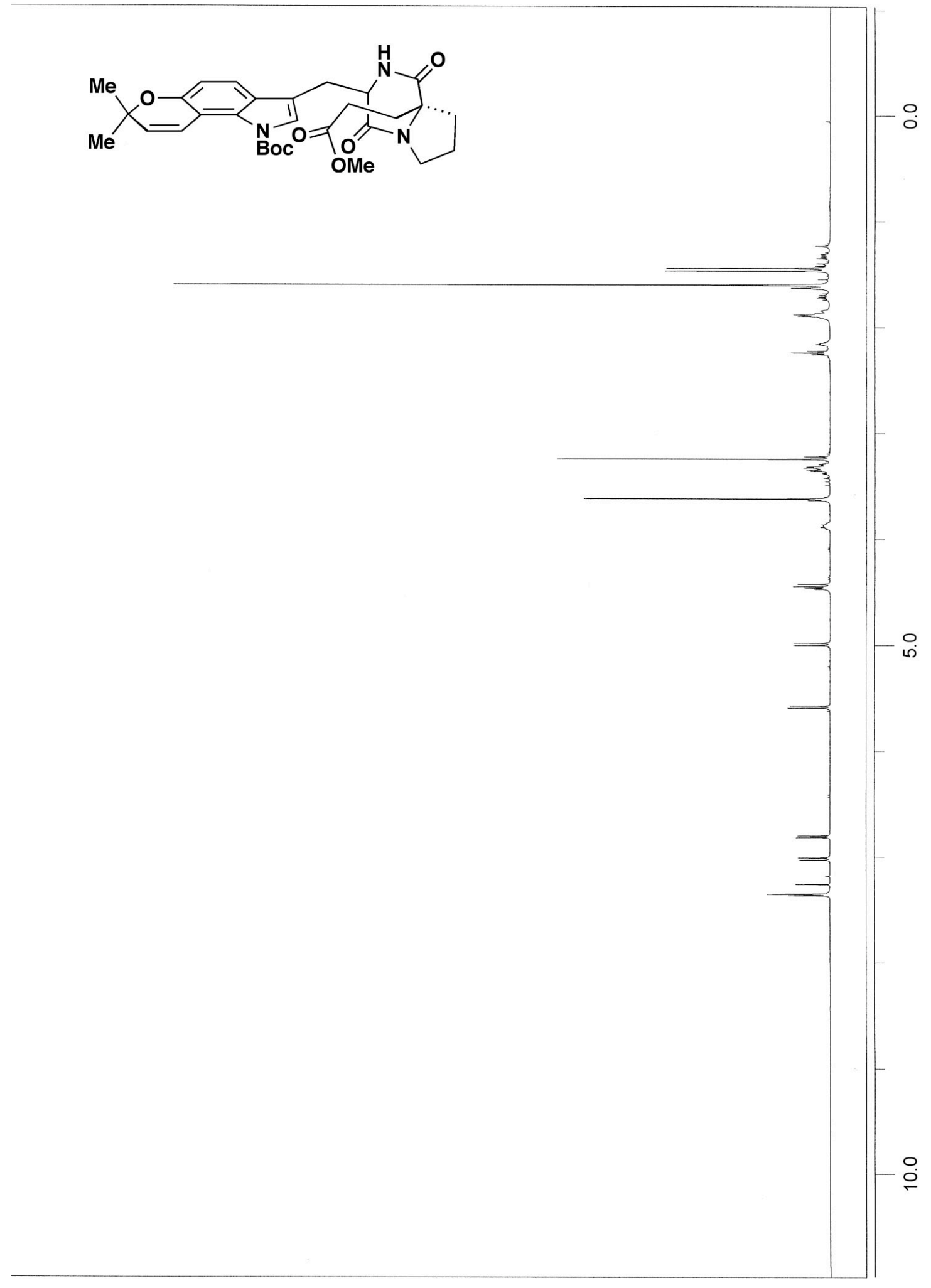

Compound 75 precursor (unprotected DKP, lower diastereomer): ${ }^{1} \mathrm{H}$ NMR (500 MHz, $\mathrm{CDCl}_{3}$ ) 


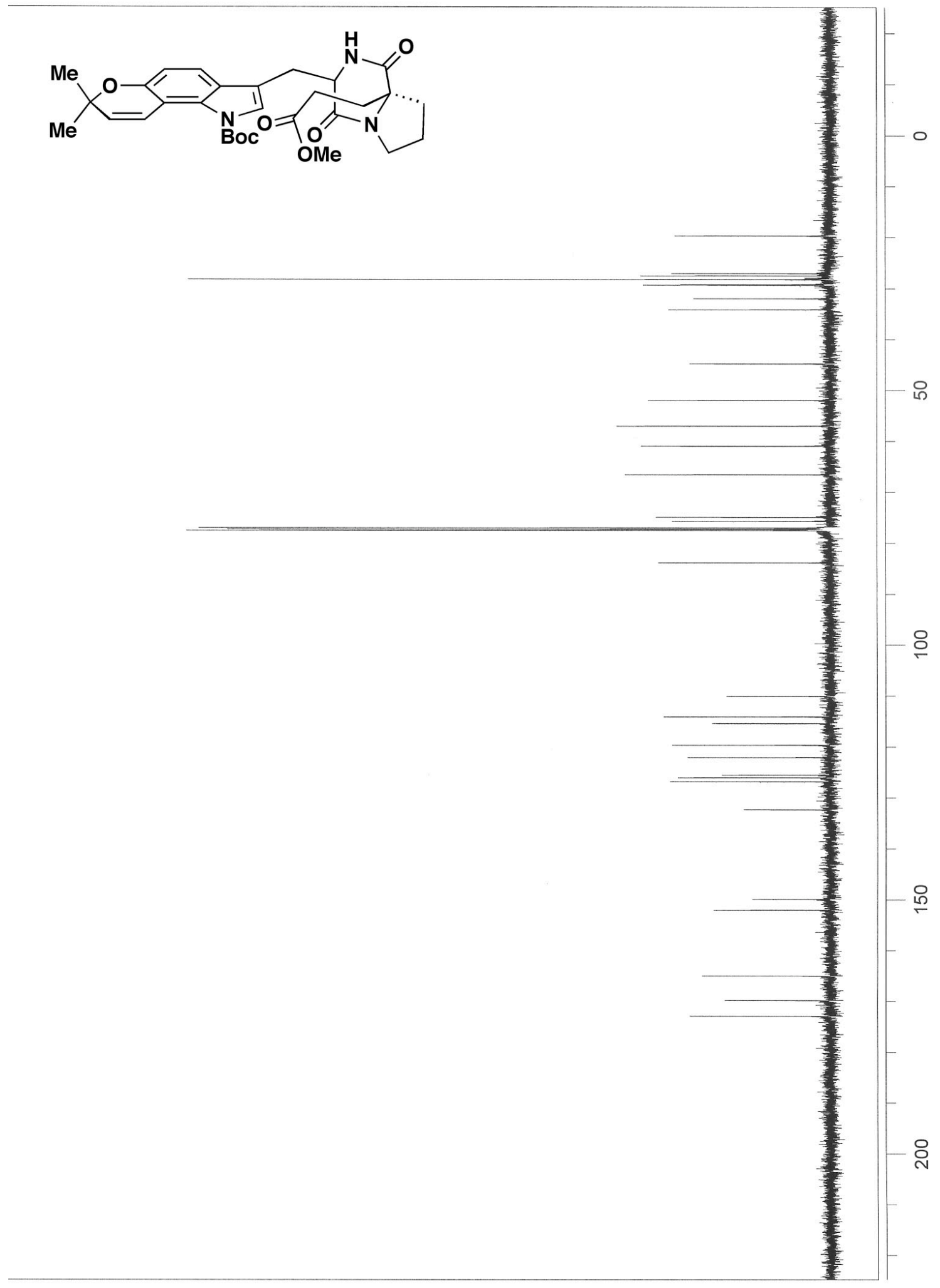

Compound 75 precursor (unprotected DKP, lower diastereomer): ${ }^{13} \mathrm{C}$ NMR $\left(125 \mathrm{MHz}, \mathrm{CDCl}_{3}\right.$ ) 


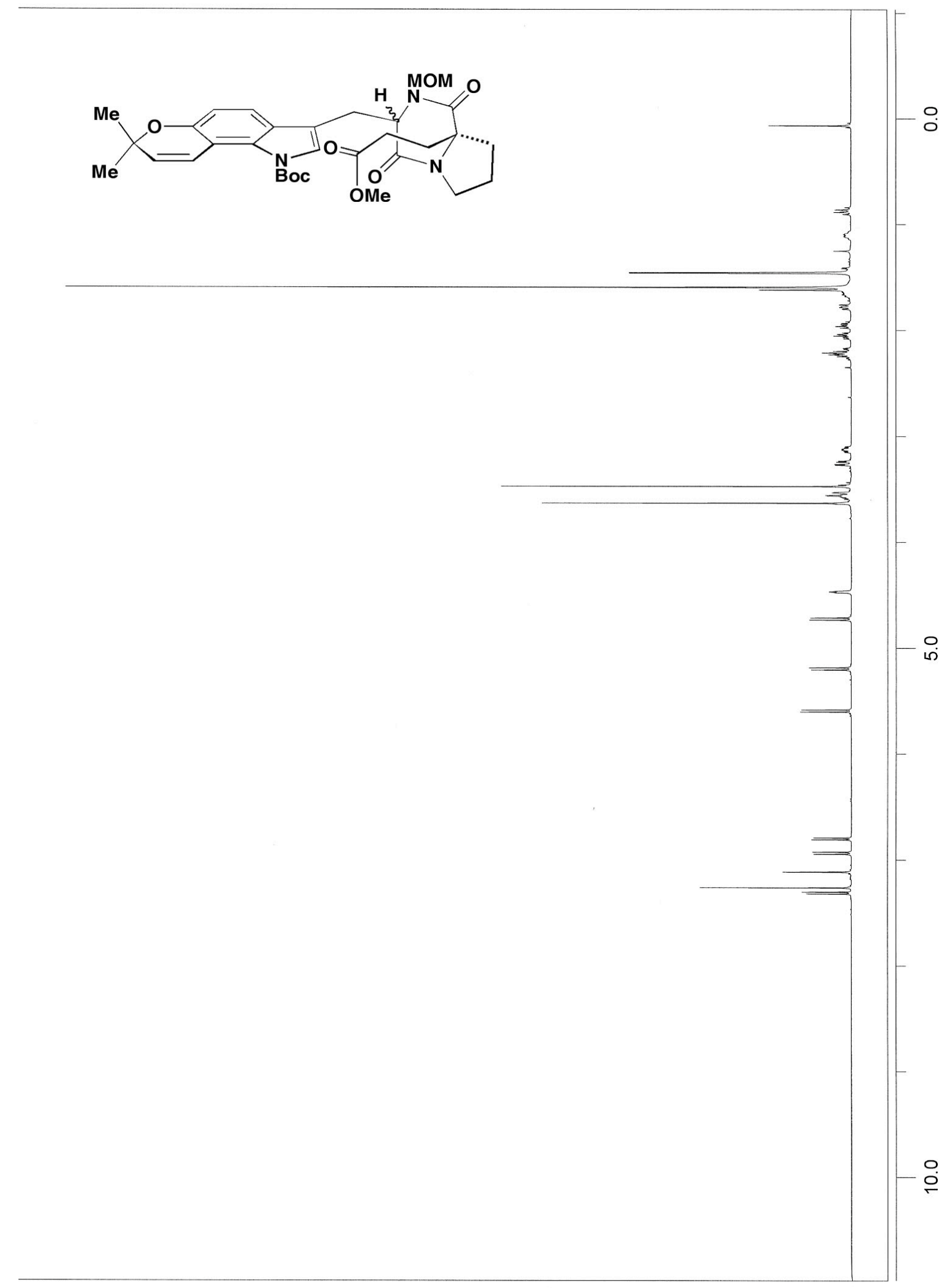

Compound 75: ${ }^{1} \mathrm{H}$ NMR (500 MHz, $\mathrm{CDCl}_{3}$ ) 

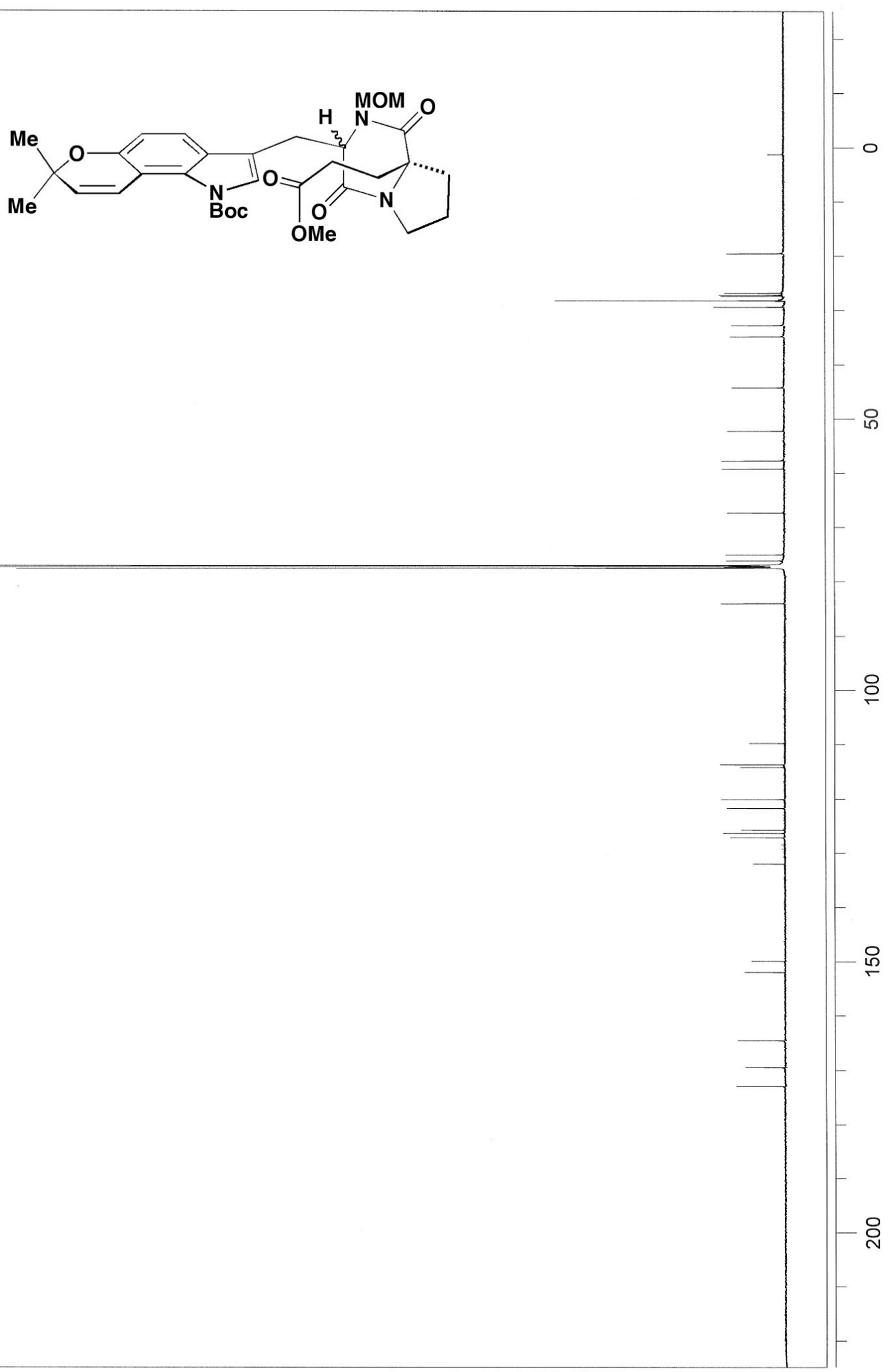

Compound 75: ${ }^{13} \mathrm{C}$ NMR (125 MHz, $\mathrm{CDCl}_{3}$ ) 


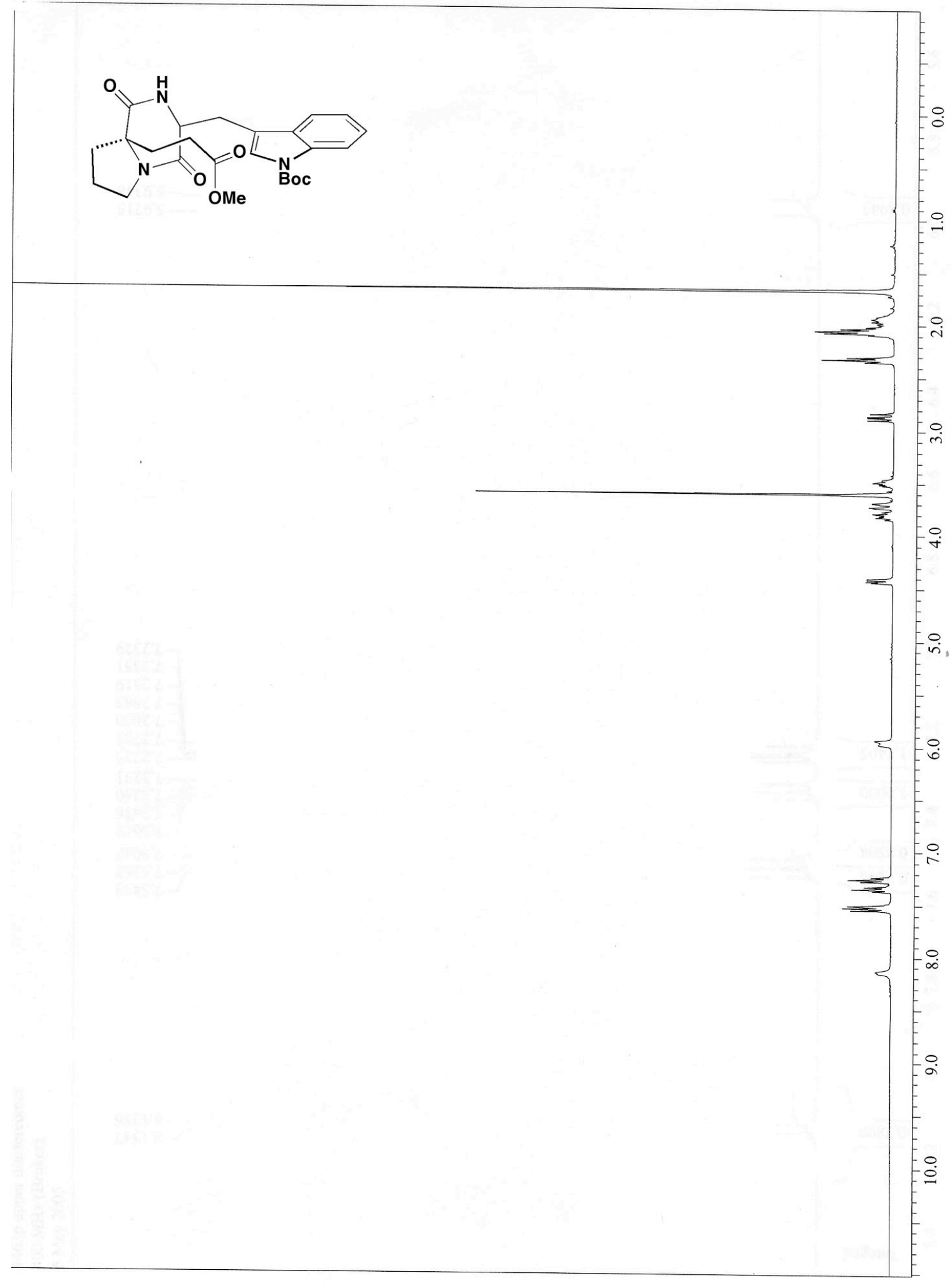

Compound $\mathbf{8 3}$ precursor (upper diastereomer, no MOM group): ${ }^{1} \mathrm{H}$ NMR (600 $\mathrm{MHz}, \mathrm{CDCl}_{3}$ ) 


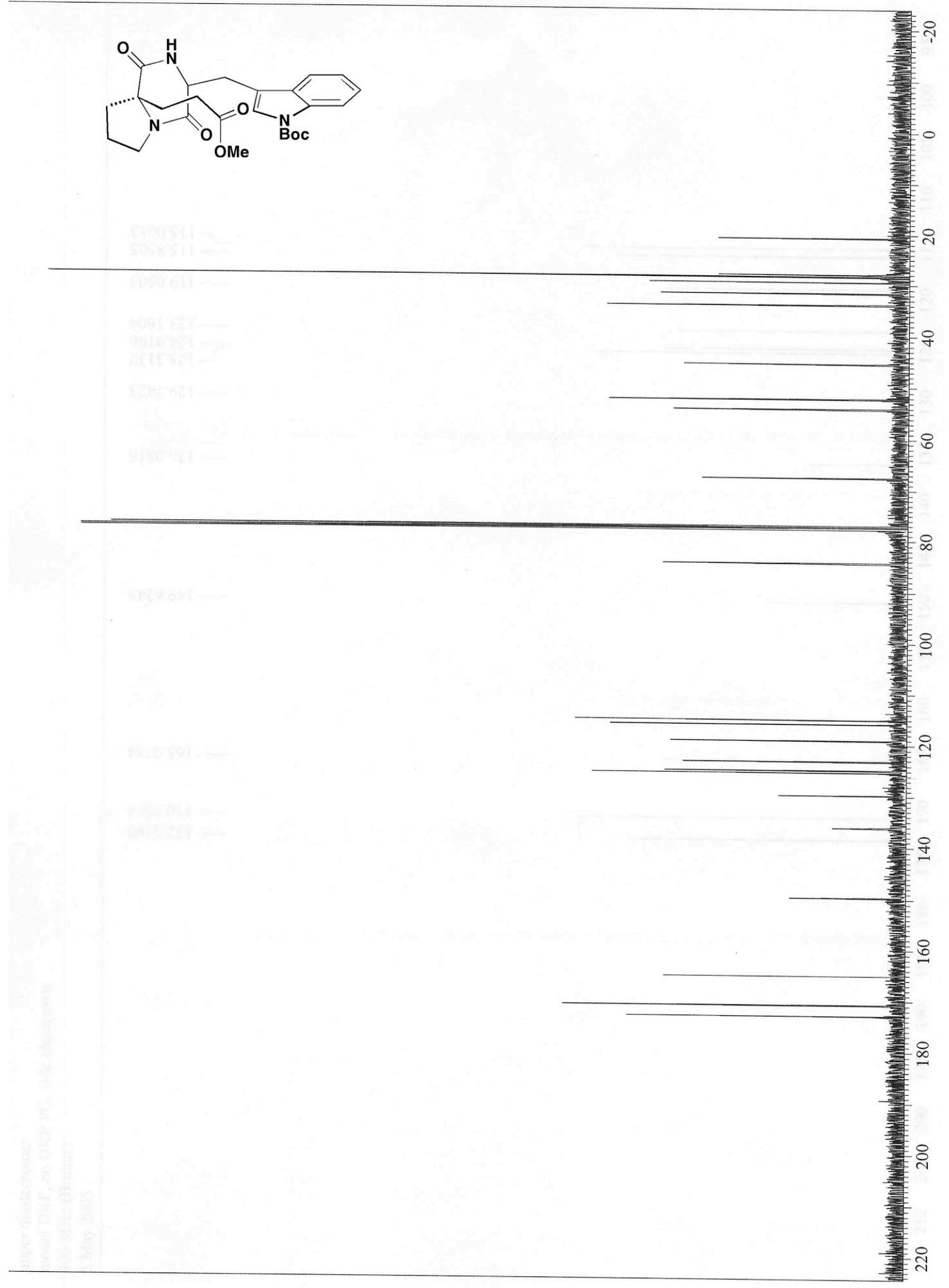

Compound 83 precursor (upper diastereomer, no MOM group): ${ }^{13} \mathrm{C} \mathrm{NMR}\left(125 \mathrm{MHz}, \mathrm{CDCl}_{3}\right)$ 

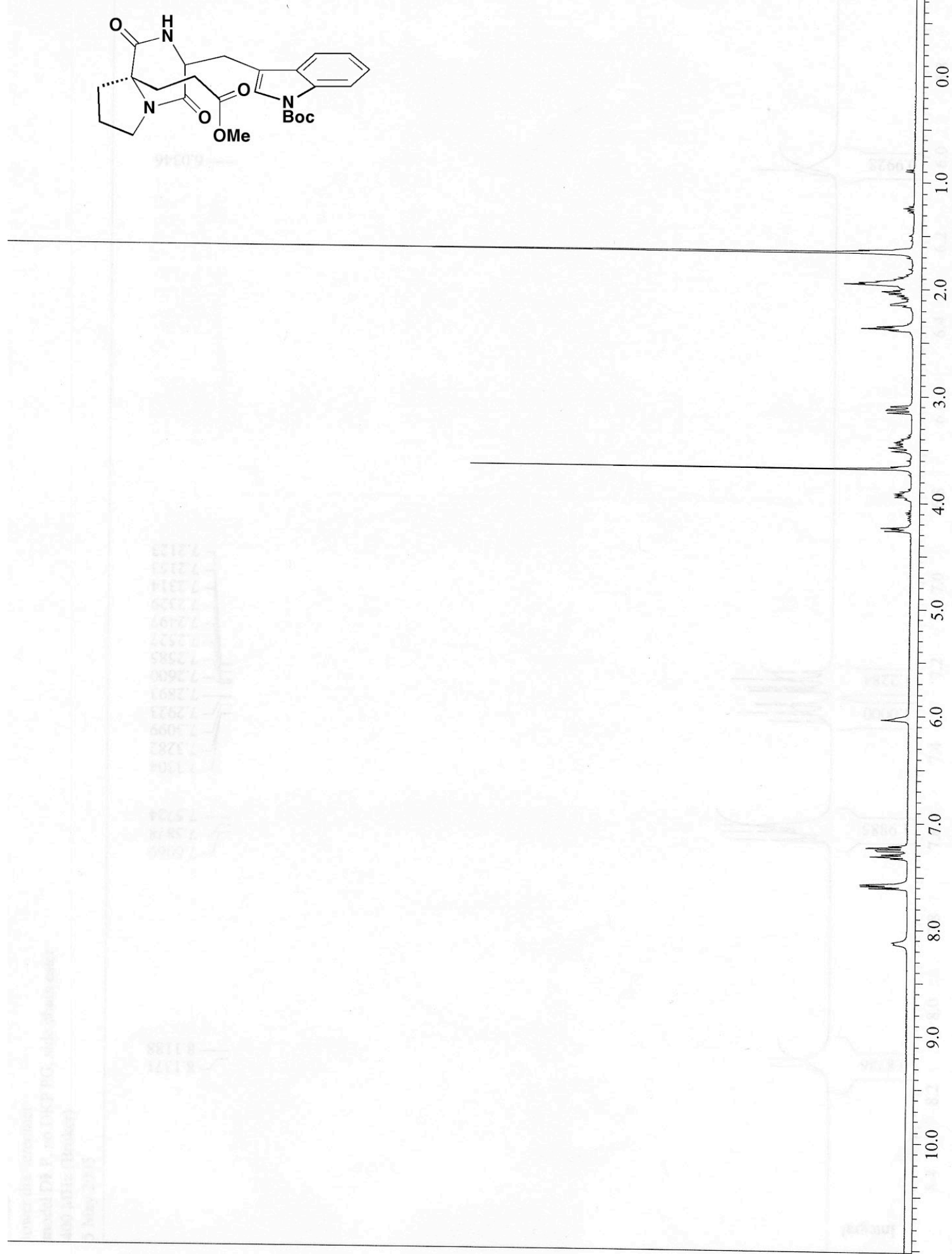

Compound 83 precursor (lower diastereomer, no MOM group): ${ }^{1} \mathrm{H}$ NMR (500 $\mathrm{MHz}, \mathrm{CDCl}_{3}$ ) 


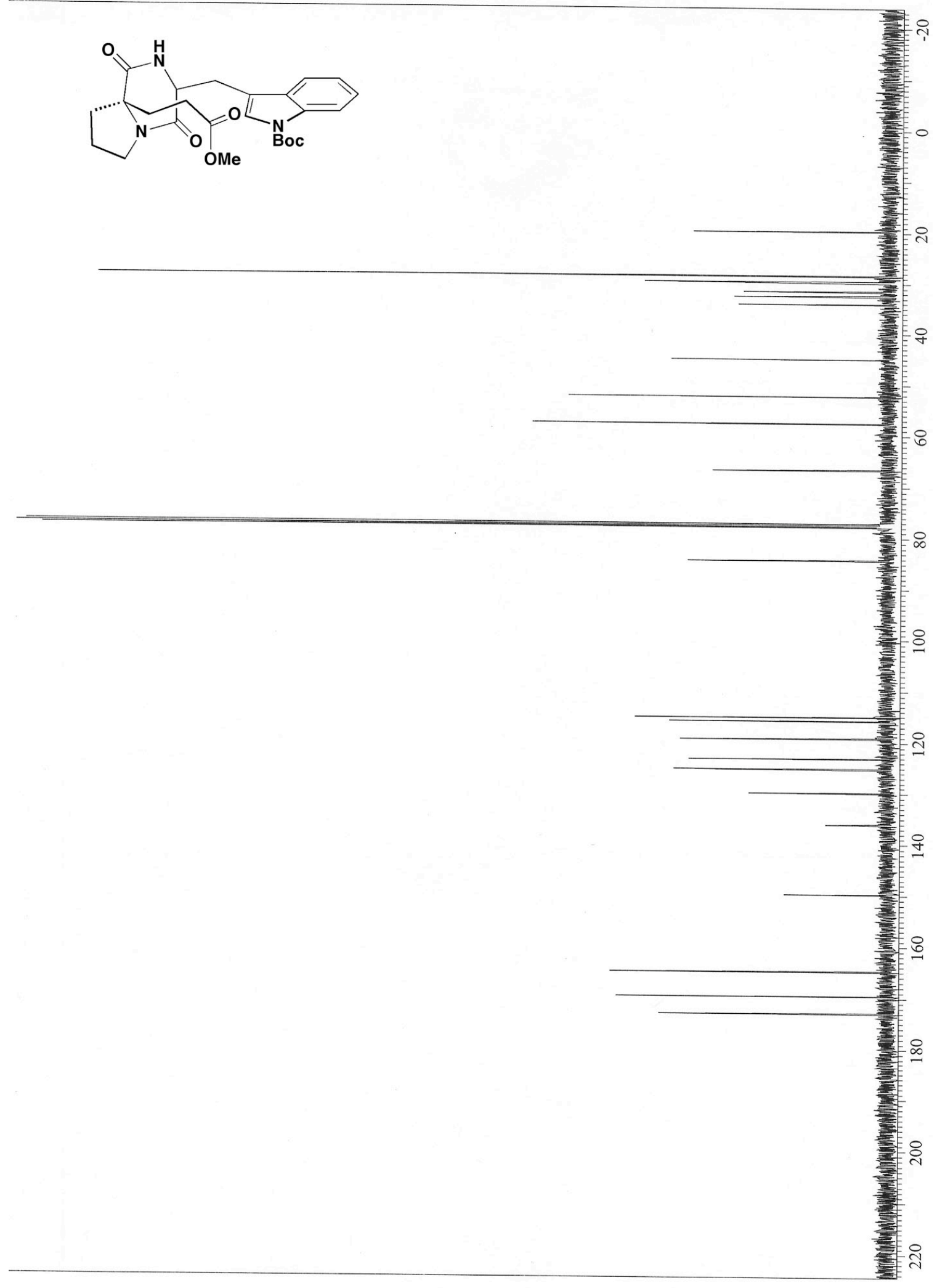

Compound 83 precursor (lower diastereomer, no MOM group): ${ }^{13} \mathrm{C} \mathrm{NMR}\left(125 \mathrm{MHz}, \mathrm{CDCl}_{3}\right.$ ) 


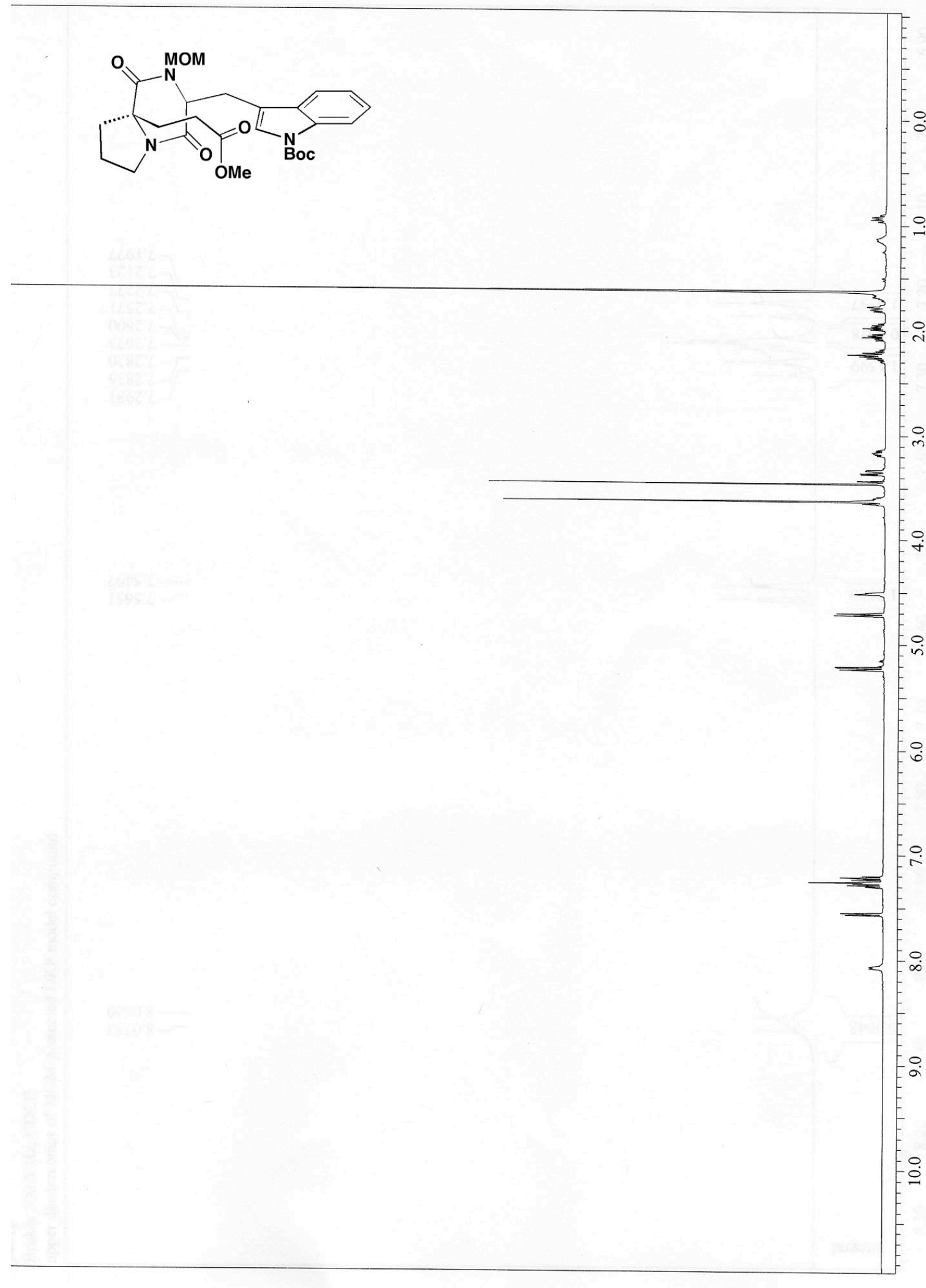

und $\mathbf{8 3}$ (upper diastereomer): ${ }^{1} \mathrm{H}$ NMR (500 MHz, $\mathrm{CDCl}_{3}$ ) 


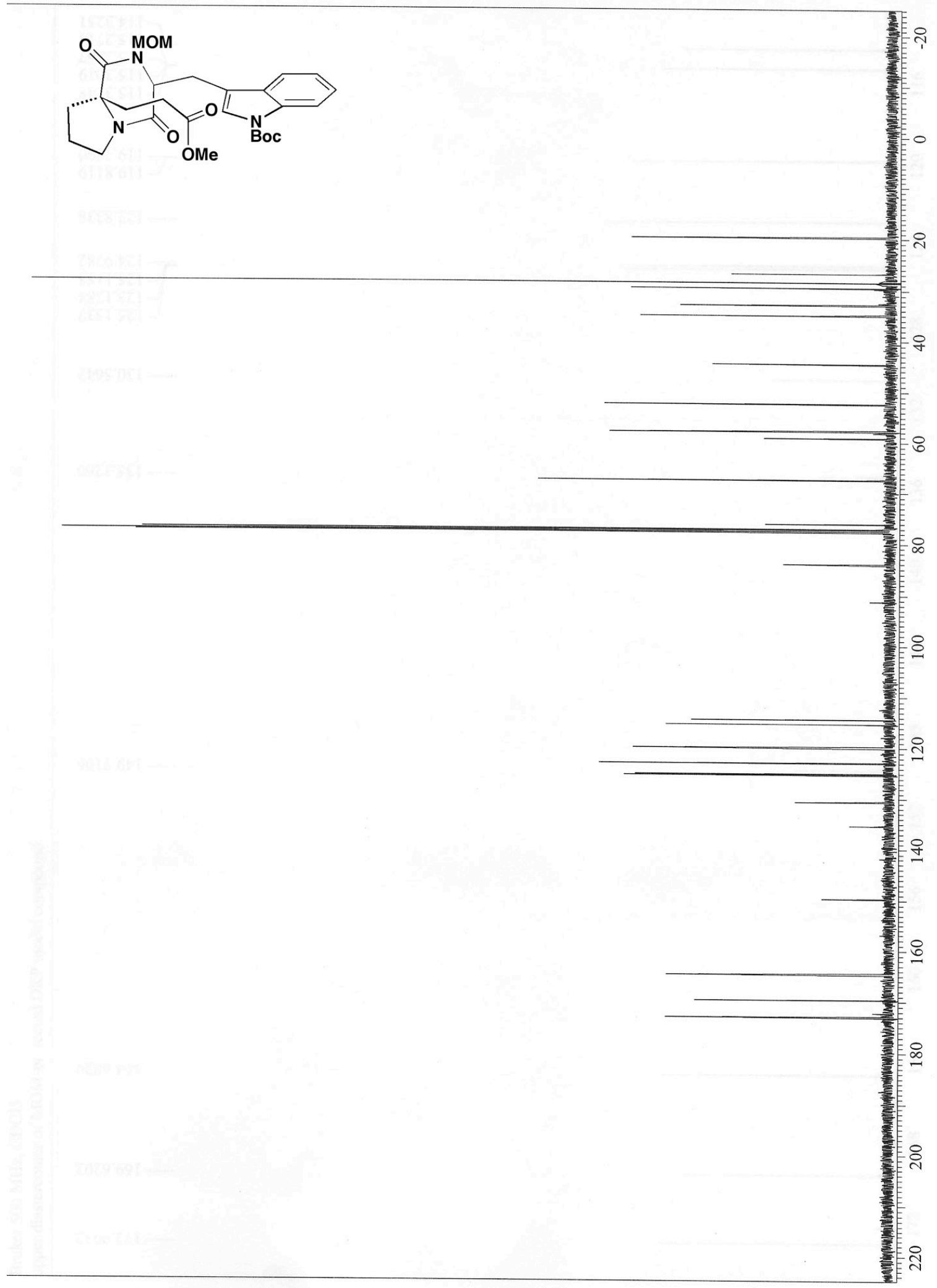

Compound 83 (upper diastereomer): ${ }^{13} \mathrm{C} \mathrm{NMR}\left(125 \mathrm{MHz}, \mathrm{CDCl}_{3}\right.$ ) 


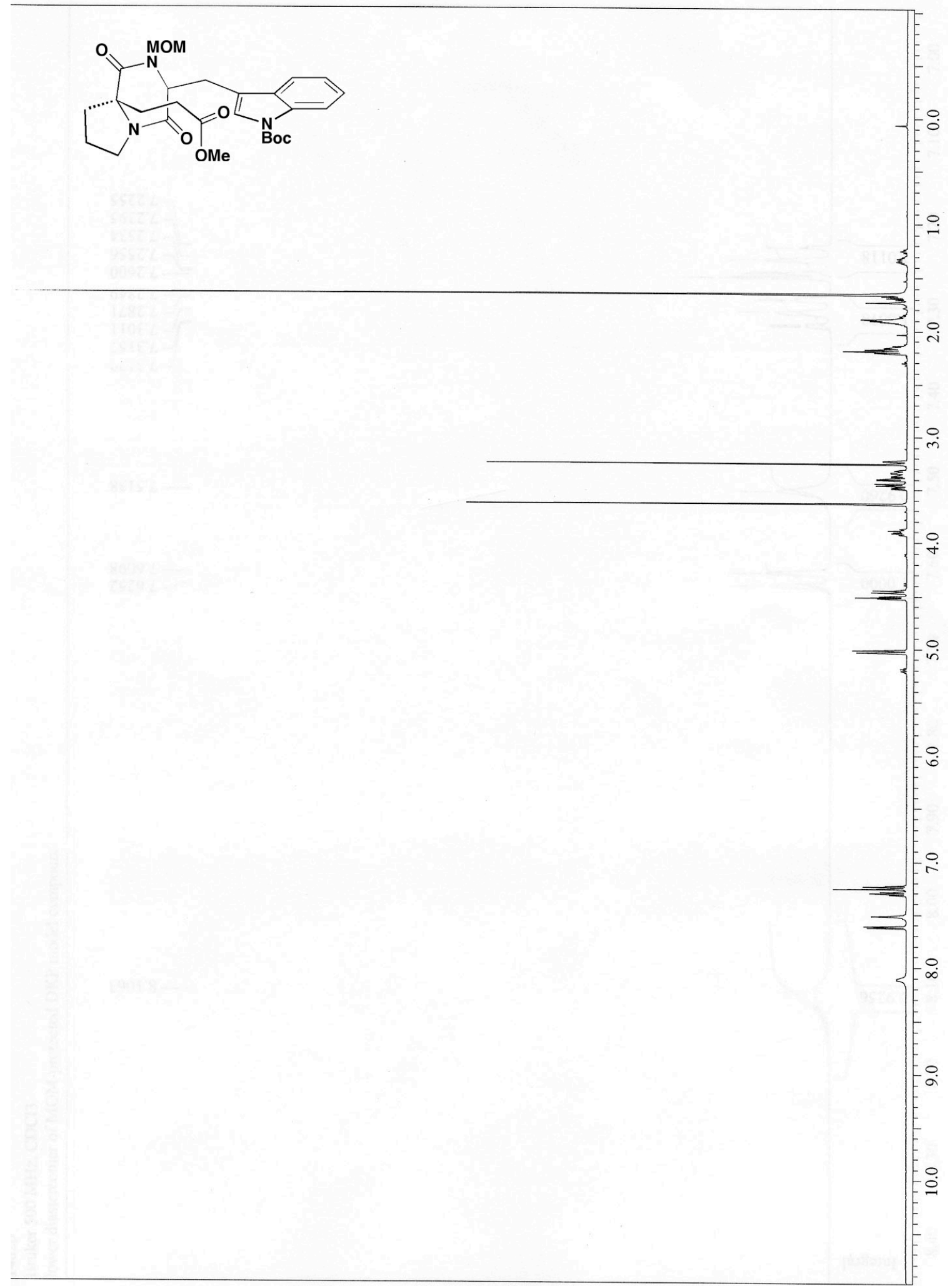

Compound 83 (lower diastereomer); ${ }^{1} \mathrm{H}$ NMR (500 MHz, $\mathrm{CDCl}_{3}$ ) 


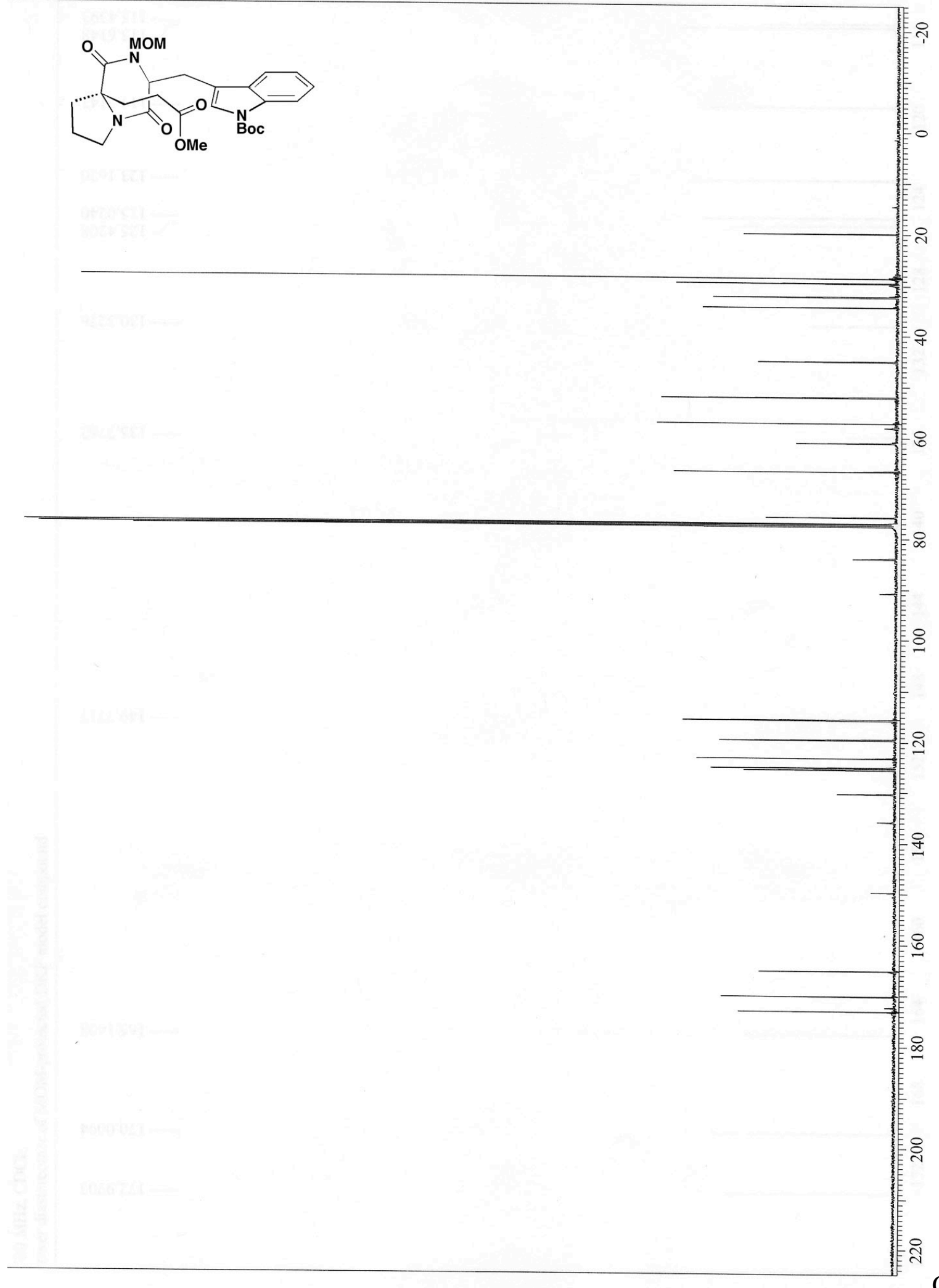

Compo

und 83 (lower diastereomer): ${ }^{13} \mathrm{C} \mathrm{NMR} \mathrm{(125} \mathrm{MHz}, \mathrm{CDCl}_{3}$ ) 


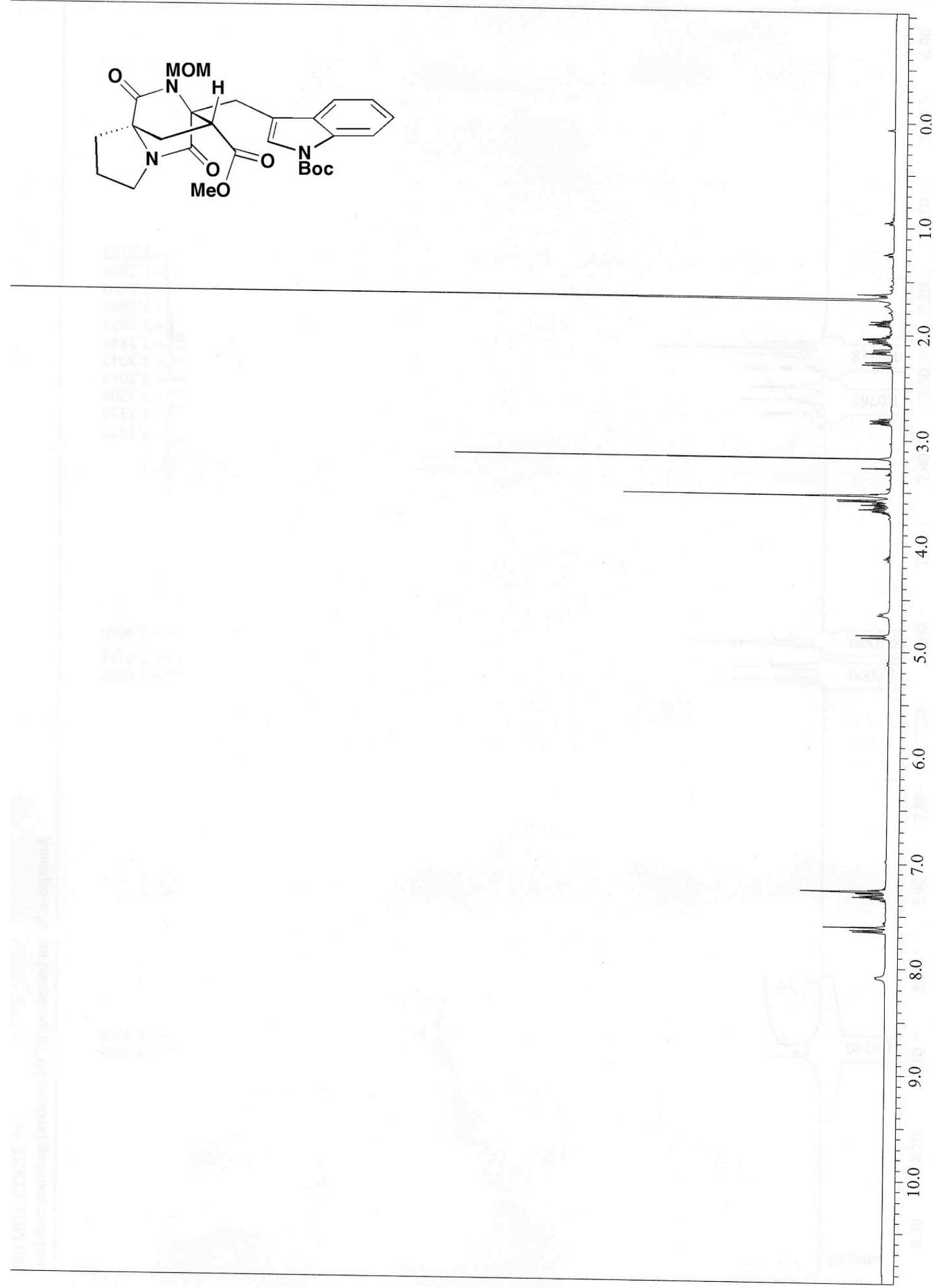

Compound 84: ${ }^{1} \mathrm{H}$ NMR (500 MHz, $\mathrm{CDCl}_{3}$ ) 


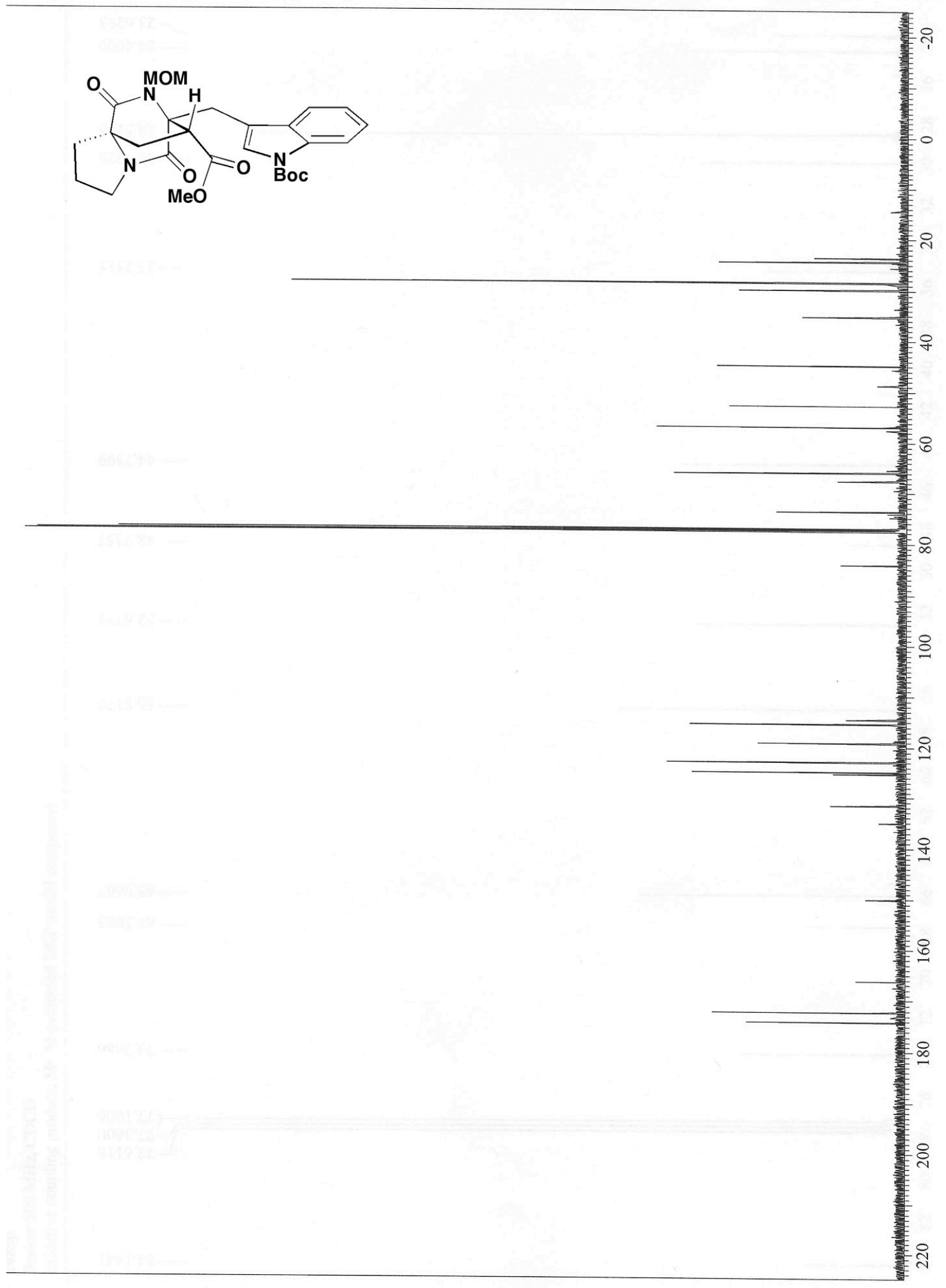

Compound 84: ${ }^{13} \mathrm{C}$ NMR (125 MHz, $\left.\mathrm{CDCl}_{3}\right)$ 


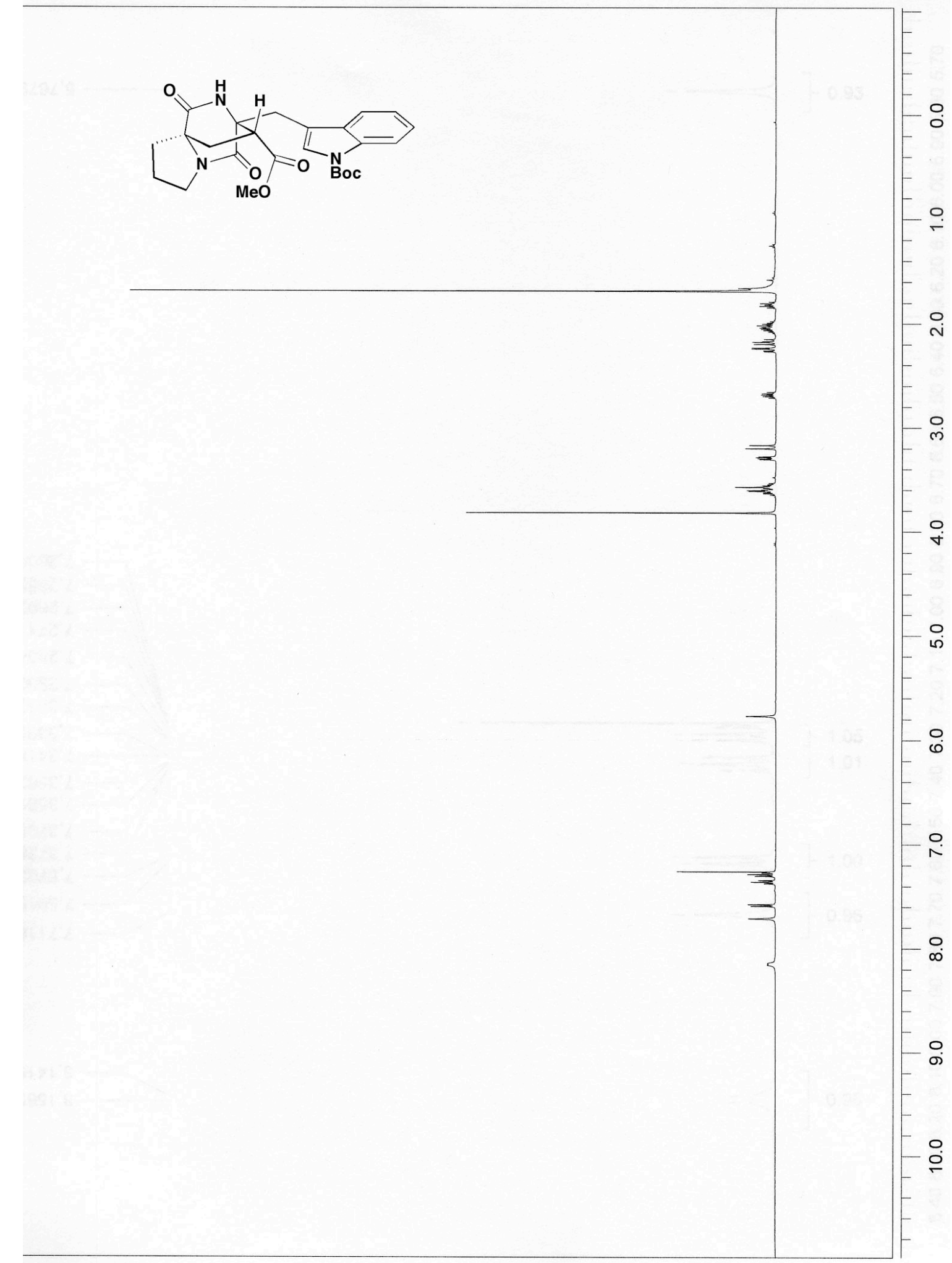

Compound 85: ${ }^{1} \mathrm{H}$ NMR (500 MHz, $\mathrm{CDCl}_{3}$ ) 

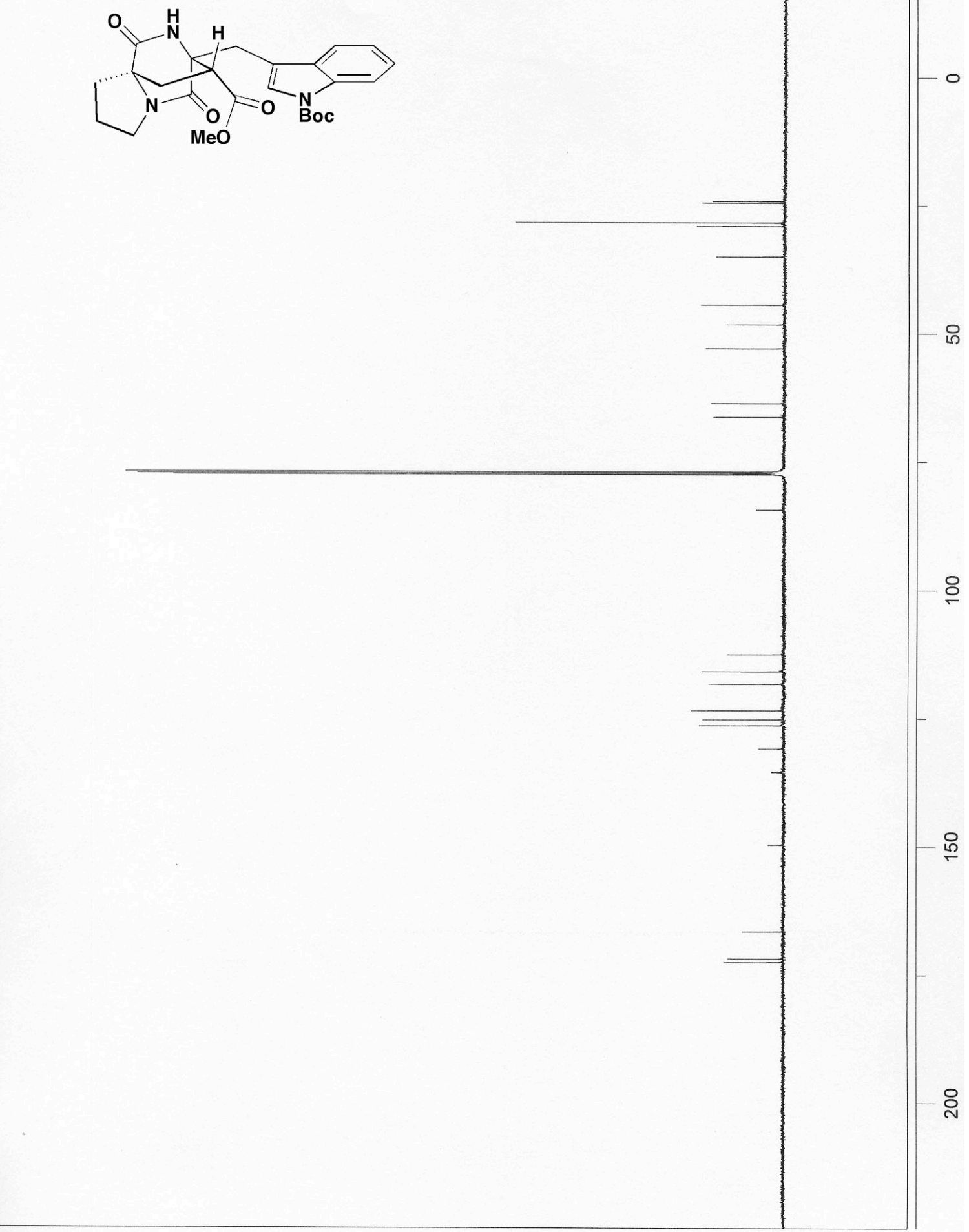

Compound 85: ${ }^{13} \mathrm{C}$ NMR (125 MHz, $\mathrm{CDCl}_{3}$ ) 


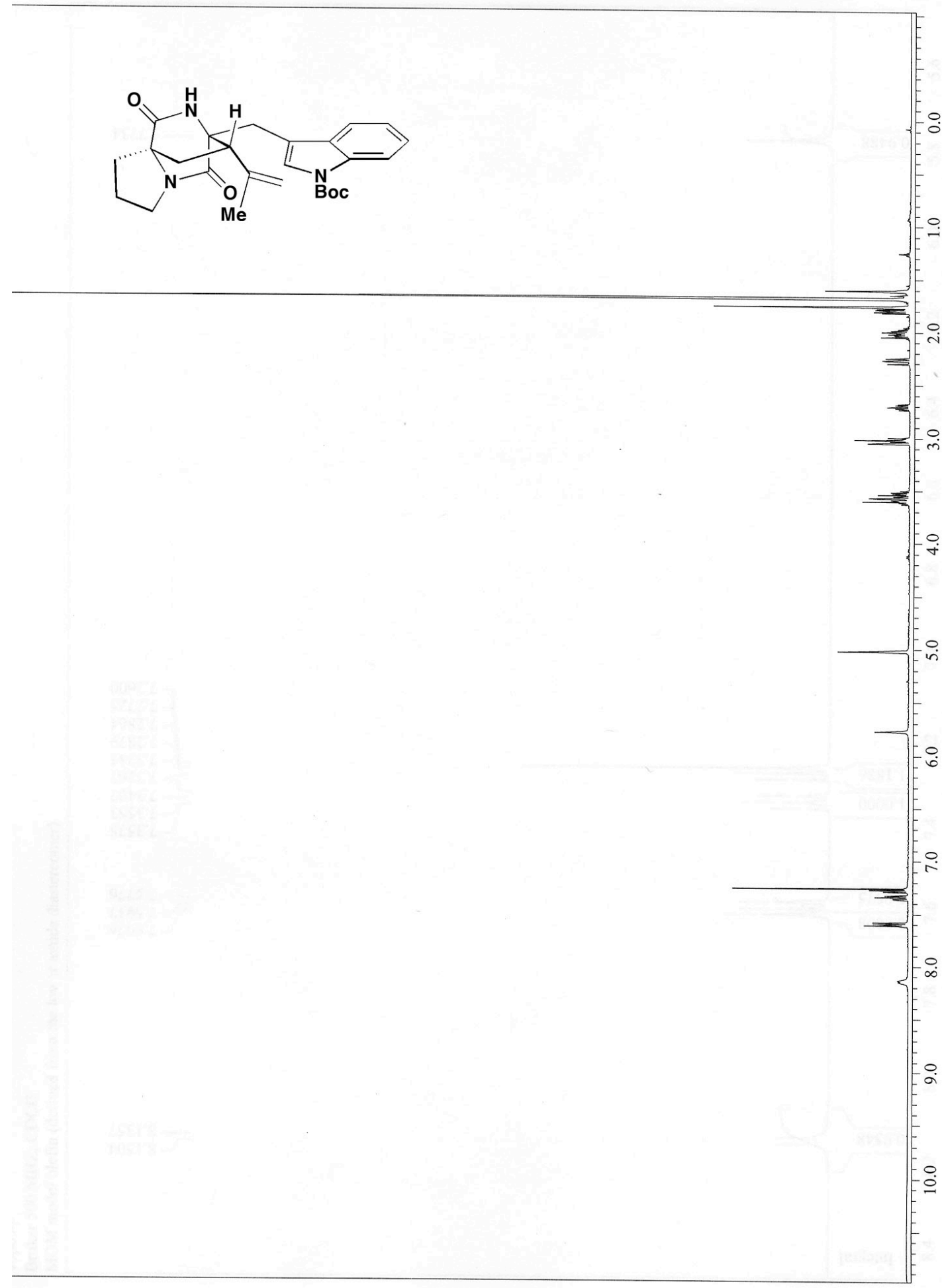

Compound 86: ${ }^{1} \mathrm{H}$ NMR (500 MHz, $\mathrm{CDCl}_{3}$ ) 

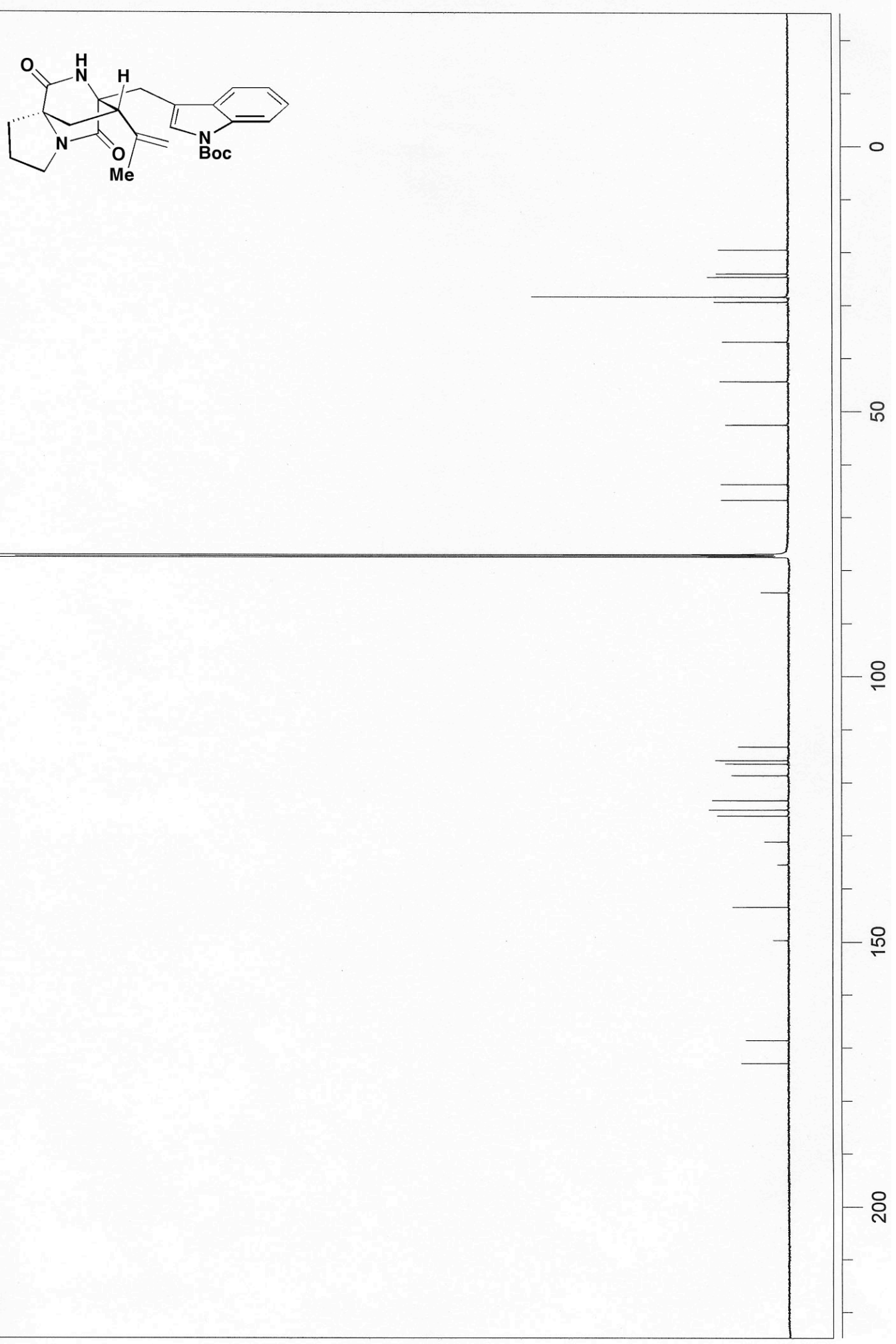

Compound 86: ${ }^{1} \mathrm{H}$ NMR (125 MHz, $\mathrm{CDCl}_{3}$ ) 

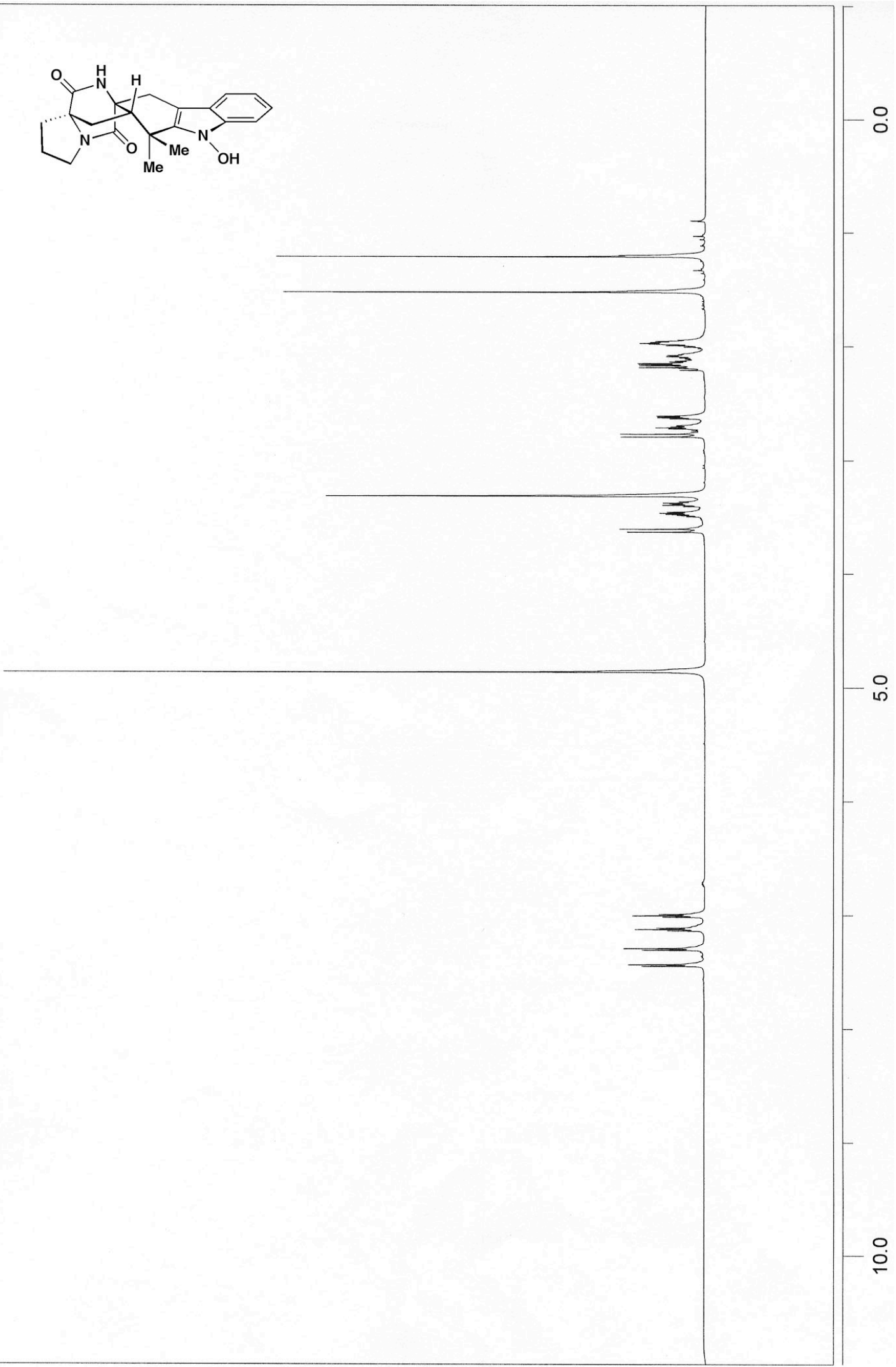

Compound 91: ${ }^{1} \mathrm{H}$ NMR (600 MHz, $\mathrm{CD}_{3} \mathrm{OD}$ ) 


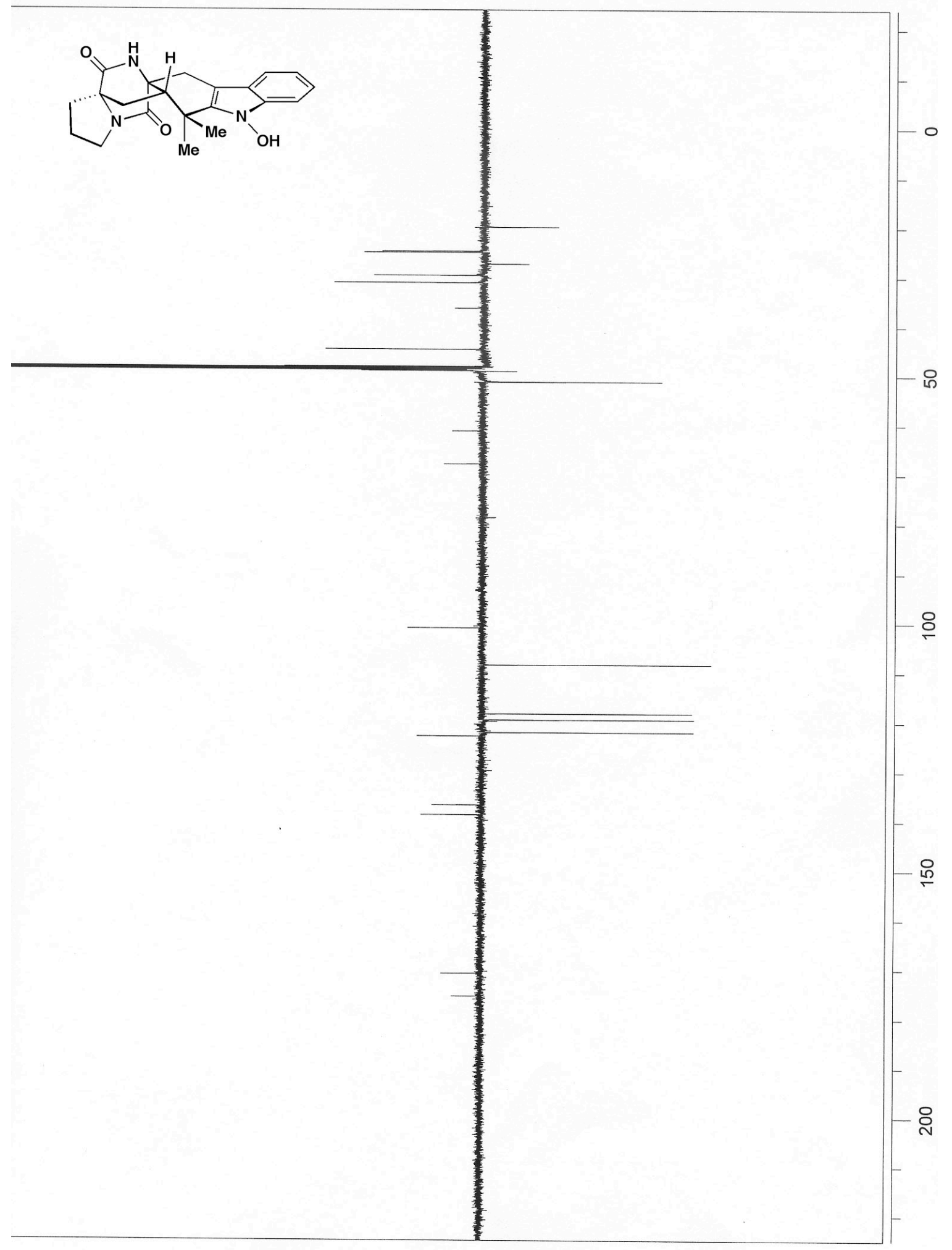

Compound 91: ${ }^{13} \mathrm{C}$ NMR (150 MHz, $\left.\mathrm{CD}_{3} \mathrm{OD}\right)$ 


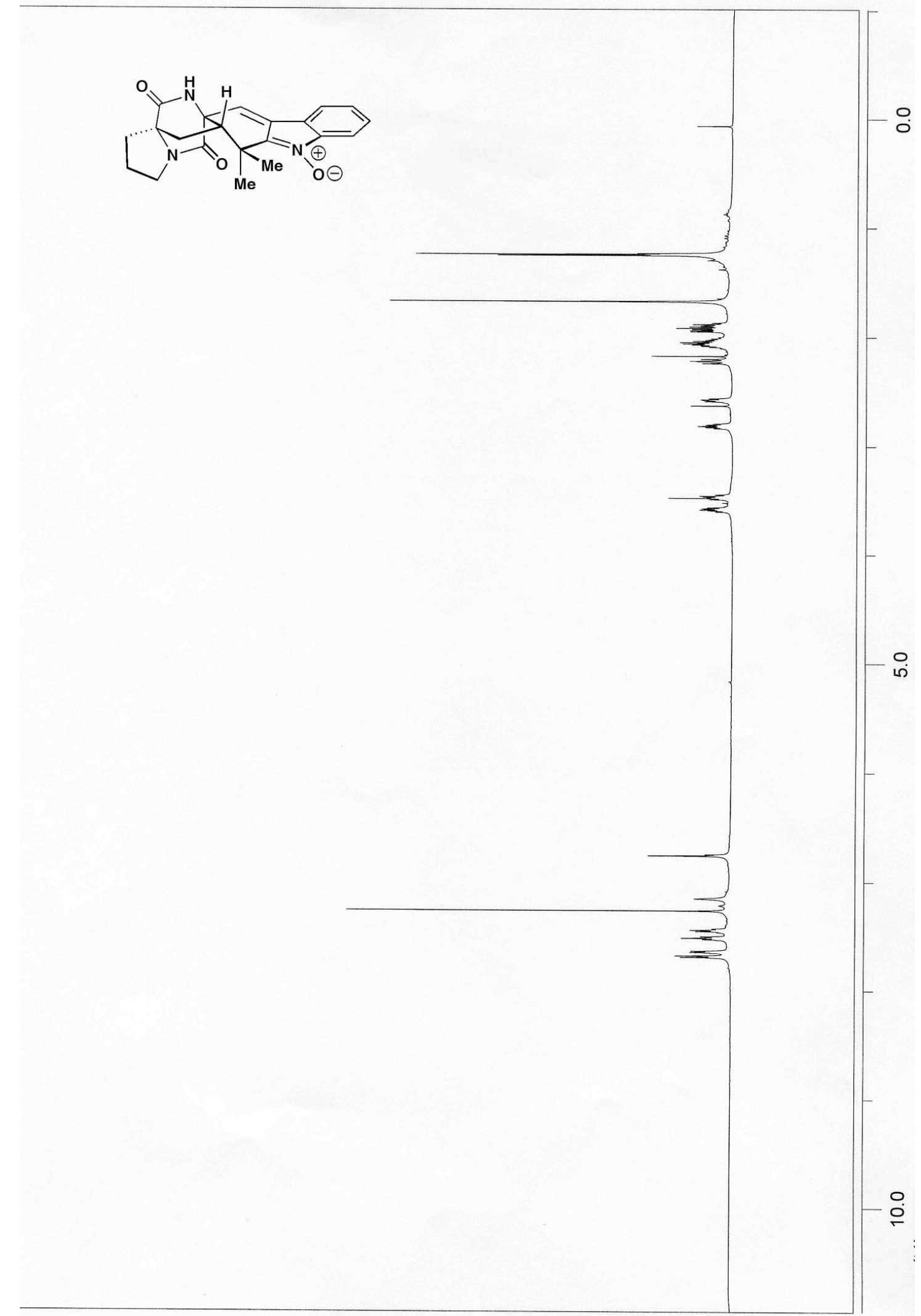

Compound 93: ${ }^{1} \mathrm{H}$ NMR (600 MHz, $\mathrm{CDCl}_{3}$ ) 


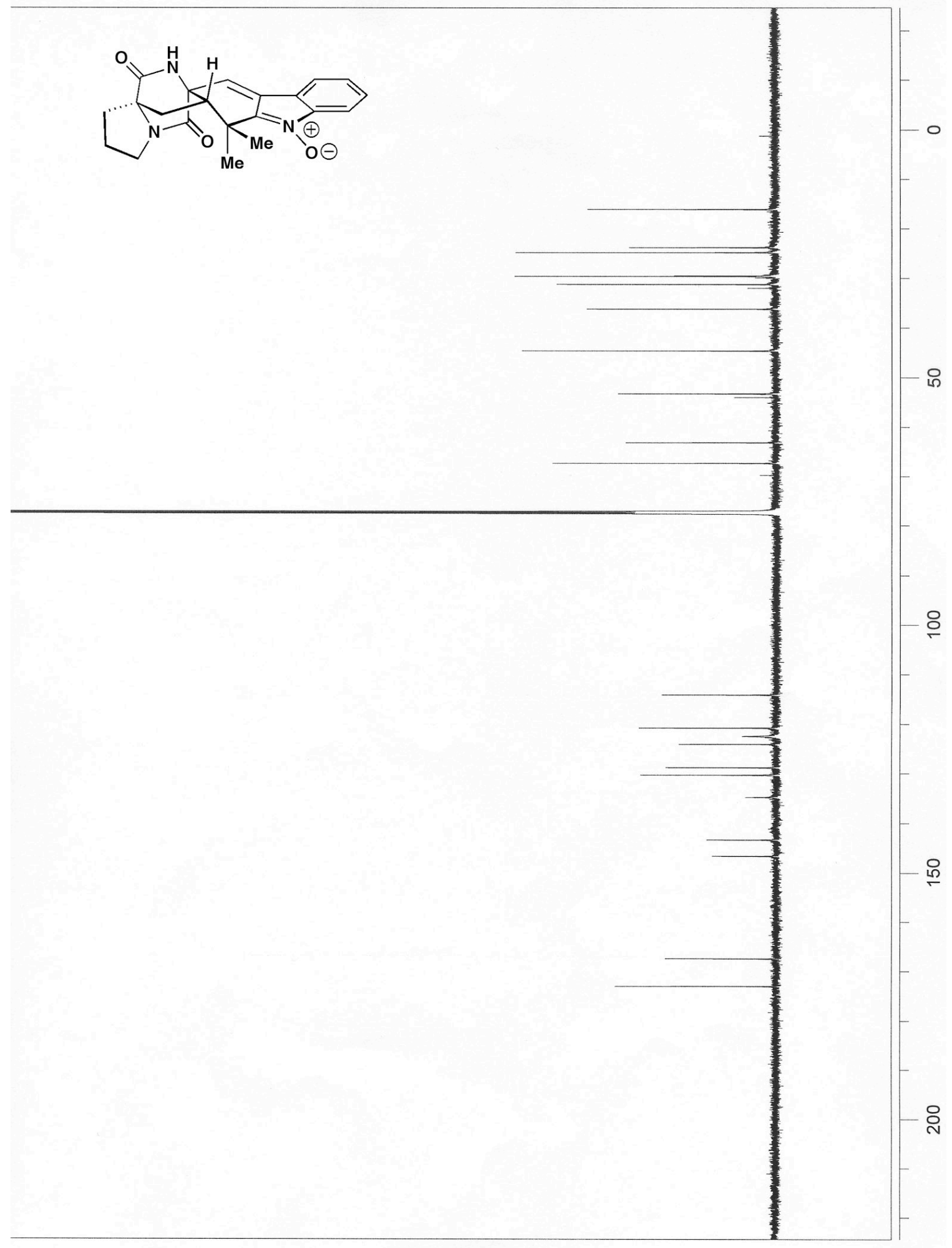

Compound 93: ${ }^{13} \mathrm{C}$ NMR (150 MHz, $\mathrm{CDCl}_{3}$ ) 


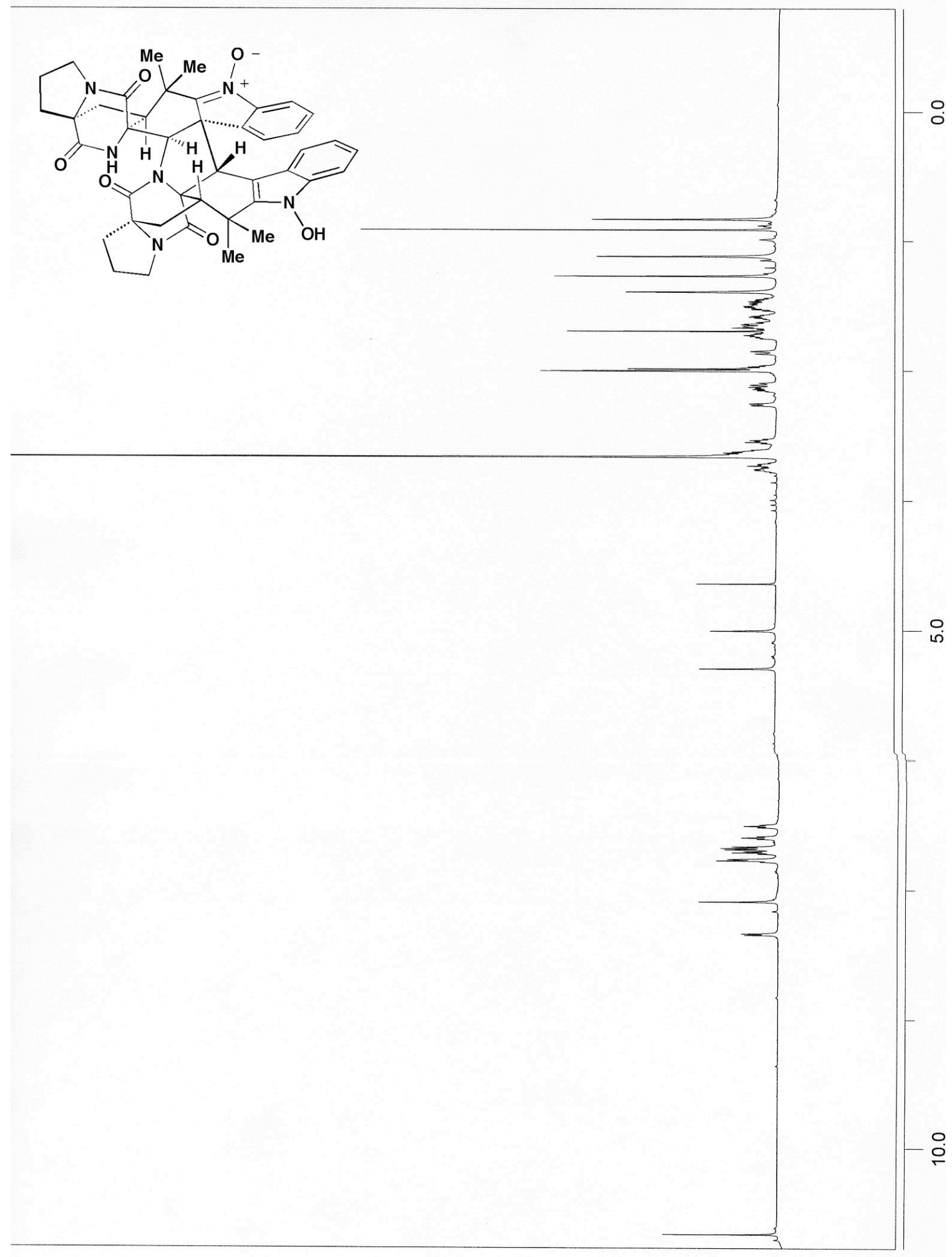

Compound 95: ${ }^{1} \mathrm{H}$ NMR (600 MHz, DMSO- $d_{6}$ ) 


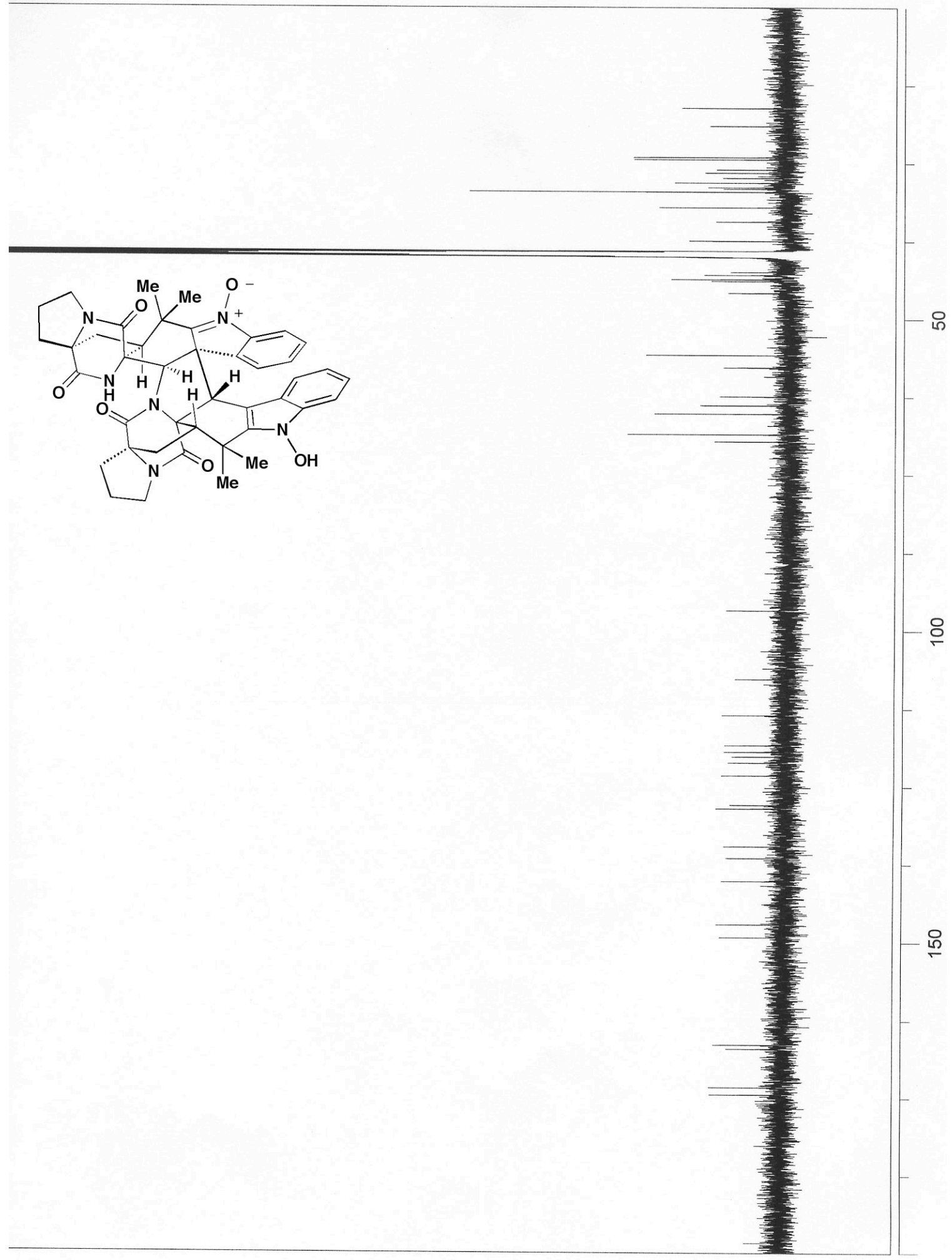

Compound 95: ${ }^{13} \mathrm{C}$ NMR (150 MHz, DMSO- $\left.d_{6}\right)$ 